NBER WORKING PAPER SERIES

\title{
AN ECONOMETRIC MODEL OF SERIAL CORRELATION AND ILLIQUIDITY IN HEDGE FUND RETURNS
}

\author{
Mila Getmansky \\ Andrew W. Lo \\ Igor Makarov \\ Working Paper 9571 \\ http://www.nber.org/papers/w9571
NATIONAL BUREAU OF ECONOMIC RESEARCH
1050 Massachusetts Avenue
Cambridge, MA 02138
March 2003

This research was supported by the MIT Laboratory for Financial Engineering. We thank Jacob Goldfield, Stephanie Hogue, Stephen Jupp, SP Kothari, Bob Merton, Myron Scholes, Bill Schwert, Svetlana Sussman, a referee, and seminar participants at Harvard, the MIT Finance Student Lunch Group, and the 2001 Fall Q Group Conference for many stimulating discussions and comments. The views expressed herein are those of the authors and not necessarily those of the National Bureau of Economic Research.

(C)2003 by Mila Getmansky, Andrew W. Lo, and Igor Makarov. All rights reserved. Short sections of text not to exceed two paragraphs, may be quoted without explicit permission provided that full credit including Cnotice, is given to the source. 
An Econometric Model of Serial Correlation and Illiquidity in Hedge Fund Returns

Mila Getmansky, Andrew W. Lo, and Igor Makarov

NBER Working Paper No. 9571

March 2003

JEL No. E0, E5, E6, F0, F3, G1, G2, O2

\section{$\underline{\text { ABSTRACT }}$}

The returns to hedge funds and other alternative investments are often highly serially correlated in sharp contrast to the returns of more traditional investment vehicles such as long-only equity portfolios and mutual funds. In this paper, we explore several sources of such serial correlation and show that the most likely explanation is illiquidity exposure, i.e., investments in securities that are not actively traded and for which market prices are not always readily available. For portfolios of illiquid securities, reported returns will tend to be smoother than true economic returns, which will understate volatility and increase risk-adjusted performance measures such as the Sharpe ratio. We propose an econometric model of illiquidity exposure and develop estimators for the smoothing profile as well as a smoothing-adjusted Sharpe ratio. For a sample of 908 hedge funds drawn from the TASS database, we show that our estimated smoothing coefficients vary considerably across hedge-fund style categories and may be a useful proxy for quantifying illiquidity exposure.

Mila Getmansky

MIT, Sloan School of Management

50 Memorial Drive

Cambridge, MA 02142

mgetman@mit.edu
Andrew W. Lo

MIT, Sloan School of Management

50 Memorial Drive

E52-432

Cambridge, MA 02142

and NBER

alo@mit.edu

Igor Makarov

MIT, Sloan School of Management

50 Memorial Drive

Cambridge, MA 02142

imakarov@mit.edu 


\section{Contents}

1 Introduction $\quad 1$

2 Literature Review $\quad 3$

3 Other Sources of Serial Correlation $\quad 5$

3.1 Time-Varying Expected Returns . . . . . . . . . . . . . . . . . . . . 8

3.2 Time-Varying Leverage . . . . . . . . . . . . . . . . . . . . . . . 11

3.3 Incentive Fees with High-Water Marks . . . . . . . . . . . . . . . . . . . . . 14

4 An Econometric Model of Smoothed Returns $\quad 17$

4.1 Implications For Performance Statistics . . . . . . . . . . . . . . . . . . . . . 21

4.2 Examples of Smoothing Profiles . . . . . . . . . . . . . . . . . . . . 24

5 Estimation of Smoothing Profiles and Sharpe Ratios 28

5.1 Maximum Likelihood Estimation . . . . . . . . . . . . . . . . . . . 29

5.2 Linear Regression Analysis . . . . . . . . . . . . . . . . . . . . . . 31

5.3 Specification Checks . . . . . . . . . . . . . . . . . . . 34

5.4 Smoothing-Adjusted Sharpe Ratios . . . . . . . . . . . . . . . . . . . . 36

6 Empirical Analysis $\quad 40$

6.1 Summary Statistics . . . . . . . . . . . . . . . . . . . . . 43

6.2 Smoothing Profile Estimates . . . . . . . . . . . . . . . . . 46

6.3 Cross-Sectional Regressions _. . . . . . . . . . . . . . . . . 55

6.4 Illiquidity Vs. Smoothing . . . . . . . . . . . . . . . . . . . . . . . . . . . 59

6.5 Smoothing-Adjusted Sharpe Ratio Estimates . . . . . . . . . . . . . . . . 62

7 Conclusions $\quad 65$

$\begin{array}{ll}\text { A Appendix } & \mathbf{6 7}\end{array}$

A.1 Proof of Proposition $3 \ldots \ldots \ldots \ldots$. . . . . . . . . . . . . . . 67

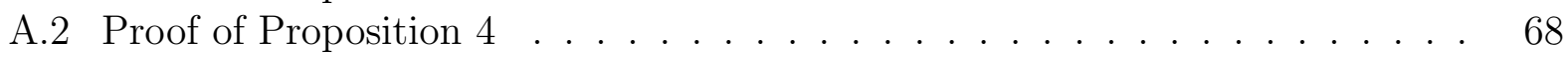

A.3 Proof of Proposition $5 \ldots \ldots \ldots \ldots \ldots \ldots$

A.4 TASS Fund Category Definitions . . . . . . . . . . . . . . . 73

A.5 Supplementary Empirical Results . . . . . . . . . . . . . . . . . . . 74 


\section{Introduction}

One of the fastest growing sectors of the financial services industry is the hedge-fund or "alternative investments" sector. Long the province of foundations, family offices, and highnet-worth investors, hedge funds are now attracting major institutional investors such as large state and corporate pension funds and university endowments, and efforts are underway to make hedge-fund investments available to individual investors through more traditional mutual-fund investment vehicles. One of the main reasons for such interest is the performance characteristics of hedge funds - often known as "high-octane investments", hedge funds typically yield double-digit returns to their investors and, in some cases, in a fashion that is uncorrelated with general market swings and with relatively low volatility. Most hedge funds accomplish this by maintaining both long and short positions in securitieshence the term "hedge" fund-which, in principle, gives investors an opportunity to profit from both positive and negative information while, at the same time, providing some degree of "market neutrality" because of the simultaneous long and short positions.

However, several recent empirical studies have challenged these characterizations of hedgefund returns, arguing that the standard methods of assessing the risk and reward of hedgefund investments may be misleading. For example, Asness, Krail and Liew (2001) show in some cases where hedge funds purport to be market neutral, i.e., funds with relatively small market betas, including both contemporaneous and lagged market returns as regressors and summing the coefficients yields significantly higher market exposure. Moreover, in deriving statistical estimators for Sharpe ratios of a sample of mutual and hedge funds, Lo (2002) shows that the correct method for computing annual Sharpe ratios based on monthly means and standard deviations can yield point estimates that differ from the naive Sharpe ratio estimator by as much as $70 \%$.

These empirical properties may have potentially significant implications for assessing the risks and expected returns of hedge-fund investments, and can be traced to a single common source: significant serial correlation in their returns.

This may come as some surprise because serial correlation is often (though incorrectly) associated with market inefficiencies, implying a violation of the Random Walk Hypothesis and the presence of predictability in returns. This seems inconsistent with the popular belief that the hedge-fund industry attracts the best and the brightest fund managers in the financial services sector. In particular, if a fund manager's returns are predictable, the implication is that the manager's investment policy is not optimal; if his returns next month can be reliably forecasted to be positive, he should increase his positions this month to take advantage of this forecast, and vice versa for the opposite forecast. By taking advantage of 
such predictability the fund manager will eventually eliminate it, along the lines of Samuelson's (1965) original "proof that properly anticipated prices fluctuate randomly". Given the outsized financial incentives of hedge-fund managers to produce profitable investment strategies, the existence of significant unexploited sources of predictability seems unlikely.

In this paper, we argue that in most cases, serial correlation in hedge-fund returns is not due to unexploited profit opportunities, but is more likely the result of illiquid securities that are contained in the fund, i.e., securities that are not actively traded and for which market prices are not always readily available. In such cases, the reported returns of funds containing illiquid securities will appear to be smoother than true economic returns-returns that fully reflect all available market information concerning those securities - and this, in turn, will impart a downward bias on the estimated return variance and yield positive serial return correlation.

The prospect of spurious serial correlation and biased sample moments in reported returns is not new. Such effects have been derived and empirically documented extensively in the literature on "nonsynchronous trading", which refers to security prices set at different times are treated as if they were sampled simultaneously. ${ }^{1}$ However, this literature has focused exclusively on equity market-microstructure effects as the sources of nonsynchronicity - closing prices that are set at different times, or prices that are stale - where the temporal displacement is on the order of minutes, hours, or, in extreme cases, several days. ${ }^{2}$ In the context of hedge funds, we argue in this paper that serial correlation is the outcome of illiquidity exposure, and while nonsynchronous trading may be one symptom or by-product of illiquidity, it is not the only aspect of illiquidity that affects hedge-fund returns. Even if prices were sampled synchronously, they may still yield highly serially correlated returns if the securities

\footnotetext{
1 For example, the daily prices of financial securities quoted in the Wall Street Journal are usually "closing" prices, prices at which the last transaction in each of those securities occurred on the previous business day. If the last transaction in security A occurs at 2:00pm and the last transaction in security B occurs at 4:00pm, then included in B's closing price is information not available when A's closing price was set. This can create spurious serial correlation in asset returns since economy-wide shocks will be reflected first in the prices of the most frequently traded securities, with less frequently traded stocks responding with a lag. Even when there is no statistical relation between securities A and B, their reported returns will appear to be serially correlated and cross-correlated simply because we have mistakenly assumed that they are measured simultaneously. One of the first to recognize the potential impact of nonsynchronous price quotes was Fisher (1966). Since then more explicit models of non-trading have been developed by Atchison, Butler, and Simonds (1987), Dimson (1979), Cohen, Hawawini, et al. (1983a,b), Shanken (1987), Cohen, Maier, et al. (1978, 1979, 1986), Kadlec and Patterson (1999), Lo and MacKinlay (1988, 1990), and Scholes and Williams (1977). See Campbell, Lo, and MacKinlay (1997, Chapter 3) for a more detailed review of this literature.

${ }^{2}$ For such application, Lo and MacKinlay (1988, 1990) and Kadlec and Patterson (1999) show that nonsynchronous trading cannot explain all of the serial correlation in weekly returns of equal- and valueweighted portfolios of US equities during the past three decades.
} 
are not actively traded. ${ }^{3}$ Therefore, although our formal econometric model of illiquidity is similar to those in the nonsynchronous trading literature, the motivation is considerably broader-linear extrapolation of prices for thinly traded securities, the use of smoothed broker-dealer quotes, trading restrictions arising from control positions and other regulatory requirements, and, in some cases, deliberate performance-smoothing behavior - and the corresponding interpretations of the parameter estimates must be modified accordingly.

Regardless of the particular mechanism by which hedge-fund returns are smoothed and serial correlation is induced, the common theme and underlying driver is illiquidity exposure. In this paper, we develop an explicit econometric model of smoothed returns and derive its implications for common performance statistics such as the mean, standard deviation, and Sharpe ratio. We find that the induced serial correlation and impact on the Sharpe ratio can be quite significant even for mild forms of smoothing. We estimate the model using historical hedge-fund returns from the TASS Database, and show how to infer the true risk exposures of a smoothed fund for a given smoothing profile. Our empirical findings are quite intuitive: funds with the highest serial correlation tend to be the more illiquid funds, e.g., emerging market debt, fixed income, etc., and after correcting for the effects of smoothed returns, some of the most successful types of funds tend to have considerably less attractive performance characteristics.

Before describing our econometric model of smoothed returns, we provide a brief literature review in Section 2 and then consider other potential sources of serial correlation in hedgefund returns in Section 3. We show that these other alternatives - time-varying expected returns, time-varying leverage, and incentive fees with high-water marks - are unlikely to be able to generate the magnitudes of serial correlation observed in the data. We develop a model of smoothed returns in Section 4 and derive its implications for serial correlation in observed returns, and we propose several methods for estimating the smoothing profile and smoothing-adjusted Sharpe ratios in Section 5. We apply these methods to a dataset of 909 hedge funds spanning the period from November 1977 to January 2001 and summarize our findings in Section 6, and conclude in Section 7.

\section{Literature Review}

Thanks to the availability of hedge-fund returns data from sources such as AltVest, Hedge Fund Research (HFR), Managed Account Reports (MAR), and TASS, a number of empirical studies of hedge funds have been published recently. For example, Ackermann, McEnally,

\footnotetext{
${ }^{3}$ In fact, for most hedge funds, returns computed on a monthly basis, hence the pricing or "mark-tomarket" of a fund's securities typically occurs synchronously on the last day of the month.
} 
and Ravenscraft (1999), Agarwal and Naik (2000b, 2000c), Edwards and Caglayan (2001), Fung and Hsieh (1999, 2000, 2001), Kao (2002), and Liang (1999, 2000, 2001) provide comprehensive empirical studies of historical hedge-fund performance using various hedgefund databases. Agarwal and Naik (2000a), Brown and Goetzmann (2001), Brown, Goetzmann, and Ibbotson (1999), Brown, Goetzmann, and Park (1997, 2000, 2001), Fung and Hsieh (1997a, 1997b), and Lochoff (2002) present more detailed performance attribution and "style" analysis for hedge funds. None of these empirical studies focus directly on the serial correlation in hedge-fund returns or the sources of such correlation.

However, several authors have examined the persistence of hedge-fund performance over various time intervals, and such persistence may be indirectly linked to serial correlation, e.g., persistence in performance usually implies positively autocorrelated returns. Agarwal and Naik (2000c) examine the persistence of hedge-fund performance over quarterly, halfyearly, and yearly intervals by examining the series of wins and losses for two, three, and more consecutive time periods. Using net-of-fee returns, they find that persistence is highest at the quarterly horizon and decreases when moving to the yearly horizon. The authors also find that performance persistence, whenever present, is unrelated to the type of a hedge fund strategy. Brown, Goetzmann, Ibbotson, and Ross (1992) show that survivorship gives rise to biases in the first and second moments and cross-moments of returns, and apparent persistence in performance where there is dispersion of risk among the population of managers. However, using annual returns of both defunct and currently operating offshore hedge funds between 1989 and 1995, Brown, Goetzmann, and Ibbotson (1999) find virtually no evidence of performance persistence in raw returns or risk-adjusted returns, even after breaking funds down according to their returns-based style classifications. None of these studies considers illiquidity and smoothed returns as a source of serial correlation in hedge-fund returns.

The findings by Asness, Krail, and Liew (2001) - that lagged market returns are often significant explanatory variables for the returns of supposedly market-neutral hedge fundsis closely related to serial correlation and smoothed returns, as we shall demonstrate in Section 4. In particular, we show that even simple models of smoothed returns can explain both serial correlation in hedge-fund returns and correlation between hedge-fund returns and lagged index returns, and our empirically estimated smoothing profiles imply lagged beta coefficients that are consistent with the lagged beta estimates reported in Asness, Krail, and Liew (2001).

With respect to the deliberate smoothing of performance by managers, a recent study of closed-end funds by Chandar and Bricker (2002) concludes that managers seem to use accounting discretion in valuing restricted securities so as to optimize fund returns with respect to a passive benchmark. Because mutual funds are highly regulated entities that are required 
to disclose considerably more information about their holdings than hedge funds, Chandar and Bricker (2002) were able to perform a detailed analysis of the periodic adjustmentsboth discretionary and non-discretionary - that fund managers made to the valuation of their restricted securities. Their findings suggest that performance smoothing may be even more relevant in the hedge-fund industry which is not nearly as transparent, and that econometric models of smoothed returns may be an important tool for detecting such behavior and unraveling its effects on true economic returns.

\section{Other Sources of Serial Correlation}

Before turning to our econometric model of smoothed returns in Section 4, we first consider four other potential sources of serial correlation in asset returns: (1) market inefficiencies; (2) time-varying expected returns; (3) time-varying leverage; and (4) incentive fees with high water marks.

Perhaps the most common explanation (at least among industry professionals) for the presence of serial correlation in asset returns is a violation of the Efficient Markets Hypothesis, one of the central pillars of modern finance theory. As with so many of the ideas of modern economics, the origins of the Efficient Markets Hypothesis can be traced back to Paul Samuelson (1965), whose contribution is neatly summarized by the title of his article: "Proof that Properly Anticipated Prices Fluctuate Randomly". In an informationally efficient market, price changes must be unforecastable if they are properly anticipated, i.e., if they fully incorporate the expectations and information of all market participants. Fama (1970) operationalizes this hypothesis, which he summarizes in the well-known epithet "prices fully reflect all available information", by placing structure on various information sets available to market participants. This concept of informational efficiency has a wonderfully counter-intuitive and seemingly contradictory flavor to it: the more efficient the market, the more random the sequence of price changes generated by such a market, and the most efficient market of all is one in which price changes are completely random and unpredictable. This, of course, is not an accident of Nature but is the direct result of many active participants attempting to profit from their information. Unable to curtail their greed, an army of investors aggressively pounce on even the smallest informational advantages at their disposal, and in doing so, they incorporate their information into market prices and quickly eliminate the profit opportunities that gave rise to their aggression. If this occurs instantaneously, which it must in an idealized world of "frictionless" markets and costless trading, then prices must always fully reflect all available information and no profits can be garnered from information-based 
trading (because such profits have already been captured).

In the context of hedge-fund returns, one interpretation of the presence of serial correlation is that the hedge-fund manager is not taking full advantage of the information or "alpha" contained in his strategy. For example, if a manager's returns are highly positively autocorrelated, then it should be possible for him to improve his performance by exploiting this fact - in months where his performance is good, he should increase his bets in anticipation of continued good performance (due to positive serial correlation), and in months where his performance is poor, he should reduce his bets accordingly. The reverse argument can be made for the case of negative serial correlation. By taking advantage of serial correlation of either sign in his returns, the hedge-fund manager will eventually eliminate it along the lines of Samuelson (1965), i.e., properly anticipated hedge-fund returns should fluctuate randomly. And if this self-correcting mechanism of the Efficient Markets Hypothesis is at work among any group of investors in the financial community, it surely must be at work among hedgefund managers, which consists of a highly trained, highly motivated, and highly competitive group of sophisticated investment professionals.

Of course, the natural counter-argument to this application of the Efficient Markets Hypothesis is that hedge-fund managers cannot fully exploit such serial correlation because of transactions costs and liquidity constraints. But once again, this leads to the main thesis of this paper, that serial correlation is a proxy for illiquidity and smoothed returns.

There are, however, three additional explanations for the presence of serial correlation. One of the central tenets of modern financial economics is the necessity of some trade-off between risk and expected return, hence serial correlation may not be exploitable in the sense that an attempt to take advantage of predictabilities in fund returns might be offset by corresponding changes in risk, leaving the fund manager indifferent at the margin between his current investment policy and other alternatives. Specifically, LeRoy (1973), Rubinstein (1976), and Lucas (1978) have demonstrated conclusively that serial correlation in asset returns need not be the result of market inefficiencies, but may be the result of time-varying expected returns, which is perfectly consistent with the Efficient Markets Hypothesis. ${ }^{4}$ If

\footnotetext{
${ }^{4}$ Grossman (1976) and Grossman and Stiglitz (1980) go even further. They argue that perfectly informationally efficient markets are an impossibility, for if markets are perfectly efficient, the return to gathering information is nil, in which case there would be little reason to trade and markets would eventually collapse. Alternatively, the degree of market inefficiency determines the effort investors are willing to expend to gather and trade on information, hence a non-degenerate market equilibrium will arise only when there are sufficient profit opportunities, i.e., inefficiencies, to compensate investors for the costs of trading and information-gathering. The profits earned by these attentive investors may be viewed as economic rents that accrue to those willing to engage in such activities. Who are the providers of these rents? Black (1986) gives us a provocative answer: noise traders, individuals who trade on what they think is information but is in fact merely noise.
} 
an investment strategy's required expected return varies through time-because of changes in its risk exposures, for example - then serial correlation may be induced in realized returns without implying any violation of market efficiency (see Figure 1). We examine this possibility more formally in Section 3.1.

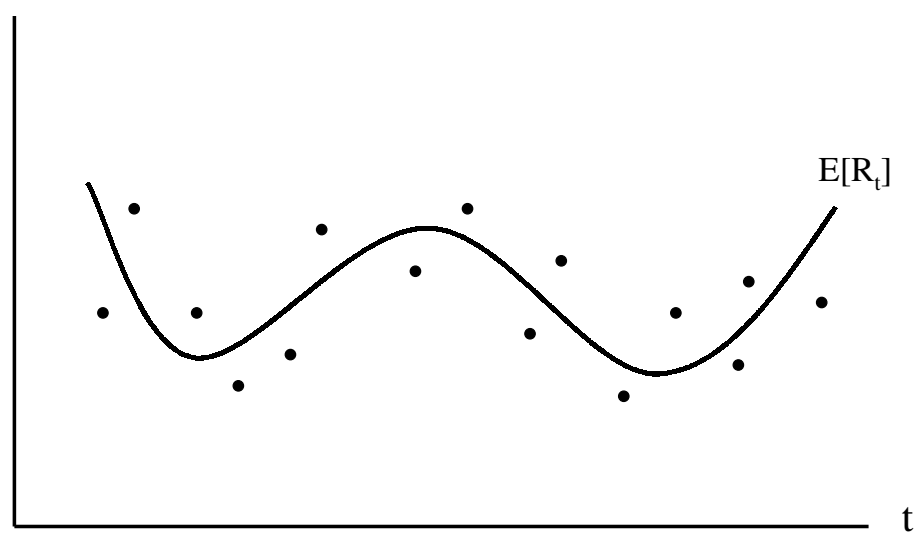

Figure 1: Time-varying expected returns can induce serial correlation in asset returns.

Another possible source of serial correlation in hedge-fund returns is time-varying leverage. If managers change the degree to which they leverage their investment strategies, and if these changes occur in response to lagged market conditions, then this is tantamount to the case of time-varying expected returns. We consider this case in Section 3.2.

Finally, we investigate one more potential explanation for serial correlation: the compensation structure of the typical hedge fund. Because most hedge funds charge an incentive fee coupled with a "high water mark" that must be surpassed before incentive fees are paid, this path dependence in the computation for net-of-fee returns may induce serial correlation. We develop a formal model of this phenomenon in Section 3.3.

The analysis of Sections 3.1-3.3 show that time-varying expected returns, time-varying leverage, and incentive fees with high water marks can all generate serial correlation in hedge-fund returns, but none of these effects can plausibly generate serial correlation to the degree observed in the data, e.g., $30 \%$ to $50 \%$ for monthly returns. Therefore, illiquidity and smoothed returns are more likely sources of serial correlation in hedge-fund returns. 


\subsection{Time-Varying Expected Returns}

Let $R_{t}$ denote a hedge fund's return in month $t$, and suppose that its dynamics are given by the following time-series process:

$$
R_{t}=\mu_{1} I_{t}+\mu_{0}\left(1-I_{t}\right)+\epsilon_{t}
$$

where $\epsilon_{t}$ is assumed to be independently and identically distributed (IID) with mean 0 and variance $\sigma_{\epsilon}^{2}$, and $I_{t}$ is a two-state Markov process with transition matrix:

$$
P \equiv \begin{aligned}
& I_{t}=1 \\
& I_{t}=0
\end{aligned}\left(\begin{array}{cc}
p & 1-p \\
1-q & q
\end{array}\right)
$$

and $\mu_{0}$ and $\mu_{1}$ are the equilibrium expected returns of fund $i$ in states 0 and 1 , respectively. This is a particularly simple model of time-varying expected returns in which we abstract from the underlying structure of the economy that gives rise to (1), but focus instead on the serial correlation induced by the Markov regime-switching process (2). ${ }^{5}$ In particular, observe that

$$
P^{k}=\frac{1}{2-p-q}\left(\begin{array}{cc}
1-q & 1-p \\
1-q & 1-p
\end{array}\right)+\frac{(p+q-1)^{k}}{2-p-q}\left(\begin{array}{rr}
1-p & -(1-p) \\
-(1-q) & 1-q
\end{array}\right)
$$

assuming that $|p+q-1|<1$, hence the steady-state probabilities and moments for the regime-switching process $I_{t}$ are:

$$
\begin{aligned}
P^{\infty} & =\left(\begin{array}{c}
\pi_{1} \\
\pi_{0}
\end{array}\right)=\left(\begin{array}{c}
\frac{1-q}{2-p-q} \\
\frac{1-p}{2-p-q}
\end{array}\right) \\
\mathrm{E}\left[I_{t}\right] & =\frac{1-q}{2-p-q} \\
\operatorname{Var}\left[I_{t}\right] & =\frac{(1-p)(1-q)}{(2-p-q)^{2}}
\end{aligned}
$$

\footnotetext{
${ }^{5}$ For examples of dynamic general equilibrium models that yield a Markov-switching process for asset prices, and econometric methods to estimate such processes, see Cecchetti and Mark (1990), Goodwin (1993), Hamilton (1989, 1990, 1996), Kandel and Stambaugh (1991), and Turner, Startz, and Nelson (1989).
} 
These, in turn, imply the following moments for $R_{t}$ :

$$
\begin{aligned}
\mathrm{E}\left[R_{t}\right] & =\mu_{1} \frac{1-q}{2-p-q}+\mu_{0} \frac{1-p}{2-p-q} \\
\operatorname{Var}\left[R_{t}\right] & =\left(\mu_{1}-\mu_{0}\right)^{2} \frac{(1-p)(1-q)}{(2-p-q)^{2}}+\sigma_{\epsilon_{i}}^{2} \\
\rho_{k} \equiv \operatorname{Corr}\left[R_{t-k}, R_{t}\right] & =\frac{(p+q-1)^{k}}{1+\sigma_{\epsilon}^{2} /\left[\left(\mu_{1}-\mu_{0}\right)^{2} \frac{(1-p)(1-q)}{(2-p-q)^{2}}\right]}
\end{aligned}
$$

By calibrating the parameters $\mu_{1}, \mu_{0}, p, q$, and $\sigma_{\epsilon}^{2}$ to empirically plausible values, we can compute the serial correlation induced by time-varying expected returns using (9).

Observe from (9) that the serial correlation of returns depends on the squared difference of expected returns, $\left(\mu_{1}-\mu_{0}\right)^{2}$, not on the particular values in either regime. Moreover, the absolute magnitudes of the autocorrelation coefficients $\rho_{k}$ are monotonically increasing in $\left(\mu_{1}-\mu_{0}\right)^{2}$ - the larger the difference in expected returns between the two states, the more serial correlation is induced. Therefore, we begin our calibration exercise by considering an extreme case where $\left|\mu_{1}-\mu_{0}\right|$ is $5 \%$ per month, or $60 \%$ per year, which yields rather dramatic shifts in regimes. To complete the calibration exercise, we fix the unconditional variance of returns at a particular value, say $(20 \%)^{2} / 12$ (which is comparable with the volatility of the S\&P 500 over the past 30 years), vary $p$ and $q$, and solve for the values of $\sigma_{\epsilon}^{2}$ that are consistent with the values of $p, q,\left(\mu_{1}-\mu_{0}\right)^{2}$, and the unconditional variance of returns.

The top panel of Table 1 reports the first-order autocorrelation coefficients for various values of $p$ and $q$ under these assumptions, and we see that even in this most extreme case, the largest absolute magnitude of serial correlation is only $15 \%$. The second panel of Table 1 shows that when the unconditional variance of returns is increased from $20 \%$ to $50 \%$ per year, the correlations decline in magnitude with the largest absolute correlation of $2.4 \%$. And the bottom panel illustrates the kind of extreme parameter values needed to obtain autocorrelations that are empirically relevant for hedge-fund returns - a difference in expected returns of $20 \%$ per month or $240 \%$ per year, and probabilities $p$ and $q$ that either both $80 \%$ or higher, or both $20 \%$ or lower. Given the implausibility of these parameter values, we conclude that time-varying expected returns - at least of this form - may not be the most likely explanation for serial correlation in hedge-fund returns. 


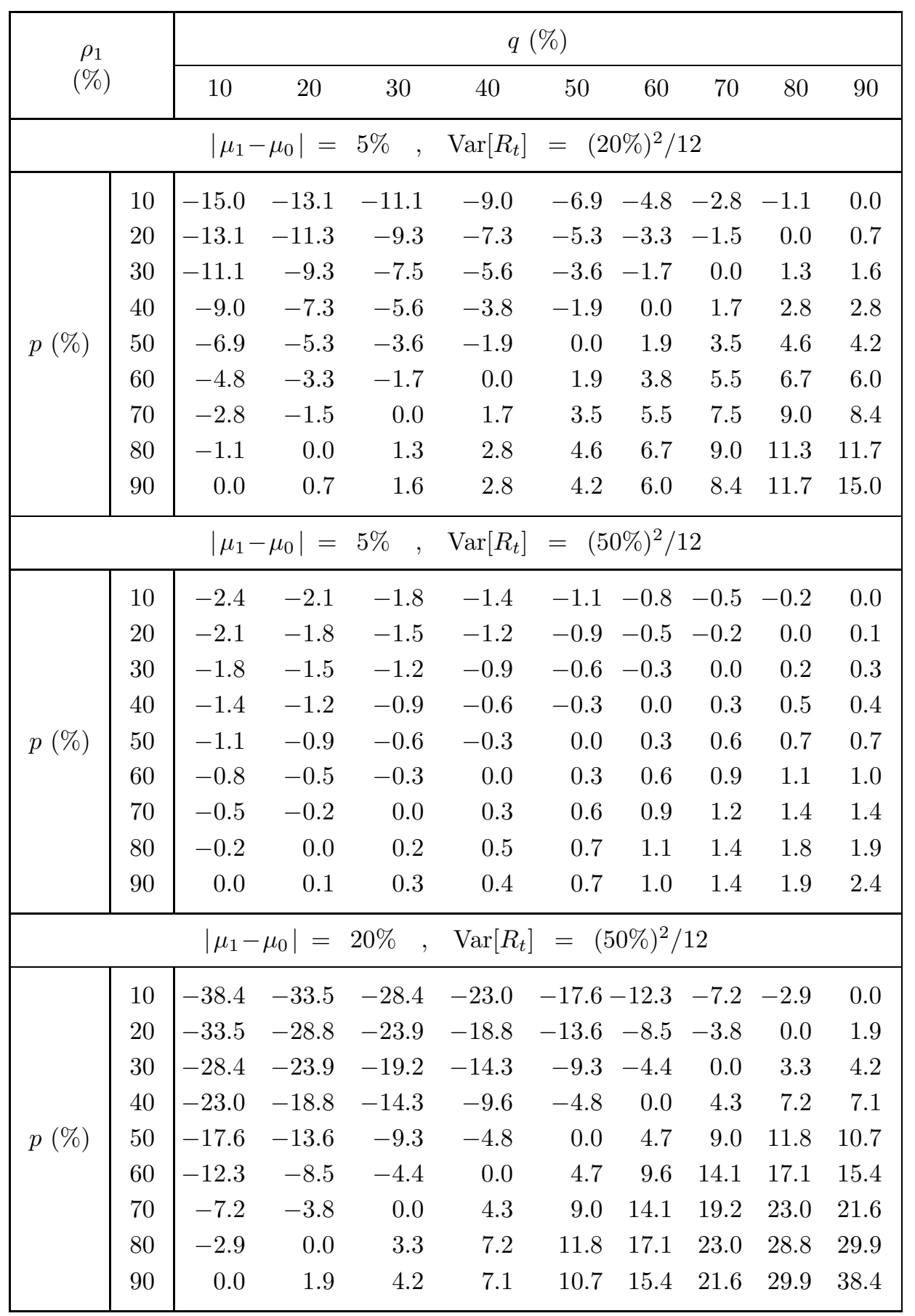

Table 1: First-order autocorrelation coefficients of returns from a two-state Markov model of time-varying expected returns, $R_{t}=\mu_{1} I_{t}+\mu_{0}\left(1-I_{t}\right)+\epsilon_{t}$, where $p \equiv \operatorname{Prob}\left(I_{t+1}=1 \mid I_{t}=1\right)$, $q \equiv \operatorname{Prob}\left(I_{t+1}=0 \mid I_{t}=0\right), \mu_{1}$ and $\mu_{0}$ are the monthly expected returns in states 1 and 0 , respectively, and $\epsilon_{t} \sim \mathcal{N}\left(0, \sigma_{\epsilon}^{2}\right)$ and $\sigma_{\epsilon}^{2}$ is calibrated to fix the unconditional variance $\operatorname{Var}\left[R_{t}\right]$ of returns at a prespecified level. 


\subsection{Time-Varying Leverage}

Another possible source of serial correlation in hedge-fund returns is time-varying leverage. Since leverage directly affects the expected return of any investment strategy, this can be considered a special case of time-varying expected returns which we examined in Section 3.1. Specifically, if $L_{t}$ denotes a hedge fund's leverage ratio, then the actual return $R_{t}^{o}$ of the fund at date $t$ is given by:

$$
R_{t}^{o}=L_{t} R_{t}
$$

where $R_{t}$ is the fund's unlevered return. ${ }^{6}$ For example if a fund's unlevered strategy yields a $2 \%$ return in a given month, but $50 \%$ of the funds are borrowed from various counterparties at fixed borrowing rates, the return to the fund's investors is approximately $4 \%,{ }^{7}$ hence the leverage ratio is 2 .

The specific mechanisms by which a hedge fund changes its leverage can be quite complex and depend on a number of factors including market volatility, credit risk, and various constraints imposed by investors, regulatory bodies, banks, brokers, and other counterparties. But the basic motivation for typical leverage dynamics is the well-known trade-off between risk and expected return: by increasing its leverage ratio, a hedge fund boosts its expected returns proportionally, but also increases its return volatility and, eventually, its credit risk or risk of default. Therefore, counterparties providing credit facilities for hedge funds will impose some ceiling on the degree of leverage they are willing to provide. More importantly, as market prices move against a hedge fund's portfolio, thereby reducing the value of the fund's collateral and increasing its leverage ratio, or as markets become more volatile and the fund's risk exposure increases significantly, creditors (and, in some cases, securities regulations) will require the fund to either post additional collateral or liquidate a portion of its portfolio to bring the leverage ratio back down to an acceptable level. As a result, the leverage ratio of a typical hedge fund varies through time in a specific manner, usually as a function of market prices and market volatility. Therefore we propose a simple data-dependent mechanism through which a hedge fund determines its ideal leverage ratio.

Denote by $R_{t}$ the return of a fund in the absence of any leverage, and to focus squarely

\footnotetext{
${ }^{6}$ For simplicity, and with little loss in generality, we have ignored the borrowing costs associated with leverage in our specification (10). Although including such costs will obviously reduce the net return, the serial correlation properties will be largely unaffected because the time variation in borrowing rates is not significant relative to $R_{t}$ and $L_{t}$.

${ }^{7}$ Less the borrowing rate, of course, which we assume is 0 for simplicity.
} 
on the ability of leverage to generate serial correlation, let $R_{t}$ be IID through time, hence:

$$
R_{t}=\mu+\epsilon_{t}, \epsilon_{t} \operatorname{IID} \mathcal{N}\left(0, \sigma_{\epsilon}^{2}\right)
$$

where we have assumed that $\epsilon_{t}$ is normally distributed only for expositional convenience. ${ }^{8}$ Given (10), the $k$-th order autocorrelation coefficient of leveraged returns $R_{t}^{o}$ is:

$$
\begin{array}{r}
\rho_{k}=\frac{1}{\operatorname{Var}\left[R_{t}^{o}\right]}\left[\mu^{2} \operatorname{Cov}\left[L_{t}, L_{t+k}\right]+\mu \operatorname{Cov}\left[L_{t}, L_{t+k} \epsilon_{t+k}\right]+\right. \\
\left.\mu \operatorname{Cov}\left[L_{t+k}, L_{t} \epsilon_{t}\right]+\operatorname{Cov}\left[L_{t} \epsilon_{t}, L_{t+k} \epsilon_{t+k}\right]\right] .
\end{array}
$$

Now suppose that the leverage process $L_{t}$ is independently distributed through time and also independent of $\epsilon_{t+k}$ for all $k$. Then (12) implies that $\rho_{k}=0$ for all $k \neq 0$, hence time-varying leverage of this sort will not induce any serial correlation in returns $R_{t}^{o}$.

However, as discussed above, leverage is typically a function of market conditions, which can induce serial dependence in $L_{t}$ and dependence between $L_{t+k}$ and $\epsilon_{t}$ for $k \geq 0$, yielding serially correlated observed returns $R_{t}^{o}$.

To see how, we propose a simple but realistic mechanism by which a hedge fund might determine its leverage. Suppose that, as part of its enterprise-wide risk management protocol, a fund has adopted a policy of limiting the 95\% Value-at-Risk of its portfolio to no worse than $\delta$-for example, if $\delta=-10 \%$, this policy requires managing the portfolio so that the probability of a loss greater than or equal to $10 \%$ is at most $5 \%$. If we assume that the only control variable available to the manager is the leverage ratio $L_{t}$ and that unleveraged

\footnotetext{
${ }^{8}$ Other distributions can easily be used instead of the normal in the Monte Carlo simulation experiment described below.
} 
returns $R_{t}$ are given by (11), this implies the following constraint on leverage:

$$
\begin{aligned}
\operatorname{Prob}\left(R_{t}^{o} \leq \delta\right) & \leq 5 \%, \quad \delta \leq 0 \\
\operatorname{Prob}\left(L_{t} R_{t} \leq \delta\right) & \leq 5 \% \\
\operatorname{Prob}\left(\frac{R_{t}-\mu}{\sigma} \leq \frac{\delta / L_{t}-\mu}{\sigma}\right) & \leq 5 \% \\
\Phi\left(\frac{\delta / L_{t}-\mu}{\sigma}\right) & \leq 5 \% \\
\delta / L_{t} & \leq \sigma \Phi^{-1}(5 \%) \\
\Rightarrow L_{t} & \leq \frac{\delta}{\sigma \Phi^{-1}(5 \%)}
\end{aligned}
$$

where, following common industry practice, we have set $\mu=0$ in (13) to arrive at (14). ${ }^{9}$ Now in implementing the constraint (15), the manager must estimate the portfolio volatility $\sigma$, which is typically estimated using some rolling window of historical data, hence the manager's estimate is likely to be time-varying but persistent to some degree. This persistence, and the dependence of the volatility estimate on past returns, will both induce serial correlation in observed returns $R_{t}^{o}$. Specifically, let:

$$
\begin{aligned}
\hat{\sigma}_{t}^{2} & \equiv \frac{1}{n} \sum_{k=1}^{n}\left(R_{t-k}-\hat{\mu}\right)^{2} \quad, \quad \hat{\mu}_{t} \equiv \frac{1}{n} \sum_{k=1}^{n} R_{t-k} \\
L_{t} & =\frac{\delta}{\hat{\sigma}_{t} \Phi^{-1}(5 \%)}
\end{aligned}
$$

where we have assumed that the manager sets his leverage ratio $L_{t}$ to the maximum allowable level subject to the VaR constraint (15).

To derive the impact of this heuristic risk management policy on the serial correlation of observed returns, we perform a Monte Carlo simulation experiment where we simulate a time series of 100,000 returns $\left\{R_{t}\right\}$ and implement the leverage policy (17) to obtain a time series of observed returns $\left\{R_{t}^{o}\right\}$, from which we compute its autocorrelation coefficients $\left\{\rho_{k}\right\}$. Given the large sample size, our estimate should yield an excellent approximation to

\footnotetext{
${ }^{9}$ Setting the expected return of a portfolio equal to 0 for purposes of risk management is often motivated by a desire to be conservative. Most portfolios will tend to have positive expected return, hence setting $\mu$ equal to 0 will generally yield larger values for VaR. However, for actively managed portfolios that contain both long and short positions, Lo (2002) shows that the practice of setting expected returns equal to 0 need not be conservative, but in some cases, can yield severely downward-biased estimates of VaR.
} 
the population values of the autocorrelation coefficients. This procedure is performed for the following combinations of parameter values:

$$
\begin{aligned}
n & =3,6,9,12,24,36,48,60 \\
12 \mu & =5 \% \\
\sqrt{12} \sigma & =10 \%, 20 \%, 50 \% \\
\delta & =-25 \%
\end{aligned}
$$

and the results are summarized in Table 2. Note that the autocorrelation of observed returns (12) is homogeneous of degree 0 in $\delta$, hence we need only simulate our return process for one value of $\delta$ without loss of generality as far as $\rho_{k}$ is concerned. Of course, the mean and standard of observed returns and leverage will be affected by our choice of $\delta$, but because these variables are homogeneous of degree 1, we can obtain results for any arbitrary $\delta$ simply by rescaling our results for $\delta=-25 \%$.

For a VaR constraint of $-25 \%$ and an annual standard deviation of unlevered returns of $10 \%$, the mean leverage ratio ranges from 9.52 when $n=3$ to 4.51 when $n=60$. For small $n$, there is considerably more sampling variation in the estimated standard deviation of returns, hence the leverage ratio - which is proportional to the reciprocal of $\hat{\sigma}_{t}$-takes on more extreme values as well and has a higher expectation in this case.

As $n$ increases, the volatility estimator becomes more stable over time since each month's estimator has more data in common with the previous month's estimator, leading to more persistence in $L_{t}$ as expected. For example, when $n=3$, the average first-order autocorrelation coefficient of $L_{t}$ is $43.2 \%$, but increases to $98.2 \%$ when $n=60$. However, even with such extreme levels of persistence in $L_{t}$, the autocorrelation induced in observed returns $R_{t}^{o}$ is still only $-0.2 \%$. In fact, the largest absolute return-autocorrelation reported in Table 2 is only $0.7 \%$, despite the fact that leverage ratios are sometimes nearly perfectly autocorrelated from month to month. This suggests that time-varying leverage, at least of the form described by the VaR constraint (15), cannot fully account for the magnitudes of serial correlation in historical hedge-fund returns.

\subsection{Incentive Fees with High-Water Marks}

Yet another source of serial correlation in hedge-fund returns is an aspect of the fee structure that is commonly used in the hedge-fund industry: an incentive fee-typically $20 \%$ of excess returns above a benchmark - which is subject to a "high-water mark", meaning that incentive 


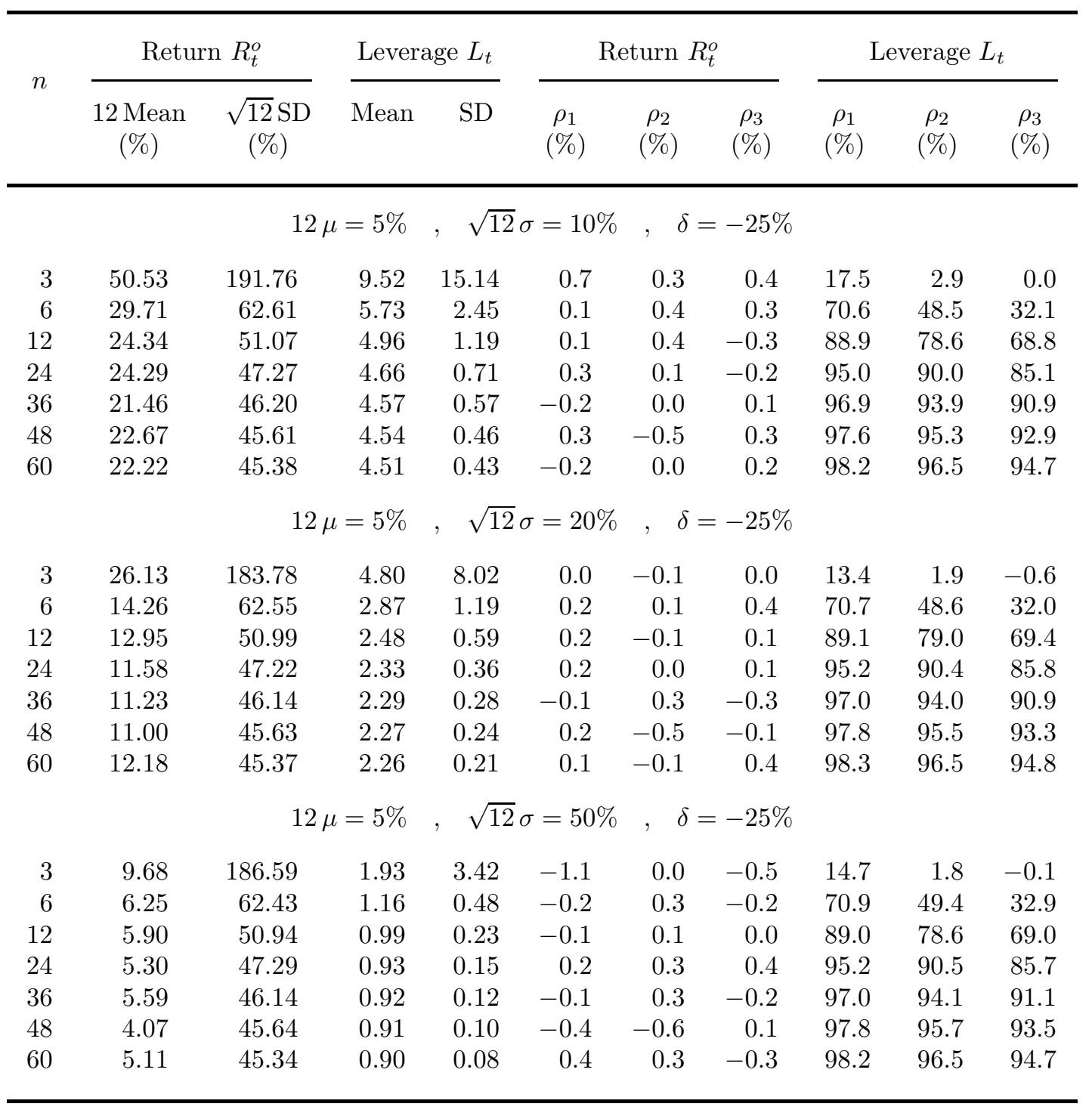

Table 2: Monte Carlo simulation results for time-varying leverage model with a VaR constraint. Each row corresponds to a separate and independent simulation of 100,000 observations of independently and identically distributed $\mathcal{N}\left(\mu, \sigma^{2}\right)$ returns $R_{t}$ which are multiplied by a time-varying leverage factor $L_{t}$ to generated observed returns $R_{t}^{o} \equiv L_{t} R_{t}$. 
fees are paid only if the cumulative returns of the fund are "above water", i.e., if they exceed the cumulative return of the benchmark since inception. ${ }^{10}$ This type of nonlinearity can induce serial correlation in net-of-fee returns because of the path dependence inherent in the definition of the high-water mark - when the fund is "below water" the incentive fee is not charged, but over time, as the fund's cumulative performance rises "above water", the incentive fee is reinstated and the net-of-fee returns is reduced accordingly.

Specifically, denote by $F_{t}$ the incentive fee paid to the manager in period $t$ and for simplicity, set the benchmark to 0 . Then:

$$
\begin{aligned}
F_{t} & \equiv \operatorname{Max}\left[0, \gamma\left(X_{t-1}+R_{t}\right)\right], \gamma>0 \\
X_{t} & \equiv \operatorname{Min}\left[0, X_{t-1}+R_{t}\right]
\end{aligned}
$$

where $X_{t}$ is a state variable that is non-zero only when the manager is "under water", in which case it measures the cumulative losses that must be recovered before an incentive fee is paid. The net-of-fee returns $R_{t}^{o}$ are then given by:

$$
R_{t}^{o}=R_{t}-F_{t}=(1-\gamma) R_{t}+\gamma\left(X_{t}-X_{t-1}\right)
$$

which is clearly serially correlated due to the presence of the lagged state variable $X_{t-1} \cdot{ }^{11}$

Because the high-water mark variable $X_{t}$ is a nonlinear recursive function of $X_{t-1}$ and $R_{t}$, its statistical properties are quite complex and difficult to derive in closed form. Therefore, we perform a Monte Carlo simulation experiment in which we simulate a time series of returns $\left\{R_{t}\right\}$ of length $T=100,000$ where $R_{t}$ is given by (11), compute the net-of-fee returns $\left\{R_{t}^{o}\right\}$, and estimate the first-order autocorrelation coefficient $\rho_{1}$. We follow this procedure

\footnotetext{
${ }^{10}$ For more detailed analyses of high water marks and other incentive-fee arrangements in the context of delegated portfolio management, see Bhattacharya and Pfleiderer (1985), Brown, Goetzmann, and Liang (2002), Carpenter (2000), Carpenter, Dybvig, and Farnsworth (2001), Elton and Gruber (2002), and Goetzmann, Ingersoll, and Ross (1997).

${ }^{11}$ This is a simplified model of how a typical hedge fund's incentive fee is structured. In particular, (18) ignores the fact that incentive fees are usually paid on an annual or quarterly basis whereas high-water marks are tracked on a monthly basis. Using the more realistic fee cycle did not have significant impact on our simulation results, hence we use (18) for expositional simplicity. Also, some funds do pay their employees and partners monthly incentive compensation, in which case (18) is the exact specification of their fee structure.
} 
for each of the combinations of the following parameter values:

$$
\begin{aligned}
12 \mu & =5 \%, 10 \%, 15 \%, \ldots, 50 \% \\
\sqrt{12} \sigma & =10 \%, 20 \%, \ldots, 50 \% \\
\gamma & =20 \%
\end{aligned}
$$

Table 3 summarizes the results of the simulations which show that although incentive fees with high-water marks do induce some serial correlation in net-of-fee returns, they are generally quite small in absolute value. For example, the largest absolute value of all the entries in Table 3 is only $4.4 \%$. Moreover, all of the averages are negative, a result of the fact that all of the serial correlation in $R_{t}^{o}$ is due to the first difference of $X_{t}$ in (19). This implies that incentive fees with high-water marks are even less likely to be able to explain the large positive serial correlation coefficients in historical hedge-fund returns.

\begin{tabular}{|c|c|rcccccccccc|}
\hline \multicolumn{2}{|c|}{$\begin{array}{c}\rho_{1} \\
(\%)\end{array}$} & \multicolumn{10}{|c|}{$12 \mu(\%)$} \\
\cline { 3 - 11 } & & 5 & 10 & 15 & 20 & 25 & 30 & 35 & 40 & 45 & 50 \\
\hline \multirow{3}{*}{$\sigma \times \sqrt{12}(\%)$} & 10 & -1.4 & -2.5 & -3.2 & -3.4 & -3.4 & -3.2 & -2.9 & -2.4 & -2.0 & -1.5 \\
& 20 & -1.6 & -2.3 & -2.9 & -3.4 & -3.8 & -4.1 & -4.3 & -4.4 & -4.4 & -4.3 \\
& 30 & -0.6 & -1.1 & -1.6 & -2.1 & -2.4 & -2.8 & -3.0 & -3.3 & -3.5 & -3.6 \\
& 40 & -0.2 & -0.7 & -1.1 & -1.4 & -1.8 & -2.1 & -2.3 & -2.6 & -2.8 & -3.0 \\
& 50 & 0.0 & -0.3 & -0.6 & -0.9 & -1.2 & -1.5 & -1.7 & -1.9 & -2.1 & -2.3 \\
\hline
\end{tabular}

Table 3: First-order autocorrelation coefficients for Monte Carlo simulation of net-of-fee returns under an incentive fee with a high-water mark. Each entry corresponds to a separate and independent simulation of 100,000 observations of independently and identically distributed $\mathcal{N}\left(\mu, \sigma^{2}\right)$ returns $R_{t}$, from which a $20 \%$ incentive fee $F_{t} \equiv \operatorname{Max}\left[0,0.2 \times\left(X_{t-1}+R_{t}\right)\right]$ is subtracted each period to yield net-of-fee returns $R_{t}^{o} \equiv R_{t}-F_{t}$, where $X_{t} \equiv \operatorname{Min}\left[0, X_{t-1}+R_{t}\right]$ is a state variable that is non-zero only when the fund is "under water", in which case it measures the cumulative losses that must be recovered before an incentive fee is paid.

\section{An Econometric Model of Smoothed Returns}

Having shown in Section 3 that other possible sources of serial correlation in hedge-fund returns are hard-pressed to yield empirically plausible levels of autocorrelation, we now turn to the main focus of this study: illiquidity and smoothed returns. Although illiquidity and smoothed returns are two distinct phenomena, it is important to consider them in tandem because one facilitates the other - for actively traded securities, both theory and empirical 
evidence suggest that in the absence of transactions costs and other market frictions, returns are unlikely to be very smooth.

As we argued in Section 1, nonsynchronous trading is a plausible source of serial correlation in hedge-fund returns. In contrast to the studies by Lo and MacKinlay $(1988,1990)$ and Kadlec and Patterson (1999) in which they conclude that it is difficult to generate serial correlations in weekly US equity portfolio returns much greater than $10 \%$ to $15 \%$ through nonsynchronous trading effects alone, we argue that in the context of hedge funds, significantly higher levels of serial correlation can be explained by the combination of illiquidity and smoothed returns, of which nonsynchronous trading is a special case. To see why, note that the empirical analysis in the nonsynchronous-trading literature is devoted exclusively to exchange-traded equity returns, not hedge-fund returns, hence their conclusions may not be relevant in our context. For example, Lo and MacKinlay (1990) argue that securities would have to go without trading for several days on average to induce serial correlations of $30 \%$, and they dismiss such nontrading intervals as unrealistic for most exchange-traded US equity issues. However, such nontrading intervals are quite a bit more realistic for the types of securities held by many hedge funds, e.g., emerging-market debt, real estate, restricted securities, control positions in publicly traded companies, asset-backed securities, and other exotic OTC derivatives. Therefore, nonsynchronous trading of this magnitude is likely to be an explanation for the serial correlation observed in hedge-fund returns.

But even when prices are synchronously measured - as they are for many funds that mark their portfolios to market at the end of the month to strike a net-asset-value at which investors can buy into or cash out of the fund - there are several other channels by which illiquidity exposure can induce serial correlation in the reported returns of hedge funds. Apart from the nonsynchronous-trading effect, naive methods for determining the fair market value or "marks" for illiquid securities can yield serially correlated returns. For example, one approach to valuing illiquid securities is to extrapolate linearly from the most recent transaction price (which, in the case of emerging-market debt, might be several months ago), which yields a price path that is a straight line, or at best a series of straight lines. Returns computed from such marks will be smoother, exhibiting lower volatility and higher serial correlation than true economic returns, i.e., returns computed from mark-to-market prices where the market is sufficiently active to allow all available information to be impounded in the price of the security. Of course, for securities that are more easily traded and with deeper markets, mark-to-market prices are more readily available, extrapolated marks are not necessary, and serial correlation is therefore less of an issue. But for securities that are thinly traded, or not traded at all for extended periods of time, marking them to market is often an expensive and time-consuming procedure that cannot easily be performed frequently. Therefore, we argue 
in this paper that serial correlation may serve as a proxy for a fund's liquidity exposure.

Even if a hedge-fund manager does not make use of any form of linear extrapolation to mark the securities in his portfolio, he may still be subject to smoothed returns if he obtains marks from broker-dealers that engage in such extrapolation. For example, consider the case of a conscientious hedge-fund manager attempting to obtain the most accurate mark for his portfolio at month end by getting bid/offer quotes from three independent brokerdealers for every security in his portfolio, and then marking each security at the average of the three quote midpoints. By averaging the quote midpoints, the manager is inadvertently downward-biasing price volatility, and if any of the broker-dealers employ linear extrapolation in formulating their quotes (and many do, through sheer necessity because they have little else to go on for the most illiquid securities), or if they fail to update their quotes because of light volume, serial correlation will also be induced in reported returns.

Finally, a more prosaic channel by which serial correlation may arise in the reported returns of hedge funds is through "performance smoothing", the unsavory practice of reporting only part of the gains in months when a fund has positive returns so as to partially offset potential future losses and thereby reduce volatility and improve risk-adjusted performance measures such as the Sharpe ratio. For funds containing liquid securities that can be easily marked to market, performance smoothing is more difficult and, as a result, less of a concern. Indeed, it is only for portfolios of illiquid securities that managers and brokers have any discretion in marking their positions. Such practices are generally prohibited by various securities laws and accounting principles, and great care must be exercised in interpreting smoothed returns as deliberate attempts to manipulate performance statistics. After all, as we have discussed above, there are many other sources of serial correlation in the presence of illiquidity, none of which is motivated by deceit. Nevertheless, managers do have certain degrees of freedom in valuing illiquid securities - for example, discretionary accruals for unregistered private placements and venture capital investments - and Chandar and Bricker (2002) conclude that managers of certain closed-end mutual funds do use accounting discretion to manage fund returns around a passive benchmark. Therefore, the possibility of deliberate performance smoothing in the less regulated hedge-fund industry must be kept in mind in interpreting our empirical analysis of smoothed returns.

To quantify the impact of all of these possible sources of serial correlation, denote by $R_{t}$ the true economic return of a hedge fund in period $t$, and let $R_{t}$ satisfy the following linear 
single-factor model:

$$
\begin{aligned}
R_{t} & =\mu+\beta \Lambda_{t}+\epsilon_{t}, \mathrm{E}\left[\Lambda_{t}\right]=\mathrm{E}\left[\epsilon_{t}\right]=0, \epsilon_{t}, \Lambda_{t} \sim \mathrm{IID} \\
\operatorname{Var}\left[R_{t}\right] & \equiv \sigma^{2} .
\end{aligned}
$$

True returns represent the flow of information that would determine the equilibrium value of the fund's securities in a frictionless market. However, true economic returns are not observed. Instead, $R_{t}^{o}$ denotes the reported or observed return in period $t$, and let

$$
\begin{aligned}
R_{t}^{o} & =\theta_{0} R_{t}+\theta_{1} R_{t-1}+\cdots+\theta_{k} R_{t-k} \\
\theta_{j} & \in[0,1], j=0, \ldots, k \\
1 & =\theta_{0}+\theta_{1}+\cdots+\theta_{k}
\end{aligned}
$$

which is a weighted average of the fund's true returns over the most recent $k+1$ periods, including the current period.

This averaging process captures the essence of smoothed returns in several respects. From the perspective of illiquidity-driven smoothing, (21) is consistent with several models in the nonsynchronous trading literature. For example, Cohen, Maier et al. (1986, Chapter 6.1) propose a similar weighted-average model for observed returns. ${ }^{12}$ Alternatively, (21) can be viewed as the outcome of marking portfolios to simple linear extrapolations of acquisition prices when market prices are unavailable, or "mark-to-model" returns where the pricing model is slowly varying through time. And of course, (21) also captures the intentional smoothing of performance.

The constraint (23) that the weights sum to 1 implies that the information driving the fund's performance in period $t$ will eventually be fully reflected in observed returns, but this

\footnotetext{
${ }^{12}$ In particular, their specification for observed returns is:

$$
r_{j, t}^{o}=\sum_{l=0}^{N}\left(\gamma_{j, t-l, l} r_{j, t-l}+\theta_{j, t-l}\right)
$$

where $r_{j, t-l}$ is the true but unobserved return for security $j$ in period $t-l$, the coefficients $\left\{\gamma_{j, t-l, l}\right\}$ are assumed to sum to 1 , and $\theta_{j, t-l}$ are random variables meant to capture "bid/ask bounce". The authors motivate their specification of nonsynchronous trading in the following way (p. 116): "Alternatively stated, the $\gamma_{j, t, 0}, \gamma_{j, t, 1}, \ldots, \gamma_{j, t, N}$ comprise a delay distribution that shows how the true return generated in period $t$ impacts on the returns actually observed during $t$ and the next $N$ periods". In other words, the essential feature of nonsynchronous trading is the fact that information generated at date $t$ may not be fully impounded into prices until several periods later.
} 
process could take up to $k+1$ periods from the time the information is generated. ${ }^{13}$ This is a sensible restriction in the current context of hedge funds for several reasons. Even the most illiquid securities will trade eventually, and when that occurs, all of the cumulative information affecting that security will be fully impounded into its transaction price. Therefore the parameter $k$ should be selected to match the kind of illiquidity of the fund - a fund comprised mostly of exchange-traded US equities fund would require a much lower value of $k$ than a private equity fund. Alternatively, in the case of intentional smoothing of performance, the necessity of periodic external audits of fund performance imposes a finite limit on the extent to which deliberate smoothing can persist. ${ }^{14}$

\subsection{Implications For Performance Statistics}

Given the smoothing mechanism outlined above, we have the following implications for the statistical properties of observed returns:

Proposition 1 Under (21)-(23), the statistical properties of observed returns are charac-

\footnotetext{
${ }^{13}$ In Lo and MacKinlay's (1990) model of nonsynchronous trading, they propose a stochastic non-trading horizon so that observed returns are an infinite-order moving average of past true returns, where the coefficients are stochastic. In that framework, the waiting time for information to become fully impounded into future returns may be arbitrarily long (but with increasingly remote probability).

${ }^{14}$ In fact, if a fund allows investors to invest and withdraw capital only at pre-specified intervals, imposing lock-ups in between, and external audits are conducted at these same pre-specified intervals, then it may be argued that performance smoothing is irrelevant. For example, no investor should be disadvantaged by investing in a fund that offers annual liquidity and engages in annual external audits with which the fund's net-asset-value is determined by a disintereted third party for purposes of redemptions and new investments. There are, however, two additional concerns that are not addressed by this practice - track records are still affected by smoothed returns, and estimates of a fund's liquidity exposure are also affected, both of which are important inputs in the typical hedge-fund investor's overall investment process.
} 
terized by:

$$
\begin{aligned}
& \mathrm{E}\left[R_{t}^{o}\right]=\mu \\
& \operatorname{Var}\left[R_{t}^{o}\right]=c_{\sigma}^{2} \sigma^{2} \leq \sigma^{2} \\
& \mathrm{SR}^{o} \equiv \frac{\mathrm{E}\left[R_{t}^{o}\right]}{\sqrt{\operatorname{Var}\left[R_{t}^{o}\right]}}=c_{s} \mathrm{SR} \geq \mathrm{SR} \equiv \frac{\mathrm{E}\left[R_{t}\right]}{\sqrt{\operatorname{Var}\left[R_{t}\right]}} \\
& \beta_{m}^{o} \equiv \frac{\operatorname{Cov}\left[R_{t}^{o}, \Lambda_{t-m}\right]}{\operatorname{Var}\left[\Lambda_{t-m}\right]}= \begin{cases}c_{\beta, m} \beta \text { if } 0 \leq m \leq k \\
0 \quad \text { if } m>k\end{cases} \\
& \operatorname{Cov}\left[R_{t}^{o}, R_{t-m}^{o}\right]= \begin{cases}\left(\sum_{j=0}^{k-m} \theta_{j} \theta_{j+m}\right) \sigma^{2} \quad \text { if } 0 \leq m \leq k \\
0 \quad \text { if } m>k & \text { if } 0 \leq m \leq k\end{cases} \\
& \operatorname{Corr}\left[R_{t}^{o}, R_{t-m}^{o}\right]=\frac{\operatorname{Cov}\left[R_{t}^{o}, R_{t-m}^{o}\right]}{\operatorname{Var}\left[R_{t}^{o}\right]}= \begin{cases}\frac{\sum_{j=0}^{k-m} \theta_{j} \theta_{j+m}}{\sum_{j=0}^{k} \theta_{j}^{2}} & \\
0 & \end{cases}
\end{aligned}
$$

where:

$$
\begin{aligned}
c_{\mu} & \equiv \theta_{0}+\theta_{1}+\cdots+\theta_{k} \\
c_{\sigma}^{2} & \equiv \theta_{0}^{2}+\theta_{1}^{2}+\cdots+\theta_{k}^{2} \\
c_{s} & \equiv 1 / \sqrt{\theta_{0}^{2}+\cdots+\theta_{k}^{2}} \\
c_{\beta, m} & \equiv \theta_{m}
\end{aligned}
$$

Proposition 1 shows that smoothed returns of the form (21)-(23) do not affect the expected value of $R_{t}^{o}$ but reduce its variance, hence boosting the Sharpe ratio of observed returns by a factor of $c_{s}$. From (27), we see that smoothing also affects $\beta_{0}^{o}$, the contemporaneous market beta of observed returns, biasing it towards 0 or "market neutrality", and induces correlation between current observed returns and lagged market returns up to lag $k$. This provides a formal interpretation of the empirical analysis of Asness, Krail, and Liew (2001) in which many hedge funds were found to have significant lagged market exposure despite relatively low contemporaneous market betas. 
Smoothed returns also exhibit positive serial correlation up to order $k$ according to (29), and the magnitude of the effect is determined by the pattern of weights $\left\{\theta_{j}\right\}$. If, for example, the weights are disproportionately centered on a small number of lags, relatively little serial correlation will be induced. However, if the weights are evenly distributed among many lags, this will result in higher serial correlation. A useful summary statistic for measuring the concentration of weights is

$$
\xi \equiv \sum_{j=0}^{k} \theta_{j}^{2} \in[0,1]
$$

which is simply the denominator of (29). This measure is well known in the industrial organization literature as the Herfindahl index, a measure of the concentration of an industry where $\theta_{j}$ represents the market share of firm $j$. Because $\theta_{j} \in[0,1], \xi$ is also confined to the unit interval, and is minimized when all the $\theta_{j}$ 's are identical, which implies a value of $1 /(k+1)$ for $\xi$, and is maximized when one coefficient is 1 and the rest are 0 , in which case $\xi=1$. In the context of smoothed returns, a lower value of $\xi$ implies more smoothing, and the upper bound of 1 implies no smoothing, hence we shall refer to $\xi$ as a "smoothing index".

In the special case of equal weights, $\theta_{j}=1 /(k+1)$ for $j=0, \ldots, k$, the serial correlation of observed returns takes on a particularly simple form:

$$
\operatorname{Corr}\left[R_{t}^{o}, R_{t-m}^{o}\right]=1-\frac{m}{k+1}, 1 \leq m \leq k
$$

which declines linearly in the lag $m$. This can yield substantial correlations even when $k$ is small-for example, if $k=2$ so that smoothing takes place only over a current quarter (i.e. this month and the previous two months), the first-order autocorrelation of monthly observed returns is $66.7 \%$.

To develop a sense for just how much observed returns can differ from true returns under the smoothed-return mechanism (21)-(23), denote by $\Delta(T)$ the difference between the cumulative observed and true returns over $T$ holding periods, where we assume that $T>k$ :

$$
\begin{aligned}
\Delta(T) & \equiv\left(R_{1}^{o}+R_{2}^{o}+\cdots+R_{T}^{o}\right)-\left(R_{1}+R_{2}+\cdots+R_{T}\right) \\
& =\sum_{j=0}^{k-1}\left(R_{-j}-R_{T-j}\right)\left(1-\sum_{i=0}^{j} \theta_{i}\right)
\end{aligned}
$$


Then we have:

Proposition 2 Under (21)-(23) and for $T>k$,

$$
\begin{aligned}
\mathrm{E}[\Delta(T)] & =0 \\
\operatorname{Var}[\Delta(T)] & =2 \sigma^{2} \sum_{j=0}^{k-1}\left(1-\sum_{l=0}^{j} \theta_{l}\right)^{2}=2 \sigma^{2} \zeta \\
\zeta & \equiv \sum_{j=0}^{k-1}\left(1-\sum_{l=0}^{j} \theta_{l}\right)^{2} \leq k
\end{aligned}
$$

Proposition 2 shows that the cumulative difference between observed and true returns has 0 expected value, and its variance is bounded above by $2 k \sigma^{2}$.

\subsection{Examples of Smoothing Profiles}

To develop further intuition for the impact of smoothed returns on observed returns, we consider the following three specific sets of weights $\left\{\theta_{j}\right\}$ or "smoothing profiles": 15

$$
\begin{aligned}
\theta_{j} & =\frac{1}{k+1} \quad(\text { Straightline }) \\
\theta_{j} & =\frac{k+1-j}{(k+1)(k+2) / 2} \quad \text { (Sum-of-Years) } \\
\theta_{j} & =\frac{\delta^{j}(1-\delta)}{1-\delta^{k+1}}, \quad \delta \in(0,1) \quad \text { (Geometric) } .
\end{aligned}
$$

The straightline profile weights each return equally. In contrast, the sum-of-years and geometric profiles weight the current return the most heavily, and then has monotonically declining weights, with the sum-of-years weights declining linearly and the geometric weights declining more rapidly (see Figure 2).

More detailed information about the three smoothing profiles is contained in Table 4 . The first panel reports the smoothing coefficients $\left\{\theta_{j}\right\}$, constants $c_{\beta, 0}, c_{\sigma}, c_{s}, \zeta$, and the first three autocorrelations of observed returns for the straightline profile for $k=0,1, \ldots, 5$. Consider the case where $k=2$. Despite the relatively short smoothing period of three months, the effects are dramatic: smoothing reduces the market beta by $67 \%$, increases the Sharpe ratio

\footnotetext{
${ }^{15}$ Students of accounting will recognize these profiles as commonly used methods for computing depreciation. The motivation for these depreciation schedules is not entirely without relevance in the smoothed-return context.
} 


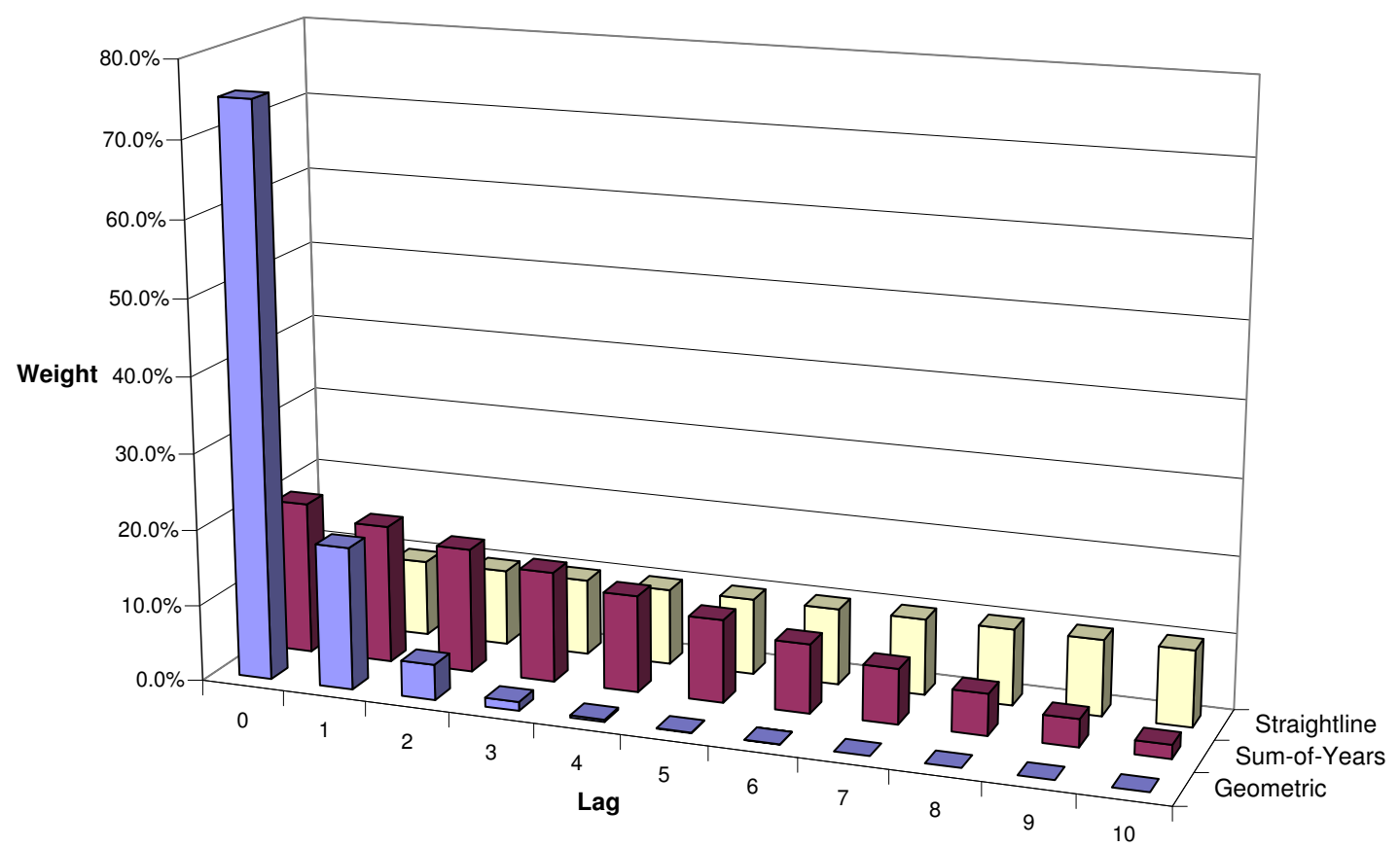

Figure 2: Straightline, sum-of-years, and geometric smoothing profiles for $k=10$. 
by $73 \%$, and induces first- and second-order serial correlation of $67 \%$ and $33 \%$, respectively, in observed returns. Moreover, the variance of the cumulative discrepancy between observed and true returns, $2 \sigma^{2} \zeta$, is only slightly larger than the variance of monthly true returns $\sigma^{2}$, suggesting that it may be difficult to detect this type of smoothed returns even over time.

As $k$ increases, the effects become more pronounced - for $k=5$, the market beta is reduced by $83 \%$, the Sharpe ratio is increased by $145 \%$, and first three autocorrelation coefficients are $83 \%, 67 \%$, and $50 \%$, respectively. However, in this extreme case, the variance of the discrepancy between true and observed returns is approximately three times the monthly variance of true returns, in which case it may be easier to identify smoothing from realized returns.

The sum-of-years profile is similar to, although somewhat less extreme than, the straightline profile for the same values of $k$ because more weight is being placed on the current return. For example, even in the extreme case of $k=5$, the sum-of-years profile reduces the market beta by $71 \%$, increases the Sharpe ratio by $120 \%$, induces autocorrelations of $77 \%, 55 \%$, and $35 \%$, respectively, in the first three lags, and has a discrepancy variance that is approximately 1.6 times the monthly variance of true returns.

The last two panels of Table 4 contain results for the geometric smoothing profile for two values of $\delta, 0.25$ and 0.50 . In the first case where $\delta=0.25$, the geometric profile places more weight on the current return than the other two smoothing profiles for all values of $k$, hence the effects tend to be less dramatic. Even in the extreme case of $k=5,75 \%$ of current true returns are incorporated into observed returns, the market beta is reduced by only $25 \%$, the Sharpe ratio is increased by only $29 \%$, the first three autocorrelations are $25 \%, 6 \%$, and $1 \%$ respectively, and the discrepancy variance is approximately $13 \%$ of the monthly variance of true returns. As $\delta$ increases, less weight is placed on the current observation and the effects on performance statistics become more significant. When $\delta=0.50$ and $k=5$, geometric smoothing reduces the market beta by $49 \%$, increases the Sharpe ratio by $71 \%$, induces autocorrelations of $50 \%, 25 \%$, and $12 \%$, respectively, for the first three lags, and yields a discrepancy variance that is approximately $63 \%$ of the monthly variance of true returns.

The three smoothing profiles have very different values for $\zeta$ in (40):

$$
\begin{aligned}
\zeta & =\frac{k(2 k+1)}{6(k+1)} \\
\zeta & =\frac{k\left(3 k^{2}+6 k+1\right)}{15(k+1)(k+2)} \\
\zeta & =\frac{\delta^{2}\left(-1+\delta^{k}\left(2+2 \delta+\delta^{k}\left(-1-2 \delta+k\left(\delta^{2}-1\right)\right)\right)\right)}{\left(\delta^{2}-1\right)\left(\delta^{k+1}-1\right)^{2}}
\end{aligned}
$$




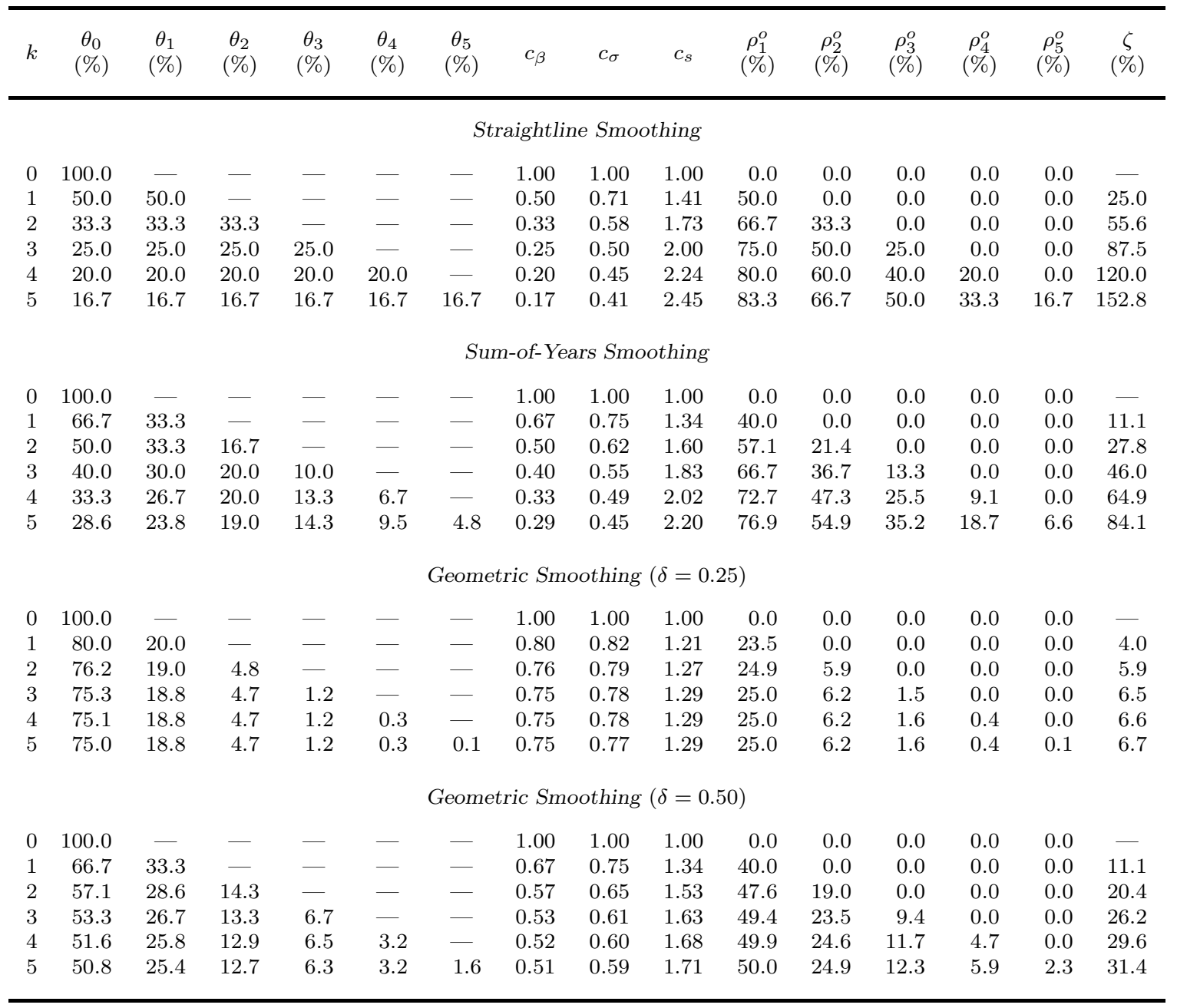

Table 4: Implications of three different smoothing profiles for observed betas, standard deviations, Sharpe ratios, and serial correlation coefficients for a fund with IID true returns. Straightline smoothing is given by $\theta_{j}=1 /(k+1)$; sum-of-years smoothing is given by $\theta_{j}=$ $(k+1-j) /[(k+1)(k+2) / 2]$; geometric smooothing is given by $\theta_{j}=\delta^{j}(1-\delta) /\left(1-\delta^{k+1}\right) . c_{\beta}$, $c_{\sigma}$, and $c_{s}$ denote multipliers associated with the beta, standard deviation, and Sharpe ratio of observed returns, respectively, $\rho_{j}^{o}$ denotes the $j$-th autocorrelation coefficient of observed returns, and $\zeta$ is proportional to the variance of the discrepancy between true and observed multi-period returns. 
with the straightline and sum-of-years profiles implying variances for $\Delta(T)$ that grow approximately linearly in $k$, and the geometric profile implying a variance for $\Delta(T)$ that asymptotes to a finite limit (see Figure 3).

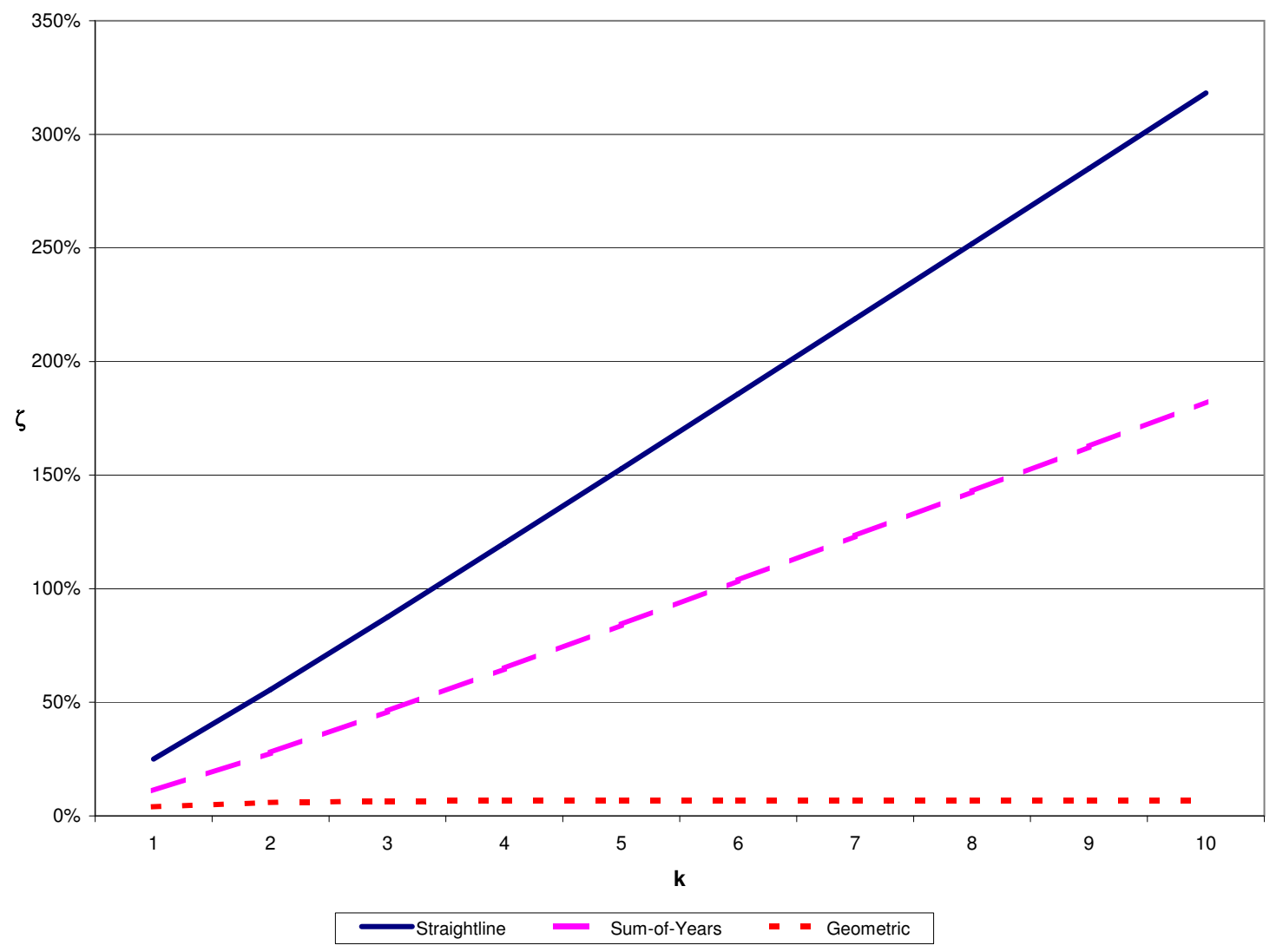

Figure 3: Straightline, sum-of-years, and geometric smoothing profiles for $k=10$.

The results in Table 4 and Figure 3 show that a rich set of biases can be generated by even simple smoothing profiles, and even the most casual empirical observation suggests that smoothed returns may be an important source of serial correlation in hedge-fund returns. To address this issue directly, we propose methods for estimating the smoothing profile in Section 5 and apply these methods to the data in Section 6 .

\section{$5 \quad$ Estimation of Smoothing Profiles and Sharpe Ratios}

Although the smoothing profiles described in Section 4.2 can all be easily estimated from the sample moments of fund returns, e.g., means, variances, and autocorrelations, we wish to 
be able to estimate more general forms of smoothing. Therefore, in this section we propose two estimation procedures - maximum likelihood and linear regression - that place fewer restrictions on a fund's smoothing profile than the three examples in Section 4.2. In Section 5.1 we review the steps for maximum likelihood estimation of an MA $(k)$ process, slightly modified to accommodate our context and constraints, and in Section 5.2 we consider a simpler alternative based on linear regression under the assumption that true returns are generated by the linear single-factor model (20). We propose several specification checks to evaluate the robustness of our smoothing model in Section 5.3, and in Section 5.4 we show how to adjust Sharpe ratios to take smoothed returns into account.

\subsection{Maximum Likelihood Estimation}

Given the specification of the smoothing process in (21)-(23), we can estimate the smoothing profile using maximum likelihood estimation in a fashion similar to the estimation of standard moving-average time series models (see, for example, Brockwell and Davis, 1991, Chapter 8). We begin by defining the de-meaned observed returns process $X_{t}$ :

$$
X_{t}=R_{t}^{o}-\mu
$$

and observing that (21)-(23) implies the following properties for $X_{t}$ :

$$
\begin{aligned}
X_{t} & =\theta_{0} \eta_{t}+\theta_{1} \eta_{t-1}+\cdots+\theta_{k} \eta_{t-k} \\
1 & =\theta_{0}+\theta_{1}+\cdots+\theta_{k} \\
\eta_{k} & \sim \mathcal{N}\left(0, \sigma_{\eta}^{2}\right)
\end{aligned}
$$

where, for purposes of estimation, we have added the parametric assumption (50) that $\eta_{k}$ is normally distributed. From (48), it is apparent that $X_{t}$ is a moving-average process of order $k$, or "MA $(k)$ ". Then for a given set of observations $\mathbf{X} \equiv\left[X_{1} \cdots X_{T}\right]^{\prime}$, the likelihood function is well known to be:

$$
\mathcal{L}\left(\boldsymbol{\theta}, \sigma_{\eta}\right)=(2 \pi)^{-T / 2}(\operatorname{det} \boldsymbol{\Gamma})^{-1 / 2} \exp \left(-\frac{1}{2} \mathbf{X}^{\prime} \boldsymbol{\Gamma}^{-1} \mathbf{X}\right), \quad \boldsymbol{\Gamma} \equiv \mathrm{E}\left[\mathbf{X X}^{\prime}\right]
$$


where $\boldsymbol{\theta} \equiv\left[\begin{array}{lll}\theta_{0} & \cdots & \theta_{k}\end{array}\right]^{\prime}$ and $\boldsymbol{\Gamma}$ is a function of the parameters $\boldsymbol{\theta}$ and $\sigma_{\eta}$. It can be shown that for any constant $\kappa$,

$$
\mathcal{L}\left(\kappa \boldsymbol{\theta}, \sigma_{\eta} / \kappa\right)=\mathcal{L}\left(\boldsymbol{\theta}, \sigma_{\eta}\right)
$$

therefore, an additional identification condition is required. The most common identification condition imposed in the time-series literature is the normalization $\theta_{0} \equiv 1$. However, in our context, we impose the condition (49) that the MA coefficients sum to 1-an economic restriction that smoothing takes place over only the most recent $k+1$ periods - and this is sufficient to identify the parameters $\boldsymbol{\theta}$ and $\sigma_{\eta}$. The likelihood function (51) may be then evaluated and maximized via the "innovations algorithm" of Brockwell and Davis (1991, Chapter 8.3), ${ }^{16}$ and the properties of the estimator are given by:

Proposition 3 Under the specification (48)-(50), $X_{t}$ is invertible on the set $\left\{\boldsymbol{\theta}: \theta_{0}+\theta_{1}+\right.$ $\left.\theta_{2}=1, \theta_{1}<1 / 2, \theta_{1}<1-2 \theta_{2}\right\}$, and the maximum likelihood estimator $\hat{\boldsymbol{\theta}}$ satisfies the following properties:

$$
1=\hat{\theta}_{0}+\hat{\theta}_{1}+\hat{\theta}_{2}
$$

${ }^{16}$ Specifically, let $\hat{\mathbf{X}}=\left[\begin{array}{lll}\hat{X}_{1} \cdots \hat{X}_{T}\end{array}\right]^{\prime}$ where $\hat{X}_{1}=0$ and $\hat{X}_{j}=\mathrm{E}\left[X_{j} \mid X_{1}, \ldots, X_{j-1}\right], j \geq 2$. Let $r_{t}=$ $\mathrm{E}\left[\left(X_{t+1}-\hat{X}_{t+1}\right)^{2}\right] / \sigma_{\eta}^{2}$. Brockwell and Davis (1991) show that (51) can be rewritten as:

$$
\mathcal{L}\left(\boldsymbol{\theta}, \sigma_{\eta}^{2}\right)=\left(2 \pi \sigma_{\eta}^{2}\right)^{-T / 2}\left(r_{0} \cdots r_{T-1}\right)^{-1 / 2} \exp \left[-\frac{1}{2} \sigma_{\eta}^{2} \sum_{t=1}^{T}\left(X_{t}-\hat{X}_{t}\right)^{2} / r_{t-1}\right]
$$

where the one-step-ahead predictors $\hat{X}_{t}$ and their normalized mean-squared errors $r_{t-1}, t=1, \ldots, T$ are calculated recursively according to the formulas given in Brockwell and Davis (1991, Proposition 5.2.2). Taking the derivative of (53) with respect to $\sigma_{\eta}^{2}$, see that the maximum likelihood estimator $\hat{\sigma}_{\eta}^{2}$ is given by:

$$
\hat{\sigma}_{\eta}^{2}=S(\boldsymbol{\theta})=T^{-1} \sum_{t=1}^{T}\left(X_{t}-\hat{X}_{t}\right)^{2} / r_{t-1}
$$

hence we can "concentrate" the likelihood function by substituting (54) into (53) to obtain:

$$
\mathcal{L}_{o}(\boldsymbol{\theta})=\log S(\boldsymbol{\theta})+T^{-1} \sum_{t=1}^{T} \log r_{t-1}
$$

which can be minimized in $\boldsymbol{\theta}$ subject to the constraint (49) using standard numerical optimization packages (we use Matlab's Optimization Toolbox in our empirical analysis). Maximum likelihood estimates obtained in this fashion need not yield an invertible MA $(k)$ process, but it is well known that any non-invertible process can always be transformed into an invertible one simply by adjusting the parameters $\sigma_{\eta}^{2}$ and $\boldsymbol{\theta}$. To address this identification problem, we impose the additional restriction that the estimated $\operatorname{MA}(k)$ process be invertible. 


$$
\begin{gathered}
\sqrt{T}\left(\left[\begin{array}{c}
\hat{\theta}_{1} \\
\hat{\theta}_{2}
\end{array}\right]-\left[\begin{array}{c}
\theta_{1} \\
\theta_{2}
\end{array}\right]\right) \stackrel{a}{\sim} \mathcal{N}\left(0, \mathbf{V}_{\theta}\right) \\
\mathbf{V}_{\theta} \equiv\left[\begin{array}{cc}
-\left(-1+\theta_{1}\right)\left(-1+2 \theta_{1}\right)\left(-1+\theta_{1}+2 \theta_{2}\right) & -\theta_{2}\left(-1+2 \theta_{1}\right)\left(-1+\theta_{1}+2 \theta_{2}\right) \\
-\theta_{2}\left(-1+2 \theta_{1}\right)\left(-1+\theta_{1}+2 \theta_{2}\right) & \left(-1+\theta_{1}-2\left(-1+\theta_{2}\right) \theta_{2}\right)\left(-1+\theta_{1}+2 \theta_{2}\right)
\end{array}\right]
\end{gathered}
$$

By applying the above procedure to observed de-meaned returns, we may obtain estimates of the smoothing profile $\hat{\boldsymbol{\theta}}$ for each fund. ${ }^{17}$ Because of the scaling property $(52)$ of the $\mathrm{MA}(k)$ likelihood function, a simple procedure for obtaining estimates of our smoothing model with the normalization (49) is to transform estimates $(\check{\boldsymbol{\theta}}, \check{\sigma})$ from standard MA $(k)$ estimation packages such as SAS or RATS by dividing each $\check{\theta}_{i}$ by $1+\check{\theta}_{1}+\cdots+\check{\theta}_{k}$ and multiplying $\check{\sigma}$ by the same factor. The likelihood function remains unchanged but the transformed smoothing coefficients will now satisfy (49).

\subsection{Linear Regression Analysis}

Although we proposed a linear single-factor model (20) in Section 4 for true returns so as to derive the implications of smoothed returns for the market beta of observed returns, the maximum likelihood procedure outlined in Section 5.1 is designed to estimate the more general specification of IID Gaussian returns, regardless of any factor structure. However, if we are willing to impose (20), a simpler method for estimating the smoothing profile is available. By substituting (20) into (21), we can re-express observed returns as:

$$
\begin{aligned}
R_{t}^{o} & =\mu+\beta\left(\theta_{0} \Lambda_{t}+\theta_{1} \Lambda_{t-1}+\cdots+\theta_{k} \Lambda_{t-k}\right)+u_{t} \\
u_{t} & =\theta_{0} \epsilon_{t}+\theta_{1} \epsilon_{t-1}+\cdots+\theta_{k} \epsilon_{t-k} .
\end{aligned}
$$

Suppose we estimate the following linear regression of observed returns on contemporaneous and lagged market returns:

$$
R_{t}^{o}=\mu+\gamma_{0} \Lambda_{t}+\gamma_{1} \Lambda_{t-1}+\cdots+\gamma_{k} \Lambda_{t-k}+u_{t}
$$

\footnotetext{
${ }^{17}$ Recall from Proposition 1 that the smoothing process (21)-(23) does not affect the expected return, i.e., the sample mean of observed returns is a consistent estimator of the true expected return. Therefore, we may use $R_{t}^{o}-\hat{\mu}$ in place of $X_{t}$ in the estimation process without altering any of the asymptotic properties of the maximum likelihood estimator.
} 
as in Asness, Krail and Liew (2001). Using the normalization (23) from our smoothing model, we can obtain estimators for $\beta$ and $\left\{\theta_{j}\right\}$ readily:

$$
\hat{\beta}=\hat{\gamma}_{0}+\hat{\gamma}_{1}+\cdots+\hat{\gamma}_{k} \quad, \quad \hat{\theta}_{j}=\hat{\gamma}_{j} / \hat{\beta}
$$

Moreover, a specification check for (59)-(60) can be performed by testing the following set of equalities:

$$
\beta=\frac{\gamma_{0}}{\theta_{0}}=\frac{\gamma_{1}}{\theta_{1}}=\cdots=\frac{\gamma_{k}}{\theta_{k}}
$$

Because of serial correlation in $u_{t}$, ordinary least squares estimates (62) will not be efficient and the usual standard errors are incorrect, but the estimates are still consistent and may be a useful first approximation for identifying smoothing in hedge-fund returns. ${ }^{18}$

There is yet another variation of the linear single-factor model that may help to disentangle the effects of illiquidity from return smoothing. ${ }^{19}$ Suppose that a fund's true economic returns $R_{t}$ satisfies:

$$
R_{t}=\mu+\beta \Lambda_{t}+\epsilon_{t}, \epsilon_{t} \sim \operatorname{IID}\left(0, \sigma_{\epsilon}^{2}\right)
$$

but instead of assuming that the common factor $\Lambda_{t}$ is IID as in (20), let $\Lambda_{t}$ be serially correlated. While this alternative may seem to be a minor variation of the smoothing model (21)-(23), the difference in interpretation is significant. A serially correlated $\Lambda_{t}$ captures the fact that a fund's returns may be autocorrelated because of an illiquid common factor, even in the absence of any smoothing process such as (21)-(23). Of course, this still begs the question of what the ultimate source of serial correlation might be, but by combining (64) with the smoothing process (21)-(23), it may be possible to distinguish between "systematic" versus "idiosyncratic" smoothing, the former attributable to the asset class and the latter resulting from fund-specific characteristics.

To see why the combination of (64) and (21)-(23) may have different implications for observed returns, suppose for the moment that there is no smoothing, i.e., $\theta_{0}=1$ and $\theta_{k}=0$

\footnotetext{
${ }^{18}$ To obtain efficient estimates of the smoothing coefficients, a procedure like the maximum likelihood estimator of Section 5.1 must be used.

${ }^{19}$ We thank the referee for encouraging us to explore this alternative.
} 
for $k>0$ in $(21)-(23)$. Then observed returns are simply given by:

$$
R_{t}^{o}=\mu+\beta \Lambda_{t}+\epsilon_{t}, \epsilon_{t} \sim \operatorname{IID}\left(0, \sigma_{\epsilon}^{2}\right)
$$

where $R_{t}^{o}$ is now serially correlated solely through $\Lambda_{t}$. This specification implies that the ratios of observed-return autocovariances will be identical across all funds with the same common factor:

$$
\frac{\operatorname{Cov}\left[R_{t}^{o}, R_{t-k}^{o}\right]}{\operatorname{Cov}\left[R_{t}^{o}, R_{t-l}^{o}\right]}=\frac{\beta \operatorname{Cov}\left[\Lambda_{t}, \Lambda_{t-k}\right]}{\beta \operatorname{Cov}\left[\Lambda_{t}, \Lambda_{t-l}\right]}=\frac{\operatorname{Cov}\left[\Lambda_{t}, \Lambda_{t-k}\right]}{\operatorname{Cov}\left[\Lambda_{t}, \Lambda_{t-l}\right]} .
$$

Moreover, (64) implies that in the regression equation (61), the coefficients of the lagged factor returns are zero and the error term is not serially correlated.

More generally, consider the combination of a serially correlated common factor (64) and smoothed returns (21)-(23). This more general econometric model of observed returns implies that the appropriate specification of the regression equation is:

$$
\begin{aligned}
R_{t}^{o} & =\mu+\gamma_{0} \Lambda_{t}+\gamma_{1} \Lambda_{t-1}+\cdots+\gamma_{k} \Lambda_{t-k}+u_{t} \\
u_{t} & =\theta_{0} \epsilon_{t}+\theta_{1} \epsilon_{t-1}+\cdots+\theta_{k} \epsilon_{t-k}, \epsilon_{t} \sim \operatorname{IID}\left(0, \sigma_{\epsilon}^{2}\right) \\
1 & =\theta_{0}+\theta_{1}+\cdots+\theta_{k} .
\end{aligned}
$$

To the extent that serial correlation in $R_{t}^{o}$ can be explained mainly by the common factor, the lagged coefficient estimates of (67) will be statistically insignificant, the residuals will be serially uncorrelated, and the ratios of autocovariance coefficients will be roughly constant across funds with the same common factor. To the extent that the smoothing process (21)(23) is responsible for serial correlation in $R_{t}^{o}$, the lagged coefficient estimates of (67) will be significant, the residuals will be serially correlated, and the ratios $\hat{\gamma}_{j} / \hat{\theta}_{j}$ will be roughly the same for all $j \geq 0$ and will be a consistent estimate of the factor loading or beta of the fund's true economic returns with respect to the factor $\Lambda_{t}$.

Perhaps the most difficult challenge in estimating (67)-(69) is to correctly identify the common factor $\Lambda_{t}$. Unlike a simple market-model regression that is meant to estimate the sensitivity of a fund's returns to a broad-based market index, the ability to distinguish between the effects of systematic illiquidity and idiosyncratic return smoothing via (67) relies heavily on the correct specification of the common factor. Using a common factor in (67) that is highly serially correlated but not exactly the right factor for a given fund may yield 
misleading estimates for the degree of smoothing in that fund's observed returns. Therefore, the common factor $\Lambda_{t}$ must be selected or constructed carefully to match the specific risk exposures of the fund, and the parameter estimates of (67) must be interpreted cautiously and with several specific alternative hypotheses at hand.

\section{$5.3 \quad$ Specification Checks}

Although the maximum likelihood estimator proposed in Section 5.1 has some attractive properties - it is consistent and asymptotically efficient under certain regularity conditionsit may not perform well in small samples or when the underlying distribution of true returns is not normal as hypothesized. ${ }^{20}$ Moreover, even if normality is satisfied and a sufficient sample size is available, our proposed smoothing model (21)-(23) may simply not apply to some of the funds in our sample. Therefore, it is important to have certain specification checks in mind when interpreting the empirical results.

The most obvious specification check is whether or not the maximum likelihood estimation procedure, which involves numerical optimization, converges. If not, this is one sign that our model is misspecified, either because of non-normality or because the smoothing process is inappropriate.

A second specification check is whether or not the estimated smoothing coefficients are all positive in sign (we do not impose non-negative restrictions in our estimation procedure, despite the fact that the specification does assume non-negativity). Estimated coefficients that are negative and significant may be a sign that the constraint (49) is violated, which suggests that a somewhat different smoothing model may apply.

A third specification check is to compare the smoothing-parameter estimates from the maximum likelihood approach of Section 5.1 with the linear regression approach of Section 5.2. If the linear single-factor model (20) holds, the two sets of smoothing-parameter estimates should be close. Of course, omitted factors could be a source of discrepancies between the two sets of estimates, so this specification check must be interpreted cautiously and with some auxiliary information about the economic motivation for the common factor $\Lambda_{t}$.

Finally, a more direct approach to testing the specification of (21)-(23) is to impose a different identification condition than (49). Suppose that the standard deviation $\sigma_{\eta}$ of true returns was observable; then the smoothing parameters $\boldsymbol{\theta}$ are identified, and a simple check of the specification (21)-(23) is to see whether the estimated parameters $\hat{\boldsymbol{\theta}}$ sum to 1 . Of

\footnotetext{
${ }^{20}$ There is substantial evidence that financial asset returns are not normally distributed, but characterized by skewness, leptokurtosis, and other non-gaussian properties (see, for example, Lo and MacKinlay, 1999). Given the dynamic nature of hedge-fund strategies, it would be even less plausible for their returns to be normally distributed.
} 
course, $\sigma_{\eta}$ is not observable, but if we had an alternative estimator $\tilde{\sigma}_{\eta}$ for $\sigma_{\eta}$, we can achieve identification of the $\mathrm{MA}(k)$ process by imposing the restriction:

$$
\sigma_{\eta}=\tilde{\sigma}_{\eta}
$$

instead of (49). If, under this normalization, the smoothing parameter estimates are significantly different, this may be a sign of misspecification.

Of course, the efficacy of this specification check depends on the quality of $\tilde{\sigma}_{\eta}$. We propose to estimate this quantity by exploiting the fact that the discrepancy between observed and true returns becomes "small" for multiperiod returns as the number of periods grows. Specifically, recall from (37) that:

$$
\begin{aligned}
\left(R_{1}^{o}+R_{2}^{o}+\cdots+R_{T}^{o}\right) & =\left(R_{1}+R_{2}+\cdots+R_{T}\right)+\sum_{j=0}^{k-1}\left(R_{-j}-R_{T-j}\right)\left(1-\sum_{i=0}^{j} \theta_{i}\right) \\
\frac{1}{T} \operatorname{Var}\left[\sum_{t=1}^{T} R_{t}^{o}\right] & =\sigma_{\eta}^{2}+\frac{\sigma_{\eta}^{2}}{T} \sum_{j=0}^{k-1}\left(1-\sum_{i=0}^{j} \theta_{i}\right)\left(1-2 \sum_{i=0}^{j} \theta_{i}\right)
\end{aligned}
$$

and under the specification (21)-(23), it is easy to show that the second term on the right side of (72) vanishes as $T$ increases without bound, hence:

$$
\lim _{T \rightarrow \infty} \frac{1}{T} \operatorname{Var}\left[\sum_{t=1}^{T} R_{t}^{o}\right]=\sigma_{\eta}^{2}
$$

To estimate this normalized variance of multiperiod observed returns, we can apply Newey and West's (1987) estimator:

$$
\tilde{\sigma}_{\eta}^{2} \equiv \frac{1}{T} \sum_{1}^{T}\left(R_{t}^{o}-\hat{\mu}\right)^{2}+\frac{2}{T} \sum_{j=1}^{m}\left(1-\frac{j}{m+1}\right)\left(\sum_{t=j+1}^{T}\left(R_{t}^{o}-\hat{\mu}\right)\left(R_{t-j}^{o}-\hat{\mu}\right)\right)
$$

where $\hat{\mu}$ is the sample mean of $\left\{R_{t}^{o}\right\}$ and $m$ is a truncation lag that must increase with $T$ but at a slower rate to ensure consistency and asymptotic normality of the estimator. By 
imposing the identification restriction

$$
\sigma_{\eta}=\tilde{\sigma}_{\eta}
$$

in estimating the smoothing profile of observed returns, we obtain another estimator of $\boldsymbol{\theta}$ which can be compared against the first. As in the case of the normalization (49), the alternate normalization (75) can be imposed by rescaling estimates $(\check{\boldsymbol{\theta}}, \check{\sigma})$ from standard $\operatorname{MA}(k)$ estimation packages, in this case by dividing each $\check{\theta}_{i}$ by $\tilde{\sigma}_{\eta} / \check{\sigma}$ and multiplying $\check{\sigma}$ by the same factor.

\subsection{Smoothing-Adjusted Sharpe Ratios}

One of the main implications of smoothed returns is that Sharpe ratios are biased upward, in some cases substantially (see Proposition 1). ${ }^{21}$ The mechanism by which this bias occurs is through the reduction in volatility because of the smoothing, but there is an additional bias that occurs when monthly Sharpe ratios are annualized by multiplying by $\sqrt{12}$. If monthly returns are independently and identically distributed, this is the correct procedure, but Lo (2002) shows that for non-IID returns, an alternative procedure must be used, one that accounts for serial correlation in returns in a very specific manner. ${ }^{22}$ Specifically, denote by $R_{t}(q)$ the following $q$-period return:

$$
R_{t}(q) \equiv R_{t}+R_{t-1}+\cdots+R_{t-q+1}
$$

\footnotetext{
${ }^{21}$ There are a number of other concerns regarding the use and interpretation of Sharpe ratios in the context of hedge funds. See Agarwal and Naik (2000a, 2002), Goetzmann et al. (2002), Lo (2001), Sharpe (1994), Spurgin (2001), and Weisman (2002) for examples where Sharpe ratios can be misleading indicators of the true risk-adjusted performance of hedge-fund strategies, and for alternate methods of constructing optimal portfolios of hedge funds.

${ }^{22}$ See also Jobson and Korkie (1981), who were perhaps the first to derive rigorous statistical properties of performance measures such as the Sharpe ratio and the Treynor measure.
} 
where we ignore the effects of compounding for computational convenience. ${ }^{23}$ For IID returns, the variance of $R_{t}(q)$ is directly proportional to $q$, hence the Sharpe ratio satisfies the simple relation:

$$
\operatorname{SR}(q)=\frac{\mathrm{E}\left[R_{t}(q)\right]-R_{f}(q)}{\sqrt{\operatorname{Var}\left[R_{t}(q)\right]}}=\frac{q\left(\mu-R_{f}\right)}{\sqrt{q} \sigma}=\sqrt{q} \mathrm{SR} .
$$

Using Hansen's (1982) GMM estimator, Lo (2002) derives the asymptotic distribution of $\widehat{\mathrm{SR}}(q)$ as:

$$
\sqrt{T}(\widehat{\mathrm{SR}}(q)-\sqrt{q} \mathrm{SR}) \stackrel{a}{\sim} \mathcal{N}\left(0, V_{\mathrm{IID}}(q)\right), \quad V_{\mathrm{IID}}(q)=q V_{\mathrm{IID}}=q\left(1+\frac{1}{2} \mathrm{SR}^{2}\right)
$$

For non-IID returns, the relation between $\mathrm{SR}$ and $\mathrm{SR}(q)$ is somewhat more involved because the variance of $R_{t}(q)$ is not just the sum of the variances of component returns, but also includes all the covariances. Specifically, under the assumption that returns $\left\{R_{t}\right\}$ are stationary,

$$
\operatorname{Var}\left[R_{t}(q)\right]=\sum_{i=0}^{q-1} \sum_{j=0}^{q-1} \operatorname{Cov}\left[R_{t-i}, R_{t-j}\right]=q \sigma^{2}+2 \sigma^{2} \sum_{k=1}^{q-1}(q-k) \rho_{k}
$$

where $\rho_{k} \equiv \operatorname{Cov}\left[R_{t}, R_{t-k}\right] / \operatorname{Var}\left[R_{t}\right]$. This yields the following relation between $\operatorname{SR}$ and $\operatorname{SR}(q)$ :

$$
\operatorname{SR}(q)=\eta(q) \mathrm{SR} \quad, \quad \eta(q) \equiv \frac{q}{\sqrt{q+2 \sum_{k=1}^{q-1}(q-k) \rho_{k}}}
$$

Note that (80) reduces to (77) if the autocorrelations $\left\{\rho_{k}\right\}$ are zero, as in the case of IID returns. However, for non-IID returns, the adjustment factor for time-aggregated Sharpe ratios is generally not $\sqrt{q}$ but a function of the first $q-1$ autocorrelations of returns, which

${ }^{23}$ The exact expression is, of course:

$$
R_{t}(q) \equiv \prod_{j=0}^{q-1}\left(1+R_{t-j}\right)-1
$$

For most (but not all) applications, (76) is an excellent approximation. Alternatively, if $R_{t}$ is defined to be the continuously compounded return, i.e., $R_{t} \equiv \log \left(P_{t} / P_{t-1}\right)$ where $P_{t}$ is the price or net asset value at time $t$, then (76) is exact. 
is readily estimated from the sample autocorrelations of returns, hence:

$$
\widehat{\mathrm{SR}}(q)=\hat{\eta}(q) \widehat{\mathrm{SR}} \quad, \quad \hat{\eta}(q) \equiv \frac{q}{\sqrt{q+2 \sum_{k=1}^{q-1}(q-k) \hat{\rho}_{k}}}
$$

where $\hat{\rho}_{k}$ is the sample $k$-th order autocorrelation coefficient.

Lo (2002) also derives the asymptotic distribution of (81) under fairly general assumptions for the returns process (stationarity and ergodicity) using generalized method of moments. However, in the context of hedge-fund returns, the usual asymptotic approximations may not be satisfactory because of the small sample sizes that characterize hedge-fund data-a fiveyear track record, which amounts to only 60 monthly observations, is considered quite a long history in this fast-paced industry. Therefore, we derive an alternative asymptotic distribution using the continuous-record asymptotics of Richardson and Stock (1989). Specifically, as the sample size $T$ increases without bound, let $q$ grow as well so that the ratio converges to some finite limit between 0 and 1 :

$$
\lim _{q, T \rightarrow \infty} q / T=\tau \in(0,1)
$$

This condition is meant to provide an asymptotic approximation that may be more accurate for small-sample situations, i.e., situations where $q$ is a significant fraction of $T$. For example, in the case of a fund with a five-year track record, computing an annual Sharpe ratio with monthly data corresponds to a value of 0.20 for the ratio $q / T$.

Now as $q$ increases without bound, $\operatorname{SR}(q)$ also tends to infinity, hence we must renormalize it to obtain a well-defined asymptotic sampling theory. In particular, observe that:

$$
\begin{aligned}
\operatorname{SR}(q) & =\frac{\mathrm{E}\left[R_{t}(q)\right]-R_{f}(q)}{\sqrt{\operatorname{Var}\left[R_{t}(q)\right]}}=\frac{q\left(\mu-R_{f}\right)}{\sqrt{\operatorname{Var}\left[R_{t}(q)\right]}} \\
\operatorname{SR}(q) / \sqrt{q} & =\frac{\mu-R_{f}}{\sqrt{\operatorname{Var}\left[R_{t}(q)\right] / q}} \\
\lim _{q \rightarrow \infty} \operatorname{SR}(q) / \sqrt{q} & =\frac{\mu-R_{f}}{\bar{\sigma}}
\end{aligned}
$$

where $\bar{\sigma}$ can be viewed as a kind of long-run average return standard deviation, which is generally not identical to the unconditional standard deviation $\sigma$ of monthly returns except in the IID case. To estimate $\bar{\sigma}$, we can either follow Lo (2002) and use sample autocorrelations 
as in (81), or estimate $\bar{\sigma}$ directly accordingly to Newey and West (1987):

$$
\hat{\bar{\sigma}}_{\mathrm{NW}}^{2} \equiv \frac{1}{T} \sum_{1}^{T}\left(R_{t}-\hat{\mu}\right)^{2}+\frac{2}{T} \sum_{j=1}^{m}\left(1-\frac{j}{m+1}\right) \sum_{t=j+1}^{T}\left(R_{t}-\hat{\mu}\right)\left(R_{t-j}-\hat{\mu}\right)
$$

where $\hat{\mu}$ is the sample mean of $\left\{R_{t}\right\}$. For this estimator of $\bar{\sigma}$, we have the following asymptotic result:

Proposition 4 As $m$ and $T$ increase without bound so that $m / T \rightarrow \lambda \in(0,1), \hat{\bar{\sigma}}_{\mathrm{NW}}^{2}$ converges weakly to the following functional $f(W)$ of standard Brownian motion on $[0,1]:^{24}$

$$
\begin{aligned}
f(W) \equiv \frac{2 \bar{\sigma}^{2}}{\lambda} & \left(\int_{0}^{1} W(r)[W(r)-W(\min (r+\lambda, 1))] d r-\right. \\
& \left.W(1) \int_{0}^{\lambda}(\lambda-r)(W(1-r)-W(r)) d r+\frac{\lambda\left(1-\frac{\lambda^{2}}{3}\right)}{2} W^{2}(1)\right) .
\end{aligned}
$$

From (87), a straightforward computation yields the following expectations:

$$
\mathrm{E}\left[\hat{\bar{\sigma}}_{\mathrm{NW}}^{2}\right]=1-\lambda+\frac{\lambda^{2}}{3} \quad, \quad \mathrm{E}\left[1 / \hat{\bar{\sigma}}_{\mathrm{NW}}\right] \approx \sqrt{\frac{1+\lambda}{1-\lambda+\lambda^{2} / 3}}
$$

hence we propose the following bias-corrected estimator for the Sharpe ratio for small samples:

$$
\widehat{\mathrm{SR}}(q)=\frac{\sqrt{q}\left(\hat{\mu}-R_{f}\right)}{\hat{\bar{\sigma}}_{\mathrm{NW}}} \sqrt{\frac{1-\lambda+\lambda^{3} / 2}{1+\lambda}}
$$

and its asymptotic distribution is given by:

Proposition 5 As $m, q$, and $T$ increase without bound so that $m / T \rightarrow \lambda \in(0,1)$ and $q / T \rightarrow \tau \in(0,1)$, the Sharpe ratio estimator $\widehat{\mathrm{SR}}(q)$ converges weakly to the following random variable:

$$
\widehat{\mathrm{SR}}(q) \Rightarrow\left(\frac{\mathrm{SR}(q)}{f(W)}+\frac{\sqrt{\tau} W(1)}{f(W)}\right) \sqrt{\frac{1-\lambda+\lambda^{3} / 2}{1+\lambda}}
$$

\footnotetext{
${ }^{24}$ See Billingsley (1968) for the definition of weak convergence and related results.
} 
where $f(W)$ is given by (87), $\mathrm{SR}(q)$ is given by (83) and $W(\cdot)$ is standard Brownian motion defined on $[0,1]$.

Monte Carlo simulations show that the second term of (90) does not account for much bias when $\tau \in\left(0, \frac{1}{2}\right]$, and that (90) is an excellent approximation to the small-sample distributions of Sharpe ratios for non-IID returns. ${ }^{25}$

\section{Empirical Analysis}

For our empirical analysis, we use the TASS database of hedge funds which consists of monthly returns and accompanying information for 2,439 hedge funds (as of January 2001) from November 1977 to January 2001. ${ }^{26}$ The database is divided into two parts: "Live" and "Graveyard" funds. Hedge funds that belong to the Live database are considered to be active as of January 1, 2001; once a hedge fund decides not to report its performance, is liquidated, restructured, or merged with other hedge funds, the fund is transferred into the Graveyard database. A hedge fund can only be listed in the Graveyard database after being listed in the Live database, but the TASS database is subject to backfill bias - when a fund decides to be included in the database, TASS adds the fund to the Live database and includes available prior performance of the fund(hedge funds do not need to meet any specific requirements to be included in the TASS database). Due to reporting delays and time lags in contacting hedge funds, some Graveyard funds can be incorrectly listed in the Live database for a period of time. However, TASS has adopted a policy of transferring funds from the Live to the Graveyard database if they do not report over a 6-8 month period.

As of January 1, 2001, the combined data set of both live and dead hedge funds contained 2,439 funds with at least one monthly net return observation. Out of these 2,439 funds, 1,512 are in the Live database and 927 are in the Graveyard database. The earliest data available for a fund in either database is November 1, 1977. The Graveyard database became active only in 1994, i.e., funds that were dropped from the Live database prior to 1994 are not included in the Graveyard database, which may yield a certain degree of survivorship bias. ${ }^{27}$

\footnotetext{
${ }^{25}$ We have tabulated the percentiles of the distribution of (90) by Monte Carlo simulation for an extensive combination of values of $q, \tau$, and $\lambda$ and would be happy to provide them to interested readers upon request.

${ }^{26}$ For further information about the database and TASS, see http://www.tassresearch.com.

${ }^{27}$ For studies attempting to quantify the degree and impact of survivorship bias, see Baquero, Horst, and Verbeek (2002), Brown, Goetzmann, Ibbotson, and Ross (1992), Brown, Goetzmann, and Ibbotson (1999), Brown, Goetzmann, and Park (1997), Carpenter and Lynch (1999), Fung and Hsieh (1997b, 2000), Horst, Nijman, T. and M. Verbeek (2001), Hendricks, Patel, and Zeckhauser (1997), and Schneeweis and Spurgin (1996).
} 
A majority of the 2,439 funds reported returns net of various fees on a monthly basis. ${ }^{28}$ We eliminated 30 funds that reported only gross returns and/or quarterly returns (15 from each of the Live and Graveyard databases, respectively), leaving 2,409 funds in our sample. We imposed an additional filter of including only those funds with at least five years of data, leaving 651 funds in the Live database and 258 in the Graveyard database for a combined total of 909 funds. This obviously creates additional survivorship bias in our sample, but since our main objective is to estimate smoothing profiles and not to make inferences about overall performance, our filter may not be as problematic. ${ }^{29}$

TASS also attempts to classify funds according to one of 17 different investment styles, listed in Table 5 and described in Appendix A.4; funds that TASS are not able to categorize are assigned a category code of ' 0 '.${ }^{30}$ Table 5 also reports the number of funds in each category for the Live, Graveyard, and Combined databases, and it is apparent from these figures that the representation of investment styles is not evenly distributed, but is concentrated among six categories: US Equity Hedge (162), Event Driven (109), Non-Directional/Relative Value (85), Pure Managed Futures (93), Pure Emerging Market (72), and Fund of Funds (132). Together, these six categories account for $72 \%$ of the funds in the Combined database.

To develop a sense of the dynamics of the TASS database and the impact of our minimum return-history filter, in Table 6 we report annual frequency counts of the funds in the database at the start of each year, funds entering during the year, funds exiting during the year, and funds entering and exiting within the year. The left panel contains counts for the entire TASS database, and the right panel contains counts for our sample of 909 funds with at least five years of returns. The left panel shows that despite the start date of November 1977, the database is relatively sparsely populated until the 1990's, with the largest increase in new funds in 1998 and, in the aftermath of the collapse of LTCM, the largest number of funds exiting the database in 1999 and 2000. The right panel of Table 6 illustrates the impact of our five-year filter - the number of funds is considerably smaller, and although the impact of survivorship bias can be ameliorated by the use of Live and Graveyard funds, our sample of 909 funds will not include any of the funds started in 1997 and later which is a substantial proportion of the TASS database.

The attrition rates reported in Table 6 are defined as the ratio of funds exiting in a given

\footnotetext{
${ }^{28}$ TASS defines returns as the change in net asset value during the month (assuming the reinvestment of any distributions on the reinvestment date used by the fund) divided by the net asset value at the beginning of the month, net of management fees, incentive fees, and other fund expenses. Therefore, these reported returns should approximate the returns realized by investors. TASS also converts all foreign-currency denominated returns to US-dollar returns using the appropriate exchange rates.

${ }^{29}$ See the references in footnote 27.

${ }^{30} \mathrm{~A}$ hedge fund can have at most 2 different categories (CAT1 and CAT2) in the TASS database. For all hedge funds in the TASS database, the second category (CAT2) is always 17, 'Fund of Funds'.
} 


\begin{tabular}{rlrrr}
\hline & & \multicolumn{3}{c}{ Number of Funds In: } \\
\cline { 3 - 5 } Code & Category & Combined & Live & Graveyard \\
& & 111 & 44 & 67 \\
\hline & Not Categorized & 162 & 139 & 23 \\
1 & US Equity Hedge & 22 & 19 & 3 \\
2 & European Equity Hedge & 5 & 5 & 0 \\
3 & Asian Equity Hedge & 27 & 24 & 3 \\
4 & Global Equity Hedge & 7 & 6 & 1 \\
5 & Dedicated Shortseller & 13 & 12 & 1 \\
6 & Fixed-Income Directional & 15 & 12 & 3 \\
7 & Convertible Fund (Long Only) & 109 & 97 & 12 \\
8 & Event Driven & 85 & 63 & 22 \\
9 & Non-Directional/Relative Value & 25 & 15 & 10 \\
10 & Global Macro & 1 & 1 & 0 \\
11 & Global Opportunity & 3 & 1 & 2 \\
12 & Natural Resources & 26 & 15 & 11 \\
13 & Pure Leveraged Currency & 93 & 28 & 65 \\
14 & Pure Managed Futures & 72 & 54 & 18 \\
15 & Pure Emerging Market & 1 & 1 & 0 \\
16 & Pure Property & 132 & 115 & 17 \\
17 & Fund of Funds & 909 & 651 & 258 \\
& All &
\end{tabular}

Table 5: Number of funds in the TASS Hedge Fund Live and Graveyard databases with at least five years of returns history during the period from November 1977 to January 2001. 
year to the number of existing funds at the start of the year. TASS began tracking the exits of funds starting only in 1994 hence attrition rates could not be computed in prior years. For the unfiltered sample of all funds, the average attrition rate from 1994-1999 is $9.11 \%$, which is very similar to the $8.54 \%$ attrition rate obtained by Liang (2001) for the same period. As observed above, the attrition rate skyrocketed in 2000 in the wake of LTCM's demise. In the right panel of Table 6, we see smaller attrition rates - the average over the 1994-1999 period is only $3.81 \%$ - because of our five-year minimum return history filter; since many hedge funds fail in their first three years, our filtered sample is likely to have a much lower attrition rate by construction.

Figure 4 contains a visual depiction of the variation in sample sizes of our 909 funds. The start and end dates of the return history for each fund are connected by a vertical line and plotted in Figure 4 according to the primary category of the fund-Categories 0-7 in the top panel and Categories 8-17 in the bottom panel. It is apparent from the increasing density of the graphs as we move from the bottom to the top that the majority of funds in our sample are relatively new.

In Section 6.1 we present summary statistics for the sample of hedge funds included in our analysis. We implement the smoothing profile estimation procedures outlined in Section 5 for each of the funds and summarize the results in Sections 6.2 and 6.3. In Section 6.5 we report smoothing-adjusted Sharpe ratios for the funds in our sample and compare them to their unadjusted counterparts.

\subsection{Summary Statistics}

Table 7 contains basic summary statistics for the 909 funds in our combined extract from the TASS Live and Graveyard databases. Not surprisingly, there is a great deal of variation in mean returns and volatilities both across and within categories. For example, the 162 US Equity Hedge funds in our sample exhibited a mean return of $22.53 \%$, but with a standard deviation of $10.80 \%$ in the cross section, and a mean volatility of $21.69 \%$ with a cross-sectional standard deviation of $11.63 \%$. Average serial correlations also vary considerably across categories, but five categories stand out as having the highest averages: ${ }^{31}$ Fixed Income Directional (21.6\%), Convertible Fund (Long Only) (22.5\%), Event Driven (20.8\%), Non-Directional/Relative Value (18.2\%), and Pure Emerging Market (18.8\%). Given the descriptions of these categories provided by TASS (see Appendix A.4) and common wisdom

\footnotetext{
${ }^{31}$ At $23.1 \%$ and $-23.1 \%$, respectively, Global Opportunity and Pure Property have higher first-order autocorrelation coefficients in absolute value than the other categories, but since these two categories contain only a single fund each, we set them aside in our discussions.
} 


\begin{tabular}{|c|c|c|c|c|c|c|c|c|c|c|c|c|}
\hline \multirow[b]{2}{*}{ Year } & \multicolumn{6}{|c|}{ All Funds } & \multicolumn{6}{|c|}{ Funds with At Least 5 Years' History } \\
\hline & $\begin{array}{l}\text { Existing } \\
\text { Funds }\end{array}$ & $\begin{array}{c}\text { New } \\
\text { Entries }\end{array}$ & $\begin{array}{l}\text { New } \\
\text { Exits }\end{array}$ & $\begin{array}{c}\text { Intrayear } \\
\text { Entry/Exit }\end{array}$ & $\begin{array}{l}\text { Total } \\
\text { Funds }\end{array}$ & $\begin{array}{l}\text { Attrition } \\
\text { Rate (\%) }\end{array}$ & $\begin{array}{l}\text { Existing } \\
\text { Funds }\end{array}$ & $\begin{array}{c}\text { New } \\
\text { Entries }\end{array}$ & $\begin{array}{l}\text { New } \\
\text { Exits }\end{array}$ & $\begin{array}{c}\text { Intrayear } \\
\text { Entry/Exit }\end{array}$ & $\begin{array}{l}\text { Total } \\
\text { Funds }\end{array}$ & $\begin{array}{l}\text { Attrition } \\
\text { Rate }(\%)\end{array}$ \\
\hline 1977 & 0 & 1 & 0 & 0 & 1 & - & 0 & 1 & 0 & 0 & 1 & - \\
\hline 1978 & 1 & 2 & 0 & 0 & 3 & 0.0 & 1 & 2 & 0 & 0 & 3 & 0.0 \\
\hline 1979 & 3 & 1 & 0 & 0 & 4 & 0.0 & 3 & 1 & 0 & 0 & 4 & 0.0 \\
\hline 1981 & 5 & 3 & 0 & 0 & 8 & 0.0 & 5 & 3 & 0 & 0 & 8 & 0.0 \\
\hline 1982 & 8 & 4 & 0 & 0 & 12 & 0.0 & 8 & 4 & 0 & 0 & 12 & 0.0 \\
\hline 1983 & 12 & 6 & 0 & 0 & 18 & 0.0 & 12 & 6 & 0 & 0 & 18 & 0.0 \\
\hline 1984 & 18 & 14 & 0 & 0 & 32 & 0.0 & 18 & 14 & 0 & 0 & 32 & 0.0 \\
\hline 1985 & 32 & 8 & 0 & 0 & 40 & 0.0 & 32 & 8 & 0 & 0 & 40 & 0.0 \\
\hline 1986 & 40 & 19 & 0 & 0 & 59 & 0.0 & 40 & 19 & 0 & 0 & 59 & 0.0 \\
\hline 1987 & 59 & 32 & 0 & 0 & 91 & 0.0 & 59 & 32 & 0 & 0 & 91 & 0.0 \\
\hline 1988 & 91 & 28 & 0 & 0 & 119 & 0.0 & 91 & 28 & 0 & 0 & 119 & 0.0 \\
\hline 1990 & 158 & 99 & 0 & 0 & 257 & 0.0 & 158 & 93 & 0 & 0 & 251 & 0.0 \\
\hline 1991 & 257 & 87 & 0 & 0 & 344 & 0.0 & 251 & 78 & 0 & 0 & 329 & 0.0 \\
\hline 1992 & 344 & 156 & 0 & 0 & 500 & 0.0 & 329 & 118 & 0 & 0 & 447 & 0.0 \\
\hline 1993 & 500 & 233 & 0 & 0 & 733 & 0.0 & 447 & 135 & 0 & 0 & 582 & 0.0 \\
\hline 1994 & 733 & 245 & 28 & 2 & 950 & 3.8 & 582 & 153 & 3 & 0 & 732 & 0.5 \\
\hline 1995 & 950 & 256 & 71 & 1 & 1135 & 7.5 & 732 & 142 & 15 & 0 & 859 & 2.0 \\
\hline 1996 & 1135 & 263 & 127 & 9 & 1271 & 11.2 & 859 & 32 & 30 & 0 & 861 & 3.5 \\
\hline 1997 & 1271 & 290 & 105 & 7 & 1456 & 8.3 & 861 & 0 & 14 & 0 & 847 & 1.6 \\
\hline 1998 & 1456 & 255 & 166 & 10 & 1545 & 11.4 & 847 & 0 & 51 & 0 & 796 & 6.0 \\
\hline 1999 & 1545 & 222 & 193 & 7 & 1574 & 12.5 & 796 & 0 & 73 & 0 & 723 & 9.2 \\
\hline 2000 & 1574 & 90 & 421 & 19 & 1243 & 26.7 & 723 & 0 & 182 & 0 & 541 & 25.2 \\
\hline
\end{tabular}

Table 6: Annual frequency counts of entries into and exits out of the TASS Hedge Fund Database from November 1977 to January 2001. 

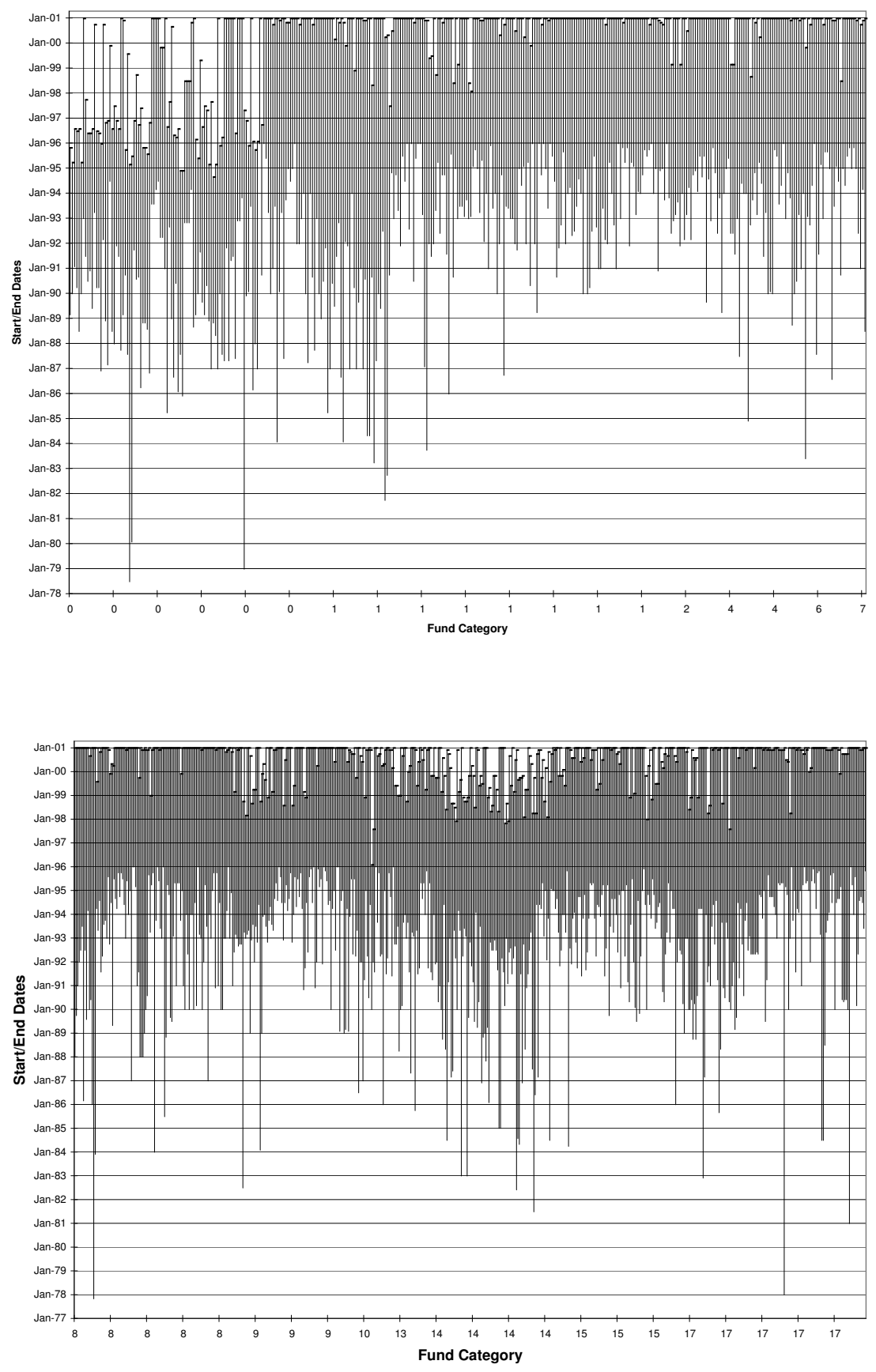

Figure 4: Length of return histories, depicted by vertical solid lines, for all funds in the TASS Hedge Fund database with at least five years of returns during the period from November 1977 to January 2001, ordered by categories 0 to 7 in the top panel and categories 8 to 17 in the bottom panel. Each fund is represented by a single solid vertical line that spans the start and end dates of the fund's return history. 
about the nature of the strategies involved - these categories include some of the most illiquid securities traded - serial correlation seems to be a reasonable proxy for illiquidity and smoothed returns. Alternatively, equities and futures are among the most liquid securities in which hedge funds invest, and not surprising, the average first-order serial correlation for US Equity Hedge funds and Pure Managed Futures is $7.8 \%$ and $-0.1 \%$, respectively. In fact, all of the equity funds have average serial correlations that are much smaller than those of the top five categories. Dedicated Shortseller funds also have a low average first-order autocorrelation, $4.4 \%$, which is consistent with the high degree of liquidity that often characterize shortsellers (since, by definition, the ability to short a security implies a certain degree of liquidity).

These summary statistics suggest that illiquidity and smoothed returns may be important attributes for hedge-fund returns which can be captured to some degree by serial correlation and our time-series model of smoothing.

\subsection{Smoothing Profile Estimates}

Using the methods outlined in Section 5, we estimate the smoothing model (21)-(23) and summarize the results in Tables 8-9. Our maximum likelihood procedure - programmed in Matlab using the Optimization Toolbox and replicated in Stata using its MA( $k)$ estimation routine - converged without difficulty for all but one of the 909 funds: ${ }^{32}$ fund 1055, a Global Macro fund with returns from June 1994 to January 2001 for which the maximum likelihood estimation procedure yielded the following parameter estimates:

$$
\hat{\theta}_{0}=490.47, \hat{\theta}_{1}=-352.63, \hat{\theta}_{2}=-136.83
$$

which suggests that our MA(2) model is severely misspecified for this fund. Therefore, we drop this fund from our sample and for the remainder of our analysis, we focus on the smoothing profile estimates for the remaining 908 funds in our sample. ${ }^{33}$

\footnotetext{
${ }^{32} \mathrm{We}$ also constrain our maximum likelihood estimators to yield invertible MA(2) processes, and this constraint was binding for only two funds: 1711 and 4298 .

${ }^{33}$ The apparent source of the problem in this case is two consecutive outliers, $39.4 \%$ in December 1999 followed by $-27.6 \%$ in January 2000 (these are monthly returns, not annualized). The effect of two outliers on the parameter estimates of the MA(2) model (21)-(23) is to pull the values of the coefficients in opposite directions so as to fit the extreme reversals. We contacted TASS to investigate these outliers and were informed that they were data errors. We also checked the remaining 908 funds in our sample for similar outliers, i.e., consecutive extreme returns of opposite sign, and found none. We also computed the maximum and minimum monthly returns for each fund in our sample, ranked the 908 funds according to these maxima and minima, and checked the parameter estimates of the top and bottom 10 funds, and none exhibited the extreme behavior of fund 1055's parameter estimates.
} 


\begin{tabular}{|c|c|c|c|c|c|c|c|c|c|c|c|c|c|c|c|c|c|}
\hline \multirow{2}{*}{ Category } & \multirow{2}{*}{$N$} & \multicolumn{2}{|c|}{ Annual Mean } & \multicolumn{2}{|c|}{ Annual SD } & \multicolumn{2}{|c|}{ Skewness } & \multicolumn{2}{|c|}{ Kurtosis } & \multicolumn{2}{|c|}{$\hat{\rho}_{1}(\%)$} & \multicolumn{2}{|c|}{$\hat{\rho}_{2}(\%)$} & \multicolumn{2}{|c|}{$\hat{\rho}_{3}(\%)$} & \multicolumn{2}{|c|}{$p$-Value $(Q)$} \\
\hline & & Mean & SD & Mean & $\mathrm{SD}$ & Mean & $\mathrm{SD}$ & Mean & $\mathrm{SD}$ & Mean & $\mathrm{SD}$ & Mean & $\mathrm{SD}$ & Mean & $\mathrm{SD}$ & Mean & $\mathrm{SD}$ \\
\hline Not Categorized & 111 & 10.78 & 6.99 & 15.60 & 11.25 & 0.12 & 1.06 & 3.67 & 4.94 & 5.5 & 17.0 & 0.9 & 14.7 & 0.5 & 11.4 & 36.1 & 30.4 \\
\hline US Equity Hedge & 162 & 22.53 & 10.80 & 21.69 & 11.63 & 0.17 & 0.96 & 3.82 & 5.02 & 7.8 & 13.5 & 0.6 & 11.2 & -4.2 & 11.0 & 33.9 & 28.8 \\
\hline European Equity Hedge & 22 & 18.01 & 7.15 & 14.71 & 6.41 & 0.39 & 0.81 & 2.97 & 2.73 & 12.7 & 10.9 & 11.2 & 11.3 & -2.0 & 8.9 & 21.2 & 23.0 \\
\hline Asian Equity Hedge & 5 & 9.16 & 7.96 & 21.13 & 6.64 & 0.50 & 0.85 & 2.32 & 0.73 & 11.7 & 13.0 & 5.0 & 5.6 & -5.4 & 13.4 & 40.2 & 21.1 \\
\hline Global Equity Hedge & 27 & 13.71 & 8.41 & 17.41 & 6.61 & -0.24 & 1.06 & 3.96 & 5.60 & 12.4 & 11.3 & -0.1 & 9.6 & -2.7 & 7.2 & 41.9 & 27.2 \\
\hline Dedicated Shortseller & 7 & 0.33 & 10.26 & 21.55 & 13.80 & 0.49 & 0.20 & 2.28 & 2.40 & 4.4 & 8.4 & -2.7 & 9.5 & -6.5 & 6.9 & 31.8 & 27.7 \\
\hline Fixed-Income Directional & 13 & 9.82 & 3.49 & 9.55 & 8.74 & -0.94 & 1.29 & 5.37 & 7.32 & 21.6 & 15.7 & 14.1 & 13.2 & 1.9 & 13.6 & 18.1 & 21.0 \\
\hline Convertible Fund (Long Only) & 15 & 14.95 & 5.33 & 11.03 & 6.76 & -0.19 & 1.68 & 6.14 & 9.97 & 22.5 & 12.3 & 6.2 & 13.4 & -2.1 & 12.5 & 17.2 & 25.2 \\
\hline Event Driven & 109 & 15.35 & 6.70 & 9.51 & 9.65 & -0.58 & 1.82 & 8.26 & 11.68 & 20.8 & 16.8 & 6.4 & 13.4 & -0.1 & 12.3 & 25.7 & 29.6 \\
\hline Non-Directional/Relative Value & 85 & 12.54 & 6.65 & 8.19 & 5.05 & -0.76 & 1.71 & 6.44 & 9.50 & 18.2 & 23.5 & 12.2 & 15.4 & 5.0 & 14.5 & 17.1 & 25.0 \\
\hline Global Macro & 25 & 16.75 & 7.94 & 18.92 & 9.53 & 0.53 & 1.03 & 4.66 & 6.82 & 7.2 & 15.0 & -0.1 & 10.8 & -0.9 & 8.1 & 33.4 & 22.9 \\
\hline Global Opportunity & 1 & -17.39 & - & 31.03 & - & -0.48 & - & 2.80 & - & 23.1 & - & 14.1 & - & 0.0 & - & 20.8 & - \\
\hline Natural Resources & 3 & 11.39 & 4.89 & 18.91 & 1.06 & 0.48 & 0.44 & 1.25 & 1.49 & 5.0 & 14.5 & 8.5 & 12.1 & 1.9 & 7.0 & 47.6 & 43.7 \\
\hline Pure Leveraged Currency & 26 & 9.29 & 7.11 & 17.18 & 8.93 & 0.44 & 1.08 & 3.50 & 4.92 & 5.2 & 8.7 & -6.2 & 9.5 & -4.4 & 8.1 & 35.5 & 26.6 \\
\hline Pure Managed Futures & 93 & 9.60 & 9.28 & 21.74 & 17.06 & 0.22 & 1.35 & 4.93 & 8.31 & -0.1 & 12.9 & -3.8 & 10.0 & -3.5 & 10.7 & 35.4 & 29.1 \\
\hline Pure Emerging Market & 72 & 9.57 & 10.94 & 26.60 & 14.44 & -0.69 & 1.49 & 6.17 & 8.05 & 18.8 & 11.8 & 4.4 & 11.6 & -1.4 & 9.0 & 32.6 & 30.6 \\
\hline Pure Property & 1 & 3.96 & - & 9.41 & - & -1.33 & - & 5.43 & - & -23.1 & - & 2.3 & - & 7.3 & - & 18.9 & - \\
\hline Fund of Funds & 132 & 11.04 & 5.16 & 10.07 & 5.63 & -0.26 & 1.30 & 4.78 & 6.16 & 17.6 & 14.1 & 5.7 & 11.5 & -0.7 & 9.3 & 26.3 & 27.5 \\
\hline All & 909 & 13.72 & 9.46 & 16.06 & 12.21 & -0.15 & 1.38 & 5.05 & 7.56 & 12.1 & 16.8 & 3.4 & 13.1 & -1.2 & 11.2 & 30.1 & 28.7 \\
\hline
\end{tabular}

Table 7: Means and standard deviations of basic summary statistics for 909 hedge funds in the TASS Hedge Fund Combined (Live and Graveyard) database with at least five years of returns history during the period from November 1977 to January 2001. The columns ' $p$-Value $(Q)$ ' contain means and standard deviations of $p$-values for the Box-Pierce $Q$-statistic for each fund using the first 6 autocorrelations of returns. 
Table 8 contains summary statistics for maximum likelihood estimate of the smoothing parameters $\left(\theta_{0}, \theta_{1}, \theta_{2}\right)$ and smoothing index $\xi$, Table 12 reports comparable statistics for the regression estimates of the smoothing parameters under the assumption of a linear onefactor model for true returns, and Table 9 presents the maximum likelihood estimates of the smoothing model for the 50 most illiquid funds of the 908 funds, as ranked by $\hat{\theta}_{0}$.

The left panel of Table 8 reports summary statistics for the maximum likelihood estimates under the normalization (49) where the smoothing coefficients sum to 1, and the right panel reports the same statistics for the maximum likelihood estimates under the normalization (75) where the variance $\sigma_{\eta}^{2}$ is set equal to a nonparametric estimate $\tilde{\sigma}_{\eta}^{2}$ given by (74). A comparison of the right and left panels reveals roughly similar characteristics, indicating the general equivalence of these two normalization methods and the fact that the smoothing model (21)-(23) may be a reasonable specification for hedge-fund returns. ${ }^{34}$

Table 8 shows that seven categories seem to exhibit smaller average values of $\hat{\theta}_{0}$ than the rest-European Equity Hedge (0.82), Fixed-Income Directional (0.76), Convertible Fund (Long Only) (0.84), Event Driven (0.81), Non-Directional/Relative Value (0.82), Pure Emerging Market (0.83), and Fund of Funds (0.85). ${ }^{35}$ Consider, in particular, the Fixed-Income Directional category, which has a mean of 0.76 for $\hat{\theta}_{0}$. This is, of course, the average across all 13 funds in this category, but if it were the point estimate of a given fund, it would imply that only $76 \%$ of that fund's true current monthly return would be reported, with the remaining $24 \%$ distributed over the next two months (recall the constraint that $\hat{\theta}_{0}+\hat{\theta}_{1}+\hat{\theta}_{2}=1$ ). The estimates 0.15 and 0.08 for $\hat{\theta}_{1}$ and $\hat{\theta}_{2}$ imply that on average, the current reported return also includes $15 \%$ of last month's true return and $8 \%$ of the true return two months ago. ${ }^{36}$ These averages suggest a significant amount of smoothing and illiquidity in this category, and are approximated by the geometric smoothing model of Section 4.2 with $\delta=0.25$ (see Table 4). Recall from Table 4 that in this case, with $k=2$, the impact of geometric smoothing was a $24 \%$ decrease in the market beta and a $27 \%$ increase in the Sharpe ratio of observed returns. Overall, the summary statistics in Table 8 are broadly consistent with common intuition about the nature of the strategies and securities involved in these fund categories, which contain the most illiquid securities and, therefore, have the most potential for smoothed returns.

\footnotetext{
${ }^{34}$ However, Table 8 contains only summary statistics, not the maximum likelihood estimators of individual funds, hence differences in the two normalizations for given funds may not be apparent from this table. In particular, side-by-side comparisons of maximum likelihood estimates for an individual under these two normalizations may still be a useful specification check despite the broad similarities that these two approaches seem to exhibit in Table 8.

${ }^{35}$ We omit the Global Opportunity category from our discussions because it consists of only a single fund.

${ }^{36}$ The averages do not sum to 1 exactly because of rounding errors.
} 


\begin{tabular}{|c|c|c|c|c|c|c|c|c|c|c|c|c|c|c|c|c|c|}
\hline \multirow{3}{*}{ Category } & \multirow{3}{*}{$N$} & \multicolumn{8}{|c|}{ MA(2) with Constrained Sum } & \multicolumn{8}{|c|}{ MA(2) with Constrained $\sigma_{\eta}$} \\
\hline & & \multicolumn{2}{|c|}{$\hat{\theta}_{0}$} & \multicolumn{2}{|c|}{$\hat{\theta}_{1}$} & \multicolumn{2}{|c|}{$\hat{\theta}_{2}$} & \multicolumn{2}{|c|}{$\hat{\xi}$} & \multicolumn{2}{|c|}{$\hat{\theta}_{0}$} & \multicolumn{2}{|c|}{$\hat{\theta}_{1}$} & \multicolumn{2}{|c|}{$\hat{\theta}_{2}$} & \multicolumn{2}{|c|}{$\hat{\xi}$} \\
\hline & & Mean & $\mathrm{SD}$ & Mean & $\mathrm{SD}$ & Mean & $\mathrm{SD}$ & Mean & $\mathrm{SD}$ & Mean & $\mathrm{SD}$ & Mean & $\mathrm{SD}$ & Mean & $\mathrm{SD}$ & Mean & $\mathrm{SD}$ \\
\hline Not Categorized & 111 & 1.04 & 0.33 & 0.01 & 0.18 & -0.05 & 0.23 & 1.27 & 1.06 & 0.97 & 0.27 & 0.01 & 0.16 & -0.04 & 0.19 & 1.08 & 0.60 \\
\hline US Equity Hedge & 162 & 0.95 & 0.21 & 0.06 & 0.15 & -0.01 & 0.15 & 1.00 & 0.54 & 0.98 & 0.20 & 0.07 & 0.14 & -0.01 & 0.15 & 1.04 & 0.42 \\
\hline European Equity Hedge & 22 & 0.82 & 0.15 & 0.08 & 0.09 & 0.11 & 0.11 & 0.72 & 0.28 & 0.90 & 0.17 & 0.09 & 0.10 & 0.13 & 0.12 & 0.88 & 0.32 \\
\hline Asian Equity Hedge & 5 & 0.94 & 0.30 & 0.05 & 0.19 & 0.01 & 0.11 & 1.00 & 0.71 & 0.90 & 0.20 & 0.06 & 0.17 & 0.01 & 0.10 & 0.88 & 0.40 \\
\hline Global Equity Hedge & 27 & 0.91 & 0.14 & 0.11 & 0.10 & -0.02 & 0.09 & 0.88 & 0.27 & 0.96 & 0.20 & 0.11 & 0.10 & -0.02 & 0.09 & 0.99 & 0.37 \\
\hline Dedicated Shortseller & 7 & 1.03 & 0.20 & 0.03 & 0.12 & -0.06 & 0.13 & 1.12 & 0.48 & 1.13 & 0.14 & 0.05 & 0.12 & -0.05 & 0.14 & 1.33 & 0.34 \\
\hline Fixed-Income Directional & 13 & 0.76 & 0.17 & 0.15 & 0.10 & 0.08 & 0.12 & 0.67 & 0.27 & 0.75 & 0.21 & 0.15 & 0.10 & 0.09 & 0.12 & 0.66 & 0.30 \\
\hline Convertible Fund (Long Only) & 15 & 0.84 & 0.35 & 0.18 & 0.08 & -0.02 & 0.35 & 0.98 & 1.36 & 0.89 & 0.27 & 0.20 & 0.10 & 0.00 & 0.24 & 0.97 & 0.58 \\
\hline Event Driven & 109 & 0.81 & 0.17 & 0.15 & 0.13 & 0.04 & 0.11 & 0.74 & 0.28 & 0.84 & 0.24 & 0.16 & 0.12 & 0.04 & 0.11 & 0.82 & 0.44 \\
\hline Non-Directional/Relative Value & 85 & 0.82 & 0.24 & 0.09 & 0.25 & 0.09 & 0.14 & 0.82 & 0.62 & 0.77 & 0.27 & 0.09 & 0.24 & 0.08 & 0.13 & 0.75 & 0.70 \\
\hline Global Macro & 24 & 0.95 & 0.18 & 0.08 & 0.11 & -0.03 & 0.15 & 0.99 & 0.40 & 0.97 & 0.23 & 0.08 & 0.10 & -0.03 & 0.17 & 1.03 & 0.51 \\
\hline Global Opportunity & 1 & 0.74 & - & 0.16 & - & 0.10 & - & 0.58 & - & 0.63 & - & 0.14 & - & 0.09 & - & 0.43 & - \\
\hline Natural Resources & 3 & 0.91 & 0.19 & 0.02 & 0.11 & 0.07 & 0.09 & 0.87 & 0.34 & 0.85 & 0.04 & 0.03 & 0.10 & 0.08 & 0.10 & 0.74 & 0.04 \\
\hline Pure Leveraged Currency & 26 & 1.10 & 0.34 & 0.03 & 0.13 & -0.13 & 0.25 & 1.41 & 1.38 & 1.00 & 0.16 & 0.04 & 0.10 & -0.10 & 0.16 & 1.07 & 0.37 \\
\hline Pure Managed Futures & 93 & 1.13 & 0.32 & -0.05 & 0.22 & -0.08 & 0.18 & 1.47 & 1.19 & 1.10 & 0.25 & -0.03 & 0.18 & -0.07 & 0.16 & 1.33 & 0.63 \\
\hline Pure Emerging Market & 72 & 0.83 & 0.16 & 0.15 & 0.09 & 0.02 & 0.13 & 0.76 & 0.31 & 0.79 & 0.17 & 0.14 & 0.08 & 0.02 & 0.13 & 0.70 & 0.30 \\
\hline Pure Property & 1 & 1.23 & - & -0.31 & - & 0.07 & - & 1.62 & - & 0.95 & - & -0.24 & - & 0.06 & - & 0.96 & - \\
\hline Fund of Funds & 132 & 0.85 & 0.21 & 0.13 & 0.13 & 0.03 & 0.13 & 0.81 & 0.50 & 0.85 & 0.23 & 0.13 & 0.12 & 0.03 & 0.13 & 0.83 & 0.45 \\
\hline All & 908 & 0.92 & 0.26 & 0.08 & 0.17 & 0.00 & 0.17 & 0.98 & 0.76 & 0.91 & 0.25 & 0.08 & 0.16 & 0.01 & 0.15 & 0.95 & 0.53 \\
\hline
\end{tabular}

Table 8: Means and standard deviations of maximum likelihood estimates of MA(2) smoothing process $R_{t}^{o}=\theta_{0} R_{t}+\theta_{1} R_{t-1}+$ $\theta_{2} R_{t-2}, \xi \equiv \theta_{0}^{2}+\theta_{1}^{2}+\theta_{2}^{2}$, for 908 hedge funds in the TASS combined database with at least five years of returns history during the period from November 1977 to January 2001. 


\begin{tabular}{|c|c|c|c|c|c|c|c|c|c|c|c|}
\hline Code & Category & Period & $T$ & Status & $\hat{\theta}_{0}$ & $\operatorname{SE}\left(\hat{\theta}_{0}\right)$ & $\hat{\theta}_{1}$ & $\operatorname{SE}\left(\hat{\theta}_{1}\right)$ & $\hat{\theta}_{2}$ & $\operatorname{SE}\left(\hat{\theta}_{2}\right)$ & $\hat{\xi}$ \\
\hline 1201 & Non-Directional/Relative Value & 199409-200101 & 77 & 1 & 0.464 & 0.040 & 0.365 & 0.025 & 0.171 & 0.047 & 0.378 \\
\hline 4346 & Event Driven & $199412-200011$ & 71 & 1 & 0.471 & 0.041 & 0.335 & 0.029 & 0.195 & 0.048 & 0.371 \\
\hline 180 & Not Categorized & 198906-199608 & 87 & 0 & 0.485 & 0.041 & 0.342 & 0.027 & 0.173 & 0.046 & 0.382 \\
\hline 1204 & Non-Directional/Relative Value & 199510-200101 & 64 & 1 & 0.492 & 0.049 & 0.339 & 0.033 & 0.169 & 0.055 & 0.386 \\
\hline 1584 & Fund of Funds & 199601-200101 & 61 & 1 & 0.504 & 0.046 & 0.245 & 0.040 & 0.251 & 0.051 & 0.377 \\
\hline 518 & Non-Directional/Relative Value & 199312-200005 & 78 & 0 & 0.514 & 0.034 & 0.142 & 0.037 & 0.343 & 0.037 & 0.403 \\
\hline 971 & Non-Directional/Relative Value & 199409-200012 & 76 & 1 & 0.515 & 0.038 & 0.176 & 0.038 & 0.309 & 0.041 & 0.392 \\
\hline 1234 & Fund of Funds & 199410-200012 & 75 & 1 & 0.527 & 0.061 & 0.446 & 0.020 & 0.027 & 0.061 & 0.477 \\
\hline 2185 & Fixed Income Directional & 199108-200101 & 114 & 1 & 0.532 & 0.040 & 0.265 & 0.032 & 0.202 & 0.043 & 0.395 \\
\hline 26 & Non-Directional/Relative Value & 199303-200101 & 95 & 1 & 0.533 & 0.047 & 0.305 & 0.033 & 0.162 & 0.050 & 0.403 \\
\hline 171 & Non-Directional/Relative Value & 199304-200101 & 94 & 1 & 0.536 & 0.040 & 0.193 & 0.037 & 0.271 & 0.043 & 0.398 \\
\hline 1696 & Fund of Funds & 199501-200001 & 61 & 0 & 0.536 & 0.067 & 0.406 & 0.030 & 0.058 & 0.068 & 0.456 \\
\hline 120 & Non-Directional/Relative Value & 198207-199810 & 196 & 0 & 0.546 & 0.032 & 0.238 & 0.026 & 0.215 & 0.034 & 0.402 \\
\hline 1396 & Non-Directional/Relative Value & 199507-200101 & 67 & 1 & 0.548 & 0.056 & 0.255 & 0.044 & 0.197 & 0.059 & 0.404 \\
\hline 2774 & Non-Directional/Relative Value & 199501-200006 & 66 & 0 & 0.553 & 0.058 & 0.262 & 0.044 & 0.185 & 0.061 & 0.409 \\
\hline 1397 & Non-Directional/Relative Value & 199410-200101 & 76 & 1 & 0.556 & 0.055 & 0.260 & 0.042 & 0.184 & 0.057 & 0.410 \\
\hline 57 & Non-Directional/Relative Value & 199210-200101 & 100 & 1 & 0.561 & 0.052 & 0.311 & 0.034 & 0.127 & 0.053 & 0.428 \\
\hline 4158 & Event Driven & 199510-200101 & 64 & 1 & 0.565 & 0.062 & 0.261 & 0.046 & 0.174 & 0.064 & 0.417 \\
\hline 1773 & Fund of Funds & 199506-200101 & 68 & 1 & 0.569 & 0.056 & 0.194 & 0.049 & 0.238 & 0.058 & 0.417 \\
\hline 415 & Not Categorized & 198807-199608 & 98 & 0 & 0.570 & 0.054 & 0.306 & 0.035 & 0.124 & 0.055 & 0.434 \\
\hline 1713 & Fixed Income Directional & 199601-200101 & 61 & 1 & 0.573 & 0.067 & 0.269 & 0.048 & 0.158 & 0.068 & 0.426 \\
\hline 1576 & Fund of Funds & 199504-200010 & 67 & 1 & 0.575 & 0.066 & 0.293 & 0.044 & 0.132 & 0.067 & 0.434 \\
\hline 1633 & Event Driven & 199304-199901 & 70 & 0 & 0.576 & 0.066 & 0.309 & 0.042 & 0.115 & 0.066 & 0.440 \\
\hline 1883 & Event Driven & 199306-200101 & 92 & 1 & 0.578 & 0.053 & 0.236 & 0.041 & 0.187 & 0.054 & 0.424 \\
\hline 1779 & Non-Directional/Relative Value & $199512-200101$ & 62 & 1 & 0.584 & 0.067 & 0.241 & 0.051 & 0.175 & 0.068 & 0.429 \\
\hline 3860 & Fund of Funds & 199511-200101 & 63 & 1 & 0.584 & 0.064 & 0.207 & 0.053 & 0.210 & 0.065 & 0.428 \\
\hline 482 & Non-Directional/Relative Value & 199406-200101 & 80 & 1 & 0.584 & 0.060 & 0.253 & 0.044 & 0.163 & 0.060 & 0.432 \\
\hline 2755 & US Equity Hedge & 199203-200010 & 104 & 1 & 0.584 & 0.057 & 0.321 & 0.034 & 0.095 & 0.056 & 0.453 \\
\hline 1968 & Fund of Funds & 199402-200012 & 83 & 1 & 0.587 & 0.060 & 0.253 & 0.044 & 0.160 & 0.060 & 0.434 \\
\hline 1240 & Fund of Funds & 199405-200101 & 81 & 1 & 0.592 & 0.055 & 0.168 & 0.049 & 0.240 & 0.056 & 0.436 \\
\hline 1884 & Event Driven & 199301-200101 & 97 & 1 & 0.592 & 0.059 & 0.298 & 0.038 & 0.110 & 0.058 & 0.451 \\
\hline 2864 & Non-Directional/Relative Value & 199408-200101 & 78 & 1 & 0.598 & 0.064 & 0.255 & 0.046 & 0.147 & 0.064 & 0.444 \\
\hline 1 & Non-Directional/Relative Value & 199101-200101 & 121 & 1 & 0.600 & 0.051 & 0.241 & 0.038 & 0.159 & 0.051 & 0.444 \\
\hline 412 & Pure Emerging Market & 199211-200101 & 99 & 1 & 0.600 & 0.061 & 0.318 & 0.036 & 0.082 & 0.059 & 0.468 \\
\hline 1046 & Pure Emerging Market & 199406-200101 & 80 & 1 & 0.603 & 0.058 & 0.169 & 0.051 & 0.228 & 0.058 & 0.444 \\
\hline 2570 & Event Driven & 199001-200101 & 133 & 1 & 0.604 & 0.046 & 0.171 & 0.039 & 0.225 & 0.046 & 0.445 \\
\hline 945 & Fund of Funds & 199210-200101 & 100 & 1 & 0.605 & 0.060 & 0.273 & 0.040 & 0.122 & 0.058 & 0.456 \\
\hline 1994 & Non-Directional/Relative Value & 199507-200101 & 67 & 1 & 0.606 & 0.069 & 0.217 & 0.053 & 0.177 & 0.068 & 0.446 \\
\hline 1691 & Event Driven & 199310-200101 & 88 & 0 & 0.610 & 0.062 & 0.232 & 0.046 & 0.158 & 0.061 & 0.451 \\
\hline 34 & Non-Directional/Relative Value & 199209-200101 & 101 & 1 & 0.612 & 0.052 & 0.143 & 0.047 & 0.245 & 0.052 & 0.455 \\
\hline 2630 & Non-Directional/Relative Value & 199001-200101 & 133 & 1 & 0.612 & 0.052 & 0.255 & 0.036 & 0.133 & 0.051 & 0.457 \\
\hline 2685 & US Equity Hedge & 199207-200101 & 103 & 1 & 0.613 & 0.060 & 0.271 & 0.040 & 0.116 & 0.058 & 0.463 \\
\hline 2549 & Non-Directional/Relative Value & 199408-200101 & 78 & 1 & 0.614 & 0.079 & 0.412 & 0.029 & -0.026 & 0.069 & 0.547 \\
\hline 490 & Event Driven & 199404-199908 & 65 & 0 & 0.615 & 0.074 & 0.237 & 0.054 & 0.148 & 0.072 & 0.456 \\
\hline 3099 & Convertible Fund (Long Only) & 199501-200101 & 73 & 1 & 0.615 & 0.060 & 0.121 & 0.057 & 0.263 & 0.060 & 0.463 \\
\hline 1326 & US Equity Hedge & 199601-200101 & 61 & 1 & 0.619 & 0.069 & 0.145 & 0.062 & 0.236 & 0.068 & 0.460 \\
\hline 1418 & Fund of Funds & 199301-199804 & 64 & 0 & 0.621 & 0.085 & 0.363 & 0.041 & 0.016 & 0.078 & 0.518 \\
\hline 3712 & Not Categorized & 199304-200101 & 94 & 1 & 0.625 & 0.062 & 0.211 & 0.047 & 0.164 & 0.060 & 0.462 \\
\hline 1534 & Fund of Funds & 199402-200101 & 84 & 1 & 0.625 & 0.068 & 0.246 & 0.048 & 0.129 & 0.065 & 0.468 \\
\hline 167 & Event Driven & 199207-200101 & 103 & 1 & 0.627 & 0.061 & 0.239 & 0.044 & 0.134 & 0.059 & 0.468 \\
\hline
\end{tabular}

Table 9: First 50 funds of ranked list of 908 hedge funds in the TASS Hedge Fund Combined (Live and Graveyard) database with at least five years of returns history during the period from November 1977 to January 2001, ranked in increasing order of the estimated smoothing parameter $\hat{\theta}_{0}$ of the MA(2) smoothing process $R_{t}^{o}=\theta_{0} R_{t}+\theta_{1} R_{t-1}+\theta_{2} R_{t-2}$, subject to the normalization $1=\theta_{0}+\theta_{1}+\theta_{2}$, and estimated via maximum likelihood. 
Table 9 provides a more direct view of illiquidity and smoothed returns by reporting the smoothing parameter estimates for the top 50 funds ranked by $\hat{\theta}_{0}$. In contrast to the averages of Table 8, the parameter estimates of $\theta_{0}$ among these 50 funds range from 0.464 to 0.627, implying that only half to two-thirds of the current month's true returns are reflected in observed returns. The asymptotic standard errors are generally quite small, ranging from 0.032 to 0.085 , hence the smoothing parameters seem to be estimated reasonably precisely.

The funds in Table 9 fall mainly into three categories: Non-Directional/Relative Value, Event Driven, and Fund of Funds. Together, these three categories account for 40 of the 50 funds in Table 9. A more complete summary of the distribution of smoothing parameter estimates across the different fund categories is provided in Figures 5 and 6 . Figure 5 contains a graph of the smoothing coefficients $\hat{\theta}_{0}$ for all 908 funds by category, and Figure 6 contains a similar graph for the smoothing index $\hat{\xi}$. These figures show that although there is considerable variation within each category, nevertheless, some differences emerge between categories. For example, categories 6-9, 15, and 17 (Fixed-Income Directional, Convertible Fund (Long Only), Event Driven Non-Directional/Relative Value, Pure Emerging Market, and Fund of Funds, respectively), have clearly discernible concentrations that are lower than the other categories, suggesting more illiquid funds and more smoothed returns. On the other hand, categories 1, 4, and 14 (US Equity Hedge, Global Equity Hedge, and Pure Managed Futures, respectively) have concentrations that are at the upper end, suggesting just the opposite - more liquidity and less return-smoothing. The smoothing index estimates $\hat{\xi}$ plotted in Figure 6 show similar patterns of concentration and dispersion within and between the categories.

To develop further intuition for the smoothing model (21)-(23) and the possible interpretations of the smoothing parameter estimates, we apply the same estimation procedure to the returns of the Ibbotson stock and bond indexes, the CSFB/Tremont hedge-fund indexes, and two mutual funds, the highly liquid Vanguard 500 Index Fund, and the considerably less liquid American Express Extra Income Fund. ${ }^{37}$ Table 10 contains summary statistics and

\footnotetext{
${ }^{37}$ As of January 31, 2003, the net assets of the Vanguard 500 Index Fund (ticker symbol: VFINX) and the AXP Extra Income Fund (ticker symbol: INEAX) are given by http://finance.yahoo.com/ as $\$ 59.7$ billion and $\$ 1.5$ billion, respectively, and the descriptions of the two funds are as follows:

"The Vanguard 500 Index Fund seeks investment results that correspond with the price and yield performance of the S\&P 500 Index. The fund employs a passive management strategy designed to track the performance of the S\&P 500 Index, which is dominated by the stocks of large U.S. companies. It attempts to replicate the target index by investing all or substantially all of its assets in the stocks that make up the index."

"AXP Extra Income Fund seeks high current income; capital appreciation is secondary. The fund ordinarily invests in long-term high-yielding, lower-rated corporate bonds. These bonds may be issued by U.S. and foreign companies and governments. The fund may invest in other instruments such as: money market securities, convertible securities, preferred stocks, derivatives (such as futures, options and forward contracts),
} 

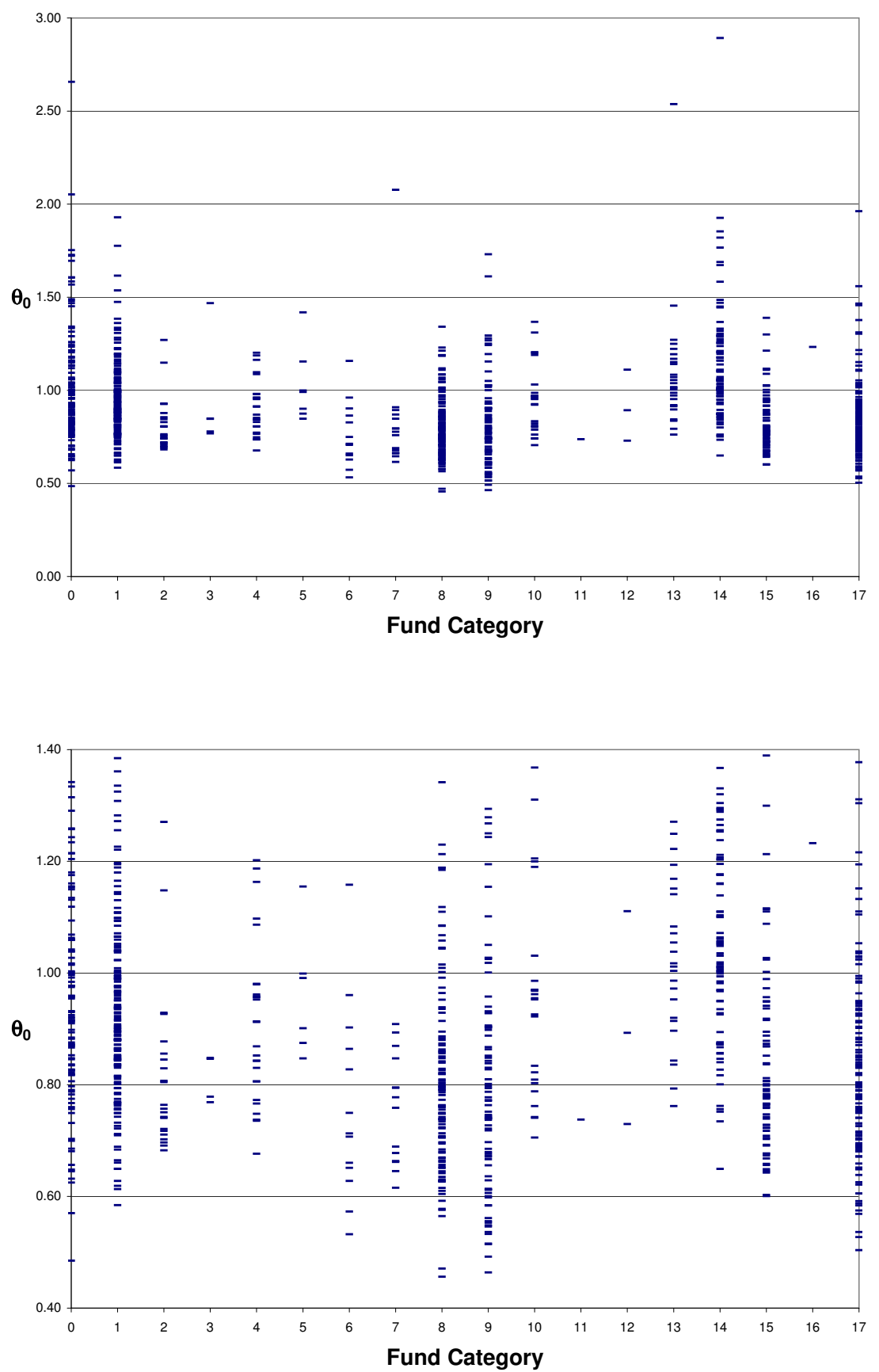

Figure 5: Estimated smoothing coefficients $\hat{\theta}_{0}$ for all funds in the TASS Hedge Fund database with at least five years of returns during the period from November 1977 to January 2001, ordered by categories 0 to 17 . The two panels differ only in the range of the vertical axis, which is smaller for the lower panel so as to provide finer visual resolution of the distribution of estimated coefficients in the sample. 

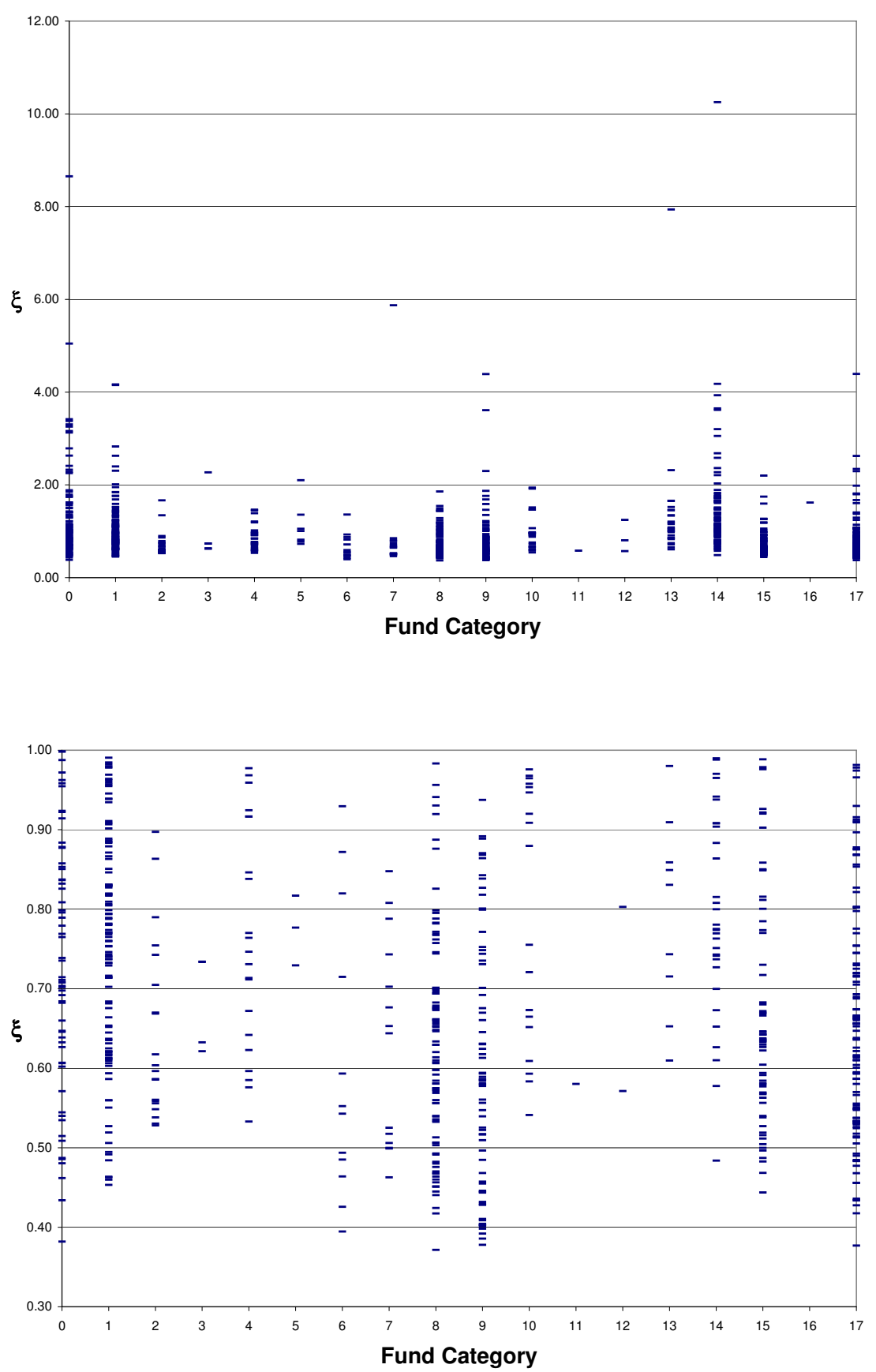

Figure 6: Estimated smoothing index $\hat{\xi}$ for all funds in the TASS Hedge Fund database with at least five years of returns during the period from November 1977 to January 2001, ordered by categories 0 to 17 . The two panels differ only in the range of the vertical axis, which is smaller for the lower panel so as to provide finer visual resolution of the distribution of estimated smoothing indexes in the sample. 
smoothing-coefficient estimates for these index and mutual-fund returns.

Consistent with our interpretation of $\hat{\theta}_{0}$ as an indicator of liquidity, the returns of the most liquid portfolios in the first panel of Table 10 - the Ibbotson Large Company Index, the Vanguard 500 Index Fund (which is virtually identical to the Ibbotson Large Company Index, except for sample period and tracking error), and the Ibbotson Long-Term Government Bond Index-have parameter estimates near 1.00: 0.92 for the Ibbotson Large Company Index, 1.12 for the Vanguard 500 Index Fund, and 0.92 for the Ibbotson Long-Term Government Bond Index. The first-order autocorrelation coefficients also confirm their lack of serial correlation; $9.8 \%$ for the Ibbotson Large Company Index, $-2.3 \%$ for the Vanguard 500 Index Fund, and $6.7 \%$ for the Ibbotson Long-Term Government Bond Index. Moreover, the values of $\hat{\theta}_{0}$ of the less liquid portfolios are less than 1.00: 0.82 for the Ibbotson Small Company Index, 0.84 for the Ibbotson Long-Term Corporate Bond Index, and 0.67 for the American Express Extra Income Fund, and their first-order serial correlation coefficients are $15.6 \%, 15.6 \%$, and $35.4 \%$, respectively, considerably higher than those of the more liquid portfolios.

The results for the CSFB Hedge Fund Indexes in the second panel of Table 10 are also consistent with the empirical results in Tables 8 and 9 -indexes corresponding to hedge-fund strategies involving less liquid securities tend to have lower $\hat{\theta}_{0}$ 's. For example, the smoothingparameter estimates $\hat{\theta}_{0}$ of the Convertible Arbitrage, Emerging Markets, and Fixed-Income Arbitrage Indexes are $0.49,0.75$, and 0.63 , respectively, and first-order serial correlation coefficients of $42.6 \%, 29.4 \%$, and $39.6 \%$, respectively. In contrast, the smoothing-parameter estimates of the more liquid hedge-fund strategies such as Dedicated Short Bias and Managed Futures are 0.99 and 1.04, respectively, with first-order serial correlation coefficients of $7.8 \%$ and $3.2 \%$, respectively. While these findings are generally consistent with the results in Tables 8 and 9, it should be noted that the process of aggregation can change the statistical behavior of any time series. For example, Granger $(1980,1988)$ observes that the aggregation of a large number of stationary autoregressive processes can yield a time series that exhibits long-term memory, characterized by serial correlation coefficients that decay very slowly (hyperbolically, as opposed to geometrically as in the case of a stationary ARMA process). Therefore, while it is true that the aggregation of a collection of illiquid funds will generally yield an index with smoothed returns, ${ }^{38}$ the reverse need not be true - smoothed index returns need not imply that all of the funds comprising the index are illiquid. The

\footnotetext{
and common stocks."

${ }^{38} \mathrm{It}$ is, of course, possible that the smoothing coefficients of some funds may exactly offset those of other funds so as to reduce the degree of smoothing in an aggregate index. However, such a possibility is extremely remote and pathological if each of the component funds exhibits a high degree of smoothing.
} 
latter inference can only be made with the benefit of additional information - essentially identification restrictions - about the statistical relations among the funds in the index, i.e., covariances and possibly other higher-order co-moments, or the existence of common factors driving fund returns.

The patterns in Table 10 confirm our interpretation of smoothing coefficients and serial correlation as proxies for liquidity, and suggest that there may be broader applications of our model of smoothed returns to other investment strategies and asset classes.

\subsection{Cross-Sectional Regressions}

A more quantitative summary of the cross-sectional properties of the smoothing parameter estimates for the 908 funds is given in Table 11, which contains the results of cross-sectional regressions of the smoothing parameter $\hat{\theta}_{0}$ and the smoothing index $\hat{\xi}$ on a number of $0 / 1$ indicator variables. ${ }^{39}$ In the first two regressions, $\hat{\theta}_{0}$ and $\hat{\xi}$ are the dependent variables, respectively, and the regressors include a constant term, 17 indicator variables corresponding to the 17 hedge-fund categories defined by TASS (see Appendix A.4), and an indicator variable that takes on the value 1 if the fund is open and 0 if it is closed to new investors. The third and fourth regressions have the same dependent variables - $\hat{\theta}_{0}$ and $\hat{\xi}$, respectively - and include the same regressors as the first two regressions but also include $0 / 1$ indicator variables that indicate whether the fund is US-based (USBASED), and whether the geographical focus of the fund is global (GF-GLB), US (GF-USA), Asia/Pacific (GF-APC), Western Europe (GF-WEU), Eastern Europe (GF-EEU), and Africa (GF-AFR).

The results of the first regression are consistent with the general intuition gleaned from Figures 5 and 6 . The category indicator variables with the most negative coefficients that are statistically significant at the $5 \%$ level are European Equity Hedge (-0.212), Fixed-Income Directional (-0.262), Event Driven (-0.218), Non-Directional/Relative Value $(-0.211)$, Pure Emerging Market $(-0.195)$, Fund of Funds $(-0.178)$, implying that on average, funds in these categories have smaller smoothing coefficients $\hat{\theta}_{0}$, i.e., less liquidity or smoother returns. These point estimates can be used to approximate the marginal impact that a given investment style has on the smoothing profile of the fund's monthly returns. For example, from a no-smoothing baseline of 1, conditioning on belonging to the Fixed-Income Directional category yields an expected smoothing parameter $\hat{\theta}_{0}$ of $1-0.262=0.738$ and an expected smoothing index of $\hat{\xi}$ of $1-0.583=0.417$, other things equal (and assuming that the remaining indicator variables in the two regression equations are 0 ).

\footnotetext{
${ }^{39}$ To conserve space, we report regression results only for the maximum likelihood estimates under the constraint (49). Table A.8 of the Appendix reports corresponding results for the maximum likelihood estimates under the alternate constraint (75).
} 


\begin{tabular}{|c|c|c|c|c|c|c|c|c|c|c|c|c|c|c|c|c|}
\hline Series & Period & $T$ & $\underset{(\%)}{\text { Mean }}$ & $\begin{array}{l}\text { SD } \\
(\%)\end{array}$ & $\begin{array}{l}\hat{\rho}_{1} \\
(\%)\end{array}$ & $\begin{array}{l}\hat{\rho}_{2} \\
(\%)\end{array}$ & $\begin{array}{l}\hat{\rho}_{3} \\
(\%)\end{array}$ & $\hat{\beta}$ & $\begin{array}{l}R^{2} \\
(\%)\end{array}$ & $\hat{\theta}_{0}$ & $\operatorname{SE}\left(\hat{\theta}_{0}\right)$ & $\hat{\theta}_{1}$ & $\operatorname{SE}\left(\hat{\theta}_{1}\right)$ & $\hat{\theta}_{2}$ & $\operatorname{SE}\left(\hat{\theta}_{2}\right)$ & $\hat{\xi}$ \\
\hline Ibbotson Small Company & 192601-200112 & 912 & 1.35 & 8.63 & 15.6 & 1.7 & -10.6 & 1.27 & 66.9 & 0.82 & 0.03 & 0.13 & 0.02 & 0.04 & 0.03 & 0.69 \\
\hline Ibbotson Long-Term Government Bonds & $192601-200112$ & 912 & 0.46 & 2.22 & 6.7 & 0.3 & -8.3 & 0.07 & 2.8 & 0.92 & 0.05 & 0.06 & 0.03 & 0.01 & 0.03 & 0.86 \\
\hline Ibbotson Long-Term Corporate Bonds & $192601-200112$ & 912 & 0.49 & 1.96 & 15.6 & 0.3 & -6.0 & 0.08 & 5.2 & 0.84 & 0.04 & 0.14 & 0.02 & 0.02 & 0.03 & 0.73 \\
\hline Ibbotson Large Company & 192601-200112 & 912 & 1.03 & 5.57 & 9.8 & -3.2 & -10.7 & 1.00 & 100.0 & 0.92 & 0.05 & 0.09 & 0.03 & -0.01 & 0.03 & 0.85 \\
\hline AXP Extra Income Fund (INEAX) & 198401-200112 & 216 & 0.67 & 2.04 & 35.4 & 13.1 & 2.5 & 0.21 & 20.7 & 0.67 & 0.03 & 0.24 & 0.03 & 0.09 & 0.04 & 0.51 \\
\hline Vanguard 500 Index Trust (VFINX) & 197609-200112 & 304 & 1.16 & 4.36 & -2.3 & -6.8 & -3.2 & 1.00 & 100.0 & 1.12 & 0.17 & -0.03 & 0.07 & -0.09 & 0.07 & 1.26 \\
\hline \multicolumn{17}{|l|}{ CSFB/Tremont Indices: } \\
\hline Aggregate Hedge Fund Index & 199401-200210 & 106 & 0.87 & 2.58 & 11.2 & 4.1 & -0.4 & 0.31 & 24.9 & 0.86 & 0.12 & 0.09 & 0.08 & 0.04 & 0.08 & 0.76 \\
\hline Convertible Arbitrage & 199401-200210 & 106 & 0.81 & 1.40 & 56.6 & 42.6 & 15.6 & 0.03 & 1.1 & 0.49 & 0.01 & 0.26 & 0.03 & 0.25 & 0.03 & 0.37 \\
\hline Dedicated Short Bias & 199401-200210 & 106 & 0.22 & 5.29 & 7.8 & -6.3 & -5.0 & -0.94 & 58.6 & 0.99 & 0.20 & 0.08 & 0.09 & -0.07 & 0.10 & 0.99 \\
\hline Emerging Markets & 199401-200210 & 106 & 0.54 & 5.38 & 29.4 & 1.2 & -2.1 & 0.62 & 24.0 & 0.75 & 0.08 & 0.24 & 0.05 & 0.01 & 0.07 & 0.62 \\
\hline Equity Market Neutral & 199401-200210 & 106 & 0.89 & 0.92 & 29.4 & 18.1 & 8.4 & 0.10 & 21.1 & 0.71 & 0.06 & 0.18 & 0.05 & 0.12 & 0.06 & 0.54 \\
\hline Event Driven & 199401-200210 & 106 & 0.83 & 1.81 & 34.8 & 14.7 & 3.8 & 0.23 & 30.2 & 0.68 & 0.05 & 0.2 & 0.05 & 0.09 & 0.06 & 0.52 \\
\hline e Arbitrage & 1994 & 106 & 0.5 & 1.18 & 39.6 & 10.8 & 5.4 & 0.02 & 0.7 & 0.6 & 0.04 & 0.2 & 0.04 & 0.08 & 0.05 & 0.49 \\
\hline Global M & $199401-200210$ & 106 & 1.1. & 3.6 & 5.6 & 4.6 & 8.3 & 0.24 & 7.5 & 0.91 & 0.1 & 0.04 & $0.0 \quad>\quad>$ & 0.05 & 0.08 & 0.84 \\
\hline Long/Short & 199401-200210 & 106 & 0.98 & 3.34 & 15.9 & 5.9 & -4.6 & 0.48 & 36.7 & 0.82 & 0.10 & 0.13 & 0.07 & 0.06 & 0.07 & 0.68 \\
\hline Managed Futures & 199401-200210 & 106 & 0.55 & 3.44 & 3.2 & -6.3 & 0.7 & -0.12 & 2.5 & 1.04 & 0.23 & 0.04 & 0.10 & -0.08 & 0.11 & 1.08 \\
\hline
\end{tabular}

Table 10: Summary statistics and maximum likelihood estimates of MA(2) smoothing process $R_{t}^{o}=\theta_{0} R_{t}+\theta_{1} R_{t-1}+\theta_{2} R_{t-2}$, $\xi \equiv \theta_{0}^{2}+\theta_{1}^{2}+\theta_{2}^{2}$, subject to the normalization $1=\theta_{0}+\theta_{1}+\theta_{2}$, for the returns of various indexes and two mutual funds, the Vanguard 500 Index Trust (which tracks the S\&P 500 index) and the AXP Extra Income Fund (which focuses on high current income and invests in long-term high-yielding lower-rated corporate bonds). 
In contrast, the coefficients for Dedicated Shortseller and Pure Leveraged Currency indicators - 0.001 and 0.069 , respectively, with $t$-statistics of 0.01 and 0.11 , respectivelyare positive and statistically insignificant at the $5 \%$ level, which is consistent with common intuition about the liquidity of these types of funds. Moreover, the coefficient for the Pure Managed Futures indicator is both positive and significant at the $5 \%$ level -0.101 with a $t$-statistic of 3.00 - which is also consistent with the intuition that managed futures involve relatively liquid securities with well established marks that cannot easily be manipulated.

The last indicator variable included in the first two regressions takes on the value 1 if the fund is open to new investors and 0 if closed. If return-smoothing is actively being pursued, we might expect it to be more important for funds that are open since such funds are still attempting to attract new investors. This implies that the coefficient for this indicator variable should be negative - open funds should be more prone to smoothing than closed funds. Table 11 confirms this hypothesis: the estimated coefficient for OPEN is -0.040 with a $t$-statistic of 2.03, implying that funds open to new investors have a smoothing coefficient $\hat{\theta}_{0}$ that is lower by 0.040 on average than funds that are closed. An alternate interpretation is that funds that are still open to new investors are typically those with smaller assets under management, and as a result, are less likely to be able to afford costly third-party valuations of illiquid securities in their portfolios. Unfortunately, many funds in the TASS database do not report assets under management so we were unable to investigate this alternative.

The third and fourth regressions in Table 11 include additional indicator variables that capture the fund's geographical base as well as the geographical focus of its investments, and we see that being in the US has a positive marginal impact on the conditional mean of $\hat{\theta}_{0}$, but being US-focused in its investments has a negative marginal impact. The latter result is somewhat counterintuitive but becomes less puzzling in light of the fact that approximately $46 \%$ of the funds are US-focused, hence many of the most illiquid funds are included in this category. Apart from this indicator, the geographical aspects of our sample of funds seem to have little impact on the cross-sectional variability in smoothing parameter estimates.

With $R^{2}$ 's ranging from $9.0 \%$ to $17.7 \%$, the regressions in Table 11 leave considerable cross-sectional variation unexplained, but this is no surprise given the noise inherent in the category assignments and the heterogeneity of investment styles even within each category. However, the general pattern of coefficients and $t$-statistics do suggest that the smoothing coefficients are capturing significant features of the cross section of hedge fund returns in our sample.

The final set of empirical estimates of the smoothing process (21)-(23) is for the linear regression model of Section 5.2, and is summarized in Table 12. Recall from Section 5.2 that the linear-regression estimates of $\left(\theta_{0}, \theta_{1}, \theta_{2}\right)$ are based on the assumption that true 


\begin{tabular}{|c|c|c|c|c|}
\hline Regressor & $\hat{\theta}_{0}$ & $\hat{\xi}$ & $\hat{\theta}_{0}$ & $\hat{\xi}$ \\
\hline Constant & $\begin{array}{r}1.059 \\
(42.05)\end{array}$ & $\begin{array}{c}1.314 \\
(17.26)\end{array}$ & $\begin{array}{c}1.086 \\
(35.62)\end{array}$ & $\begin{array}{r}1.407 \\
(15.21)\end{array}$ \\
\hline US Equity Hedge & $\begin{array}{r}-0.077 \\
(2.56)\end{array}$ & $\begin{array}{c}-0.255 \\
(2.82)\end{array}$ & $\begin{array}{c}-0.076 \\
(2.36)\end{array}$ & $\begin{array}{r}-0.257 \\
(2.62)\end{array}$ \\
\hline European Equity Hedge & $\begin{array}{c}-0.212 \\
(3.79)\end{array}$ & $\begin{array}{r}-0.531 \\
(3.14)\end{array}$ & $\begin{array}{c}-0.260 \\
(4.06)\end{array}$ & $\begin{array}{c}-0.676 \\
(3.48)\end{array}$ \\
\hline Asian Equity Hedge & $\begin{array}{c}-0.086 \\
(0.78)\end{array}$ & $\begin{array}{c}-0.254 \\
(0.77)\end{array}$ & $\begin{array}{c}-0.076 \\
(0.65)\end{array}$ & $\begin{array}{c}-0.248 \\
(0.71)\end{array}$ \\
\hline Global Equity Hedge & $\begin{array}{c}-0.113 \\
(2.19)\end{array}$ & $\begin{array}{c}-0.366 \\
(2.35)\end{array}$ & $\begin{array}{c}-0.084 \\
(1.55)\end{array}$ & $\begin{array}{c}-0.294 \\
(1.80)\end{array}$ \\
\hline Dedicated Shortseller & $\begin{array}{c}0.001 \\
(0.01)\end{array}$ & $\begin{array}{c}-0.128 \\
(0.45)\end{array}$ & $\begin{array}{r}0.001 \\
(0.01)\end{array}$ & $\begin{array}{c}-0.130 \\
(0.46)\end{array}$ \\
\hline Fixed-Income Directional & $\begin{array}{c}-0.262 \\
(3.73)\end{array}$ & $\begin{array}{c}-0.583 \\
(2.75)\end{array}$ & $\begin{array}{c}-0.258 \\
(3.64)\end{array}$ & $\begin{array}{c}-0.575 \\
(2.67)\end{array}$ \\
\hline Convertible Fund (Long Only) & $\begin{array}{c}-0.180 \\
(2.73)\end{array}$ & $\begin{array}{c}-0.264 \\
(1.32)\end{array}$ & $\begin{array}{c}-0.188 \\
(2.83)\end{array}$ & $\begin{array}{c}-0.289 \\
(1.44)\end{array}$ \\
\hline Event Driven & $\begin{array}{c}-0.218 \\
(6.69)\end{array}$ & $\begin{array}{c}-0.514 \\
(5.23)\end{array}$ & $\begin{array}{c}-0.223 \\
(6.57)\end{array}$ & $\begin{array}{r}-0.527 \\
(5.12)\end{array}$ \\
\hline Non-Directional/Relative Value & $\begin{array}{c}-0.211 \\
(6.07)\end{array}$ & $\begin{array}{c}-0.432 \\
(4.12)\end{array}$ & $\begin{array}{c}-0.194 \\
(5.37)\end{array}$ & $\begin{array}{c}-0.399 \\
(3.64)\end{array}$ \\
\hline Global Macro & $\begin{array}{c}-0.075 \\
(1.38)\end{array}$ & $\begin{array}{r}-0.271 \\
(1.66)\end{array}$ & $\begin{array}{c}-0.049 \\
(0.86)\end{array}$ & $\begin{array}{c}-0.230 \\
(1.33)\end{array}$ \\
\hline Global Opportunity & $\begin{array}{c}-0.282 \\
(1.17)\end{array}$ & $\begin{array}{c}-0.656 \\
(0.9)\end{array}$ & $\begin{array}{c}-0.275 \\
(1.14)\end{array}$ & $\begin{array}{r}-0.647 \\
(0.89)\end{array}$ \\
\hline Natural Resources & $\begin{array}{c}-0.109 \\
(0.78)\end{array}$ & $\begin{array}{c}-0.363 \\
(0.86)\end{array}$ & $\begin{array}{c}-0.112 \\
(0.8)\end{array}$ & $\begin{array}{c}-0.372 \\
(0.87)\end{array}$ \\
\hline Pure Leveraged Currency & $\begin{array}{c}0.069 \\
(1.32)\end{array}$ & $\begin{array}{c}0.152 \\
(0.96)\end{array}$ & $\begin{array}{c}0.073 \\
(1.37)\end{array}$ & $\begin{array}{c}0.158 \\
(0.98)\end{array}$ \\
\hline Pure Managed Futures & $\begin{array}{c}0.101 \\
(3.00)\end{array}$ & $\begin{array}{c}0.210 \\
(2.06)\end{array}$ & $\begin{array}{c}0.116 \\
(3.29)\end{array}$ & $\begin{array}{c}0.244 \\
(2.29)\end{array}$ \\
\hline Pure Emerging Market & $\begin{array}{c}-0.195 \\
(5.34)\end{array}$ & $\begin{array}{c}-0.486 \\
(4.40)\end{array}$ & $\begin{array}{c}-0.189 \\
(4.33)\end{array}$ & $\begin{array}{c}-0.481 \\
(3.63)\end{array}$ \\
\hline Pure Property & $\begin{array}{c}0.173 \\
(0.72)\end{array}$ & $\begin{array}{c}0.304 \\
(0.42)\end{array}$ & $\begin{array}{l}0.195 \\
(0.80\end{array}$ & $\begin{array}{c}0.339 \\
(0.46)\end{array}$ \\
\hline Fund of Funds & $\begin{array}{c}-0.178 \\
(5.66)\end{array}$ & $\begin{array}{c}-0.433 \\
(4.57)\end{array}$ & $\begin{array}{c}-0.170 \\
(5.28)\end{array}$ & $\begin{array}{c}-0.419 \\
(4.29)\end{array}$ \\
\hline OPEN & $\begin{array}{c}-0.040 \\
(2.03)\end{array}$ & $\begin{array}{r}-0.077 \\
(1.30)\end{array}$ & $\begin{array}{c}-0.024 \\
(1.17)\end{array}$ & $\begin{array}{c}-0.041 \\
(0.65)\end{array}$ \\
\hline USBASED & & & $\begin{array}{c}0.018 \\
(1.00)\end{array}$ & $\begin{array}{c}0.030 \\
(0.54)\end{array}$ \\
\hline GF-GLB & & & $\begin{array}{c}-0.050 \\
(2.37)\end{array}$ & $\begin{array}{c}-0.139 \\
(2.19)\end{array}$ \\
\hline GF-USA & & & $\begin{array}{c}-0.053 \\
(2.45)\end{array}$ & $\begin{array}{c}-0.144 \\
(2.19)\end{array}$ \\
\hline GF-APC & & & $\begin{array}{c}-0.049 \\
(1.59)\end{array}$ & $\begin{array}{c}-0.128 \\
(1.37)\end{array}$ \\
\hline GF-WEU & & & $\begin{array}{c}0.018 \\
(0.61)\end{array}$ & $\begin{array}{c}0.052 \\
(0.58)\end{array}$ \\
\hline GF-EEU & & & $\begin{array}{r}-0.011 \\
(0.26)\end{array}$ & $\begin{array}{c}-0.045 \\
(0.35)\end{array}$ \\
\hline GF-AFR & & & $\begin{array}{c}0.016 \\
(0.28)\end{array}$ & $\begin{array}{c}0.054 \\
(0.31)\end{array}$ \\
\hline Sample Size & 908 & 908 & 891 & 891 \\
\hline Adjusted $R^{2}(\%)$ & 16.5 & 9.0 & 17.7 & 9.9 \\
\hline
\end{tabular}

Table 11: Regressions of maximum likelihood estimated smoothing coefficient $\hat{\theta}_{0}$ and smoothing index $\hat{\xi}$ on indicator variables for 908 hedge funds in the TASS Hedge Fund Combined (Live and Graveyard) database with at least five years of returns history during the period from November 1977 to January 2001, where the maximum likelihood estimators of the MA coefficients $\left(\theta_{0}, \theta_{1}, \theta_{2}\right)$ are constrained to sum to 1 . Absolute values of $t$-statistics are given in parentheses. The indicator variables are OPEN ( 1 if the fund is open, 0 otherwise); the fund categories ( 1 if the fund belongs to the category, 0 otherwise); USBASED ( 1 if the fund is based in the US, 0 otherwise); and geographical focus categories (1 if the geographical focus of the fund is in a given region, 0 otherwise, where the regions are USA, Asia Pacific, Western Europe, Eastern Europe, and Africa, respectively). 
returns are given by the linear single-factor model (20) where the factor is the return on the S\&P 500 index. To the extent that this assumption is a poor approximation to the true return-generating process, the corresponding smoothing parameter estimates will be flawed as well.

Table 12 reports the means and standard deviations of the estimates $\left(\hat{\theta}_{0}, \hat{\theta}_{1}, \hat{\theta}_{2}\right)$ and $\hat{\xi}$ for each of the categories, as well as the Durbin-Watson statistic and the regression $R^{2}$. In contrast to the maximum likelihood estimates of Table 8, the regression estimates are considerably more noisy, with cross-sectional standard deviations for the coefficients that are often an order of magnitude larger than the means, and in almost every case larger than the standard deviations of Table 8 . For example, the average $\hat{\theta}_{0}$ for the Not Categorized category is 0.659 , but the standard deviation is 8.696. The mean of $\hat{\theta}_{0}$ for Fixed-Income Directional funds is -1.437 and the standard deviation is 6.398 . These results are not unexpected given the role that the linear single-factor model plays in the estimation process - if true returns contain additional common factors, then the linear-regression approach (62) will yield biased and inconsistent estimators for the smoothing parameters in (21)-(23).

The $R^{2}$ statistics in Table 12 yield some indication of the likelihood of omitted factors among the different categories. The highest mean $R^{2}$ 's are for the US Equity Hedge, Dedicated Shortseller, and Convertible Fund (Long Only) categories, with values of 26.1\%, 43.0\%, and $25.0 \%$, respectively, which is consistent with the fact that our single factor is the S\&P $500 .{ }^{40}$ However, several categories have mean $R^{2}$ 's below $10 \%$, implying relatively poor explanatory power for the single-factor model and, therefore, noisy and unreliable estimates of the smoothing process.

Overall, the results in Table 12 suggest that the linear regression approach is dominated by the maximum likelihood procedure, and that while the regression coefficients of lagged market returns may provide some insight into the net market exposure of some funds, they are considerably less useful for making inferences about illiquidity and smoothed returns.

\subsection{Illiquidity Vs. Smoothing}

To address the issue of systematic versus idiosyncratic effects of illiquidity and returnsmoothing, we estimate the more general linear factor model of smoothing (67)-(69) with $k=3$ for a group of 10 randomly selected convertible arbitrage funds from our sample of 908 funds. ${ }^{41}$ We take as our common factor $\Lambda_{t}$ the CSFB/Tremont Convertible Arbitrage Index,

\footnotetext{
${ }^{40}$ We have omitted the Global Opportunity category from this comparison despite its $R^{2}$ of $30.9 \%$ because it contains only a single fund.

${ }^{41}$ In particular, we selected the first 10 convertible arbitrage funds in our sample, ranked according to TASS fund identifiers.
} 


\begin{tabular}{|c|c|c|c|c|c|c|c|c|c|c|c|c|c|}
\hline \multirow{2}{*}{ Category } & \multirow{2}{*}{$N$} & \multicolumn{2}{|c|}{$\hat{\theta}_{0}$} & \multicolumn{2}{|c|}{$\hat{\theta}_{1}$} & \multicolumn{2}{|c|}{$\hat{\theta}_{2}$} & \multicolumn{2}{|r|}{$\hat{\xi}$} & \multicolumn{2}{|c|}{ D.W. } & \multicolumn{2}{|c|}{$R^{2}(\%)$} \\
\hline & & Mean & $\mathrm{SD}$ & Mean & $\mathrm{SD}$ & Mean & $\mathrm{SD}$ & Mean & $\mathrm{SD}$ & Mean & $\mathrm{SD}$ & Mean & SD \\
\hline Not Categorized & 111 & 0.659 & 8.696 & 0.459 & 9.363 & -0.118 & 2.260 & 167.540 & 1432.164 & 1.86 & 0.33 & 13.6 & 16.8 \\
\hline US Equity Hedge & 162 & 0.695 & 1.502 & 0.094 & 0.415 & 0.211 & 1.220 & 4.427 & 38.503 & 1.80 & 0.28 & 26.1 & 17.5 \\
\hline European Equity Hedge & 22 & 0.561 & 0.155 & 0.340 & 0.683 & 0.099 & 0.708 & 1.386 & 4.287 & 1.76 & 0.19 & 18.0 & 10.8 \\
\hline Asian Equity Hedge & 5 & 0.405 & 0.252 & 0.323 & 0.179 & 0.272 & 0.088 & 0.425 & 0.086 & 1.82 & 0.24 & 7.4 & 4.5 \\
\hline Global Equity Hedge & 27 & 0.846 & 0.400 & 0.057 & 0.331 & 0.097 & 0.364 & 1.115 & 0.913 & 1.65 & 0.22 & 22.1 & 19.8 \\
\hline Dedicated Shortseller & 7 & 0.908 & 0.182 & 0.115 & 0.101 & -0.023 & 0.203 & 0.911 & 0.360 & 1.94 & 0.16 & 43.0 & 14.7 \\
\hline Fixed-Income Directional & 13 & -1.437 & 6.398 & 4.385 & 14.552 & -1.948 & 8.179 & 320.099 & 1151.235 & 1.62 & 0.29 & 13.1 & 9.9 \\
\hline Convertible Fund (Long Only) & 15 & 0.538 & 0.262 & 0.343 & 0.152 & 0.120 & 0.178 & 0.536 & 0.219 & 1.53 & 0.24 & 25.0 & 15.0 \\
\hline Event Driven & 109 & 0.582 & 0.479 & 0.293 & 0.493 & 0.125 & 0.225 & 0.958 & 3.568 & 1.63 & 0.36 & 18.0 & 11.3 \\
\hline Non-Directional/Relative Value & 85 & 0.643 & 4.057 & 0.895 & 2.321 & -0.538 & 4.761 & 45.493 & 244.844 & 1.62 & 0.46 & 12.2 & 9.2 \\
\hline Global Macro & 24 & 0.558 & 0.349 & 0.194 & 0.341 & 0.247 & 0.190 & 0.674 & 0.409 & 1.76 & 0.28 & 13.5 & 8.0 \\
\hline Global Opportunity & 1 & 0.619 & - & 0.191 & - & 0.191 & - & 0.455 & - & 1.55 & - & 30.9 & - \\
\hline Natural Resources & 3 & 0.691 & 0.138 & 0.106 & 0.087 & 0.203 & 0.068 & 0.551 & 0.163 & 1.88 & 0.31 & 2.6 & 0.9 \\
\hline Pure Leveraged Currency & 26 & -0.080 & 1.376 & 0.360 & 1.066 & 0.720 & 1.987 & 7.363 & 24.457 & 1.89 & 0.16 & 4.4 & 6.0 \\
\hline Pure Managed Futures & 93 & -0.032 & 1.588 & 0.696 & 1.649 & 0.336 & 1.611 & 8.350 & 26.079 & 1.99 & 0.26 & 5.9 & 5.9 \\
\hline Pure Emerging Market & 72 & 0.899 & 0.801 & 0.157 & 0.465 & -0.056 & 0.452 & 1.883 & 6.486 & 1.51 & 0.29 & 22.8 & 10.6 \\
\hline Pure Property & 1 & 1.319 & - & -0.024 & - & -0.295 & - & 1.828 & - & 2.31 & - & 15.4 & - \\
\hline Fund of Funds & 132 & 0.674 & 1.516 & -0.049 & 2.566 & 0.375 & 3.059 & 18.694 & 171.624 & 1.63 & 0.30 & 21.6 & 15.0 \\
\hline All & 908 & 0.554 & 3.534 & 0.366 & 3.950 & 0.081 & 2.401 & 34.268 & 529.561 & 1.73 & 0.34 & 17.8 & 15.1 \\
\hline
\end{tabular}

Table 12: Means and standard deviations of linear regression estimates of MA(2) smoothing process $R_{t}^{o}=\theta_{0} R_{t}+\theta_{1} R_{t-1}+\theta_{2} R_{t-2}$, $\xi \equiv \theta_{0}^{2}+\theta_{1}^{2}+\theta_{2}^{2}$ under the assumption of a linear single-factor model for $R_{t}$ where the factor is the total return of the S\&P 500 Index, for 908 hedge funds in the TASS Hedge Fund Combined (Live and Graveyard) database with at least five years of returns history during the period from November 1977 to January 2001. 
and estimate the linear regression equation via maximum likelihood and then renormalize the MA coefficients according to (69) and recompute the standard errors accordingly. Table 13 contains the regression coefficients as well as the smoothing coefficients, and $t$-statistics are reported instead of standard errors because we have specific null hypotheses to test as described in Section 5.2.

The estimates in Table 13 show that including a common factor can have a significant impact on the smoothing parameter estimates. For example, the value of $\hat{\theta}_{0}$ for Fund 45 under the smoothing process $(21)-(23)$ is 0.648 , and its $t$-statistic under the null hypothesis that $\theta_{0}=1$ is 4.64 . However, under the linear factor specification (67)-(69), the smoothing coefficient estimate is 0.960 with a $t$-statistic of 0.05 . Nevertheless, for other funds in our sample of 10, the smoothing parameter estimates are virtually unchanged by including the contemporaneous and lagged common factors. For example, the value of $\hat{\theta}_{0}$ for Fund 171 under the smoothing process (21)-(23) and the linear factor model (67)-(69) is 0.536 and 0.533 , respectively, with $t$-statistics of 11.46 and 10.33 , respectively.

We see from Table 13 that the Convertible Arbitrage Index is statistically significant for several, but not all, of the 10 funds, and that its lags are significant for only two funds, 1 and 34. For these two funds, the lagged-index coefficients are negative in sign, which is not consistent with the smoothing model (68)-(69) (assuming that the funds' contemporaneous factor loadings and smoothing parameters are positive). For Fund 1, the smoothing parameter estimate $\hat{\theta}_{0}$ is still significantly different from 1 even after accounting for the common factor, but for Fund 34, it is not.

It is tempting to conclude from these results that the linear factor model (67)-(69) is capable of distinguishing between systematic illiquidity and idiosyncratic return-smoothing behavior. For example, we might argue that those funds which continue to exhibit significant smoothing parameters $\hat{\theta}_{0}$ even after accounting for common factors must be engaged in return-smoothing behavior. However, several caveats must be kept in mind before reaching such conclusions. First, we cannot be certain that the CSFB/Tremont Convertible Arbitrage Index is the appropriate common factor for these funds, despite the TASS classificationsome funds may be involved in complex versions of convertible arbitrage while others are engaged in plain-vanilla implementations. ${ }^{42}$ Regressing a fund's returns on a highly serially correlated common factor that is not directly relevant to that fund's investment process will, nevertheless, have an effect on the smoothing-parameter estimates $\hat{\theta}_{k}$, and the effect

\footnotetext{
${ }^{42}$ For example, TASS defines their "Convertible Fund (Long Only)" category as convertible arbitrage funds that take only long positions. Funds that use convertible arbitrage strategies are also included in the "Fixed Income" and "Non-Directional/Relative Value" categories in the TASS database. However, convertible arbitrage in CSFB database involves all funds that use convertible arbitrage strategy, not only long-only funds.
} 
may be in either direction depending on the relation between the common factor and the fund's observed returns. Second, even if a common factor can account for much of the serial correlation in a fund's observed returns, an explanation for the source of the factor's serial correlation is still required - if the fund is a buy-and-hold version of the common factor, e.g., a fund-of-funds designed to replicate the CSFB/Tremont Convertible Arbitrage Index, then it is of small comfort to investors in such a fund-of-funds that there is not much smoothing in observed returns beyond what is already present in the common factor. And finally, no econometric model can fully capture the many qualitative and often subjective characteristics of a fund's investment process, and such information is likely to be of particular relevance in distinguishing between illiquidity and smoothed returns at the fund level.

These caveats suggest that a more comprehensive econometric analysis of hedge-fund returns may be worthwhile, with particular emphasis on constructing common factors for hedge funds with similar investment mandates and processes. By developing a better understanding for the common risk exposures that certain hedge funds share, it may be possible to differentiate between systematic and idiosyncratic illiquidity and provide investors and managers with a more refined set of tools with which to optimize their investment plans.

\subsection{Smoothing-Adjusted Sharpe Ratio Estimates}

For each of the 908 funds in our sample, we compute annual Sharpe ratios in three ways relative to a benchmark return of 0 : the standard method $(\sqrt{12}$ times the ratio of the mean monthly return to the monthly return standard deviation), the serial-correlation-adjusted method in Lo (2002), and the small-sample method described in Section 5.4. The results are summarized in Table 14.

The largest differences between standard and smoothing-adjusted Sharpe ratios are found in the same categories that the smoothing-process estimates of Section 6.2 identified as the most illiquid: Fixed-Income Directional (20.3\% higher average Sharpe ratio relative to SR ${ }^{* *}$ ), Convertible Fund (Long Only) (17.8\%), Non-Directional/Relative Value (16.0\%), Pure Emerging Market (16.3\%), and Fund of Funds (17.8\%). For two categories-Dedicated Shortseller and Managed Futures - the bias is reversed, a result of negative serial correlation in their returns. For the other categories, Table 14 shows that the smoothing-adjusted Sharpe ratios are similar in magnitude to the usual estimates. These differences across categories suggest the importance of taking illiquidity and smoothed returns into account in evaluating the performance of hedge funds. 


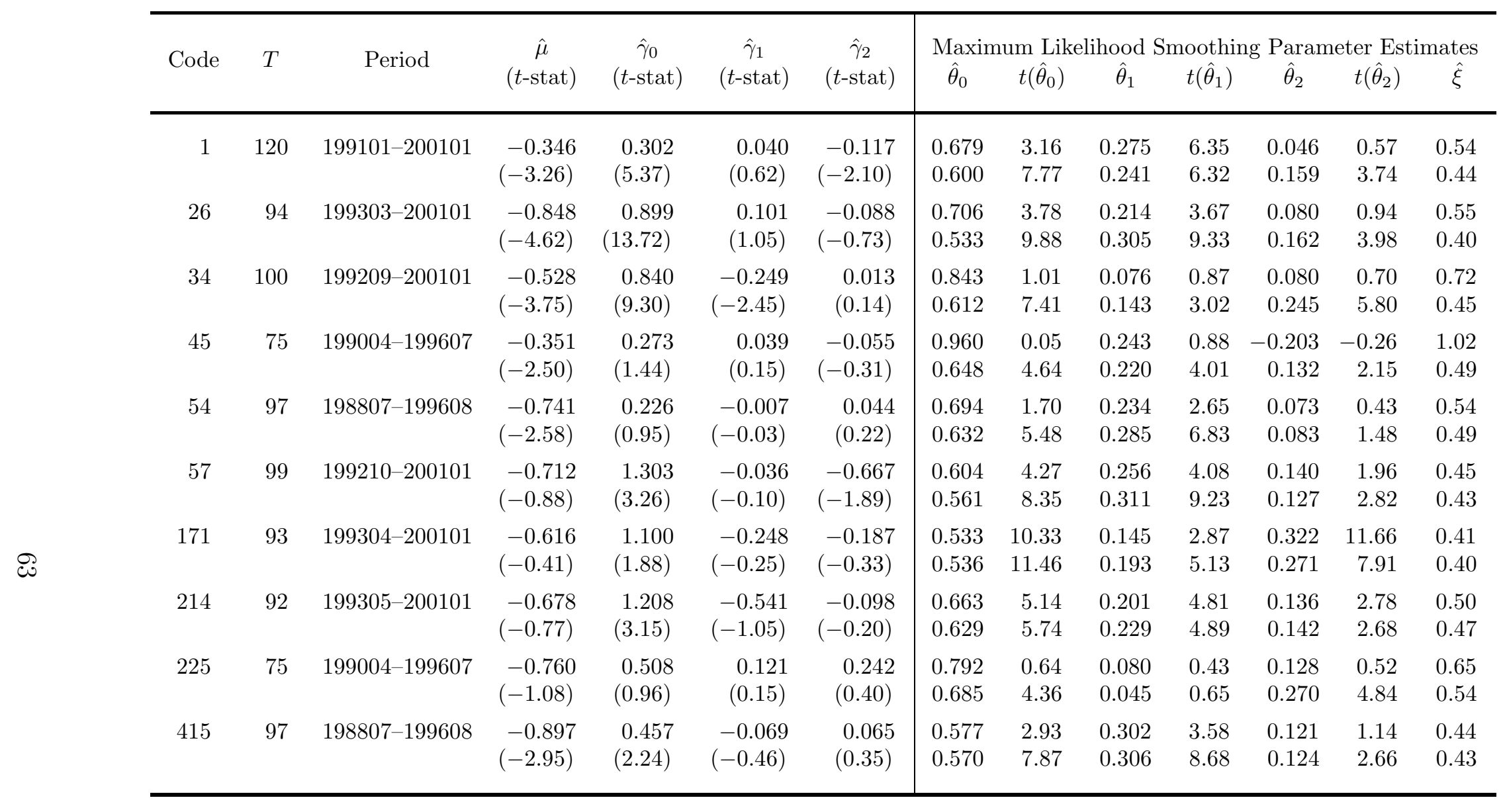

Table 13: Maximum likelihood estimates of linear regression model with MA(2) errors, $R_{t}^{o}=\mu+\gamma_{0} \Lambda_{t}+\gamma_{1} \Lambda_{t-1}+\gamma_{2} \Lambda_{t-2}+u_{t}$, $u_{t}=\theta_{0} \epsilon_{t}+\theta_{1} \epsilon_{t-1}+\theta_{2} \epsilon_{t-2}$, subject to the normalization $1=\theta_{0}+\theta_{1}+\theta_{2}$, for 10 randomly selected convertible arbitrage funds from the sample of 908 hedge funds in the TASS Hedge Fund Combined (Live and Graveyard) database with at least five years of returns history during the period from November 1977 to January 2001. The factor $\Lambda_{t}$ is taken to be the CSFB/Tremont Convertible Arbitrage Index. For comparison, maximum likelihood estimates of $\theta_{0}, \theta_{1}, \theta_{2}$, and $t$-statistics from the MA(2) smoothing process $R_{t}^{o}=\theta_{0} R_{t}+\theta_{1} R_{t-1}+\theta_{2} R_{t-2}$, subject to the normalization $1=\theta_{0}+\theta_{1}+\theta_{2}$, are provided below each of the main rows. $t$-statistics are computed with respect to the null hypothesis that the coefficient is 0 , except for $\hat{\theta}_{0}$, for which the null hypothesis $\theta_{0}=1$ is used, hence the $t$-statistic is computed as $\left(\hat{\theta}_{0}-1\right) / \operatorname{SE}\left(\hat{\theta}_{0}\right)$. 


\begin{tabular}{|c|c|c|c|c|c|c|c|}
\hline \multirow{3}{*}{ Category } & \multicolumn{7}{|c|}{ Sharpe Ratios For Combined Sample } \\
\hline & \multirow{2}{*}{$N$} & \multicolumn{2}{|c|}{$\mathrm{SR}$} & \multicolumn{2}{|c|}{$\mathrm{SR}^{*}$} & \multicolumn{2}{|c|}{$\mathrm{SR}^{* *}$} \\
\hline & & Mean & $\mathrm{SD}$ & Mean & $\mathrm{SD}$ & Mean & SD \\
\hline Not Categorized & 111 & 1.12 & 1.09 & 1.06 & 0.87 & 1.00 & 0.82 \\
\hline US Equity Hedge & 162 & 1.26 & 0.75 & 1.31 & 0.75 & 1.23 & 0.69 \\
\hline European Equity Hedge & 22 & 1.43 & 0.74 & 1.43 & 0.80 & 1.33 & 0.74 \\
\hline Asian Equity Hedge & 5 & 0.50 & 0.39 & 0.52 & 0.39 & 0.49 & 0.37 \\
\hline Global Equity Hedge & 27 & 0.90 & 0.61 & 0.95 & 0.66 & 0.89 & 0.61 \\
\hline Dedicated Shortseller & 7 & 0.28 & 0.59 & 0.32 & 0.64 & 0.30 & 0.61 \\
\hline Fixed-Income Directional & 13 & 2.02 & 2.35 & 1.80 & 2.23 & 1.68 & 2.06 \\
\hline Convertible Fund (Long Only) & 15 & 1.83 & 1.20 & 1.66 & 0.85 & 1.55 & 0.80 \\
\hline Event Driven & 109 & 2.36 & 1.45 & 2.21 & 1.57 & 2.08 & 1.47 \\
\hline Non-Directional/Relative Value & 85 & 2.20 & 1.86 & 2.03 & 2.39 & 1.89 & 2.22 \\
\hline Global Macro & 24 & 1.08 & 0.67 & 1.14 & 0.73 & 1.07 & 0.70 \\
\hline Global Opportunity & 1 & -0.56 & - & -0.39 & - & -0.37 & - \\
\hline Natural Resources & 3 & 0.60 & 0.25 & 0.56 & 0.23 & 0.52 & 0.21 \\
\hline Pure Leveraged Currency & 26 & 0.63 & 0.49 & 0.65 & 0.50 & 0.61 & 0.47 \\
\hline Pure Managed Futures & 93 & 0.54 & 0.55 & 0.63 & 0.60 & 0.60 & 0.56 \\
\hline Pure Emerging Market & 72 & 0.39 & 0.45 & 0.36 & 0.44 & 0.34 & 0.40 \\
\hline Pure Property & 1 & 0.42 & - & 0.45 & - & 0.41 & - \\
\hline Fund of Funds & 132 & 1.44 & 1.01 & 1.30 & 0.88 & 1.22 & 0.82 \\
\hline All & 908 & 1.32 & 1.24 & 1.27 & 1.27 & 1.19 & 1.18 \\
\hline
\end{tabular}

Table 14: Means and standard deviations of Sharpe ratios of 908 hedge funds in the TASS Hedge Fund Combined (Live and Graveyard) database with at least five years of returns history during the period from November 1977 to January 2001. SR is the standard Sharpe ratio, SR* is the smoothing-adjusted Sharpe ratio of Lo (2002), and $\mathrm{SR}^{* *}$ is the smoothingadjusted Sharpe ratio using $\hat{\sigma}_{\mathrm{NW}}$. All Sharpe ratios are computed with respect to a 0 benchmark. 


\section{Conclusions}

Although there are several potential explanations for serial correlation in asset returns, we have argued in this paper that the serial correlation present in the returns of hedge funds is due primarily to illiquidity and smoothed returns. Using a simple econometric model in which observed returns are a finite moving-average of unobserved economic returns, we are able to generate empirically realistic levels of serial correlation for historical hedge-fund returns while, at the same time, explaining the findings of Asness, Krail and Liew (2001) regarding the significance of lagged market returns in market-model regressions for hedge funds. Although our moving-average specification is similar to some of the early models of nonsynchronous trading, our motivation is quite different and is meant to cover a broader set of factors that give rise to serial correlation and smoothed returns, even in the presence of synchronously recorded prices.

Maximum likelihood estimates of our smoothing model for the returns of 908 hedge funds in the TASS Hedge Fund database yield empirically plausible estimates of smoothing coefficients and suggest that simple time-series measures such as our smoothing index may serve as useful proxies for a hedge fund's illiquidity risk exposure. In some cases, our econometric model may also be useful for flagging possible cases of deliberate performance-smoothing behavior, although additional information will need to be gathered before any firm conclusions regarding such behavior can be made. Regardless of the sources of serial correlation, illiquidity exposure is the main implication and this has potentially important consequences for both managers and investors. Therefore, we also develop a set of tools for quantifying the degree of smoothing in the data and adjusting for smoothed returns in computing performance statistics such as means, variances, and Sharpe ratios, and derive their asymptotic distributions using continuous-record asymptotics which address the small sample sizes which typify hedge-fund datasets.

Our empirical results suggest several applications for our econometric model of illiquidity and smoothed returns. Despite the general consistency of our empirical results with common intuition regarding the levels of illiquidity among the various hedge-fund investment styles, the variation in estimated smoothing coefficients within each category indicates that there may be better ways of categorizing hedge funds. Given the importance of liquidity for the typical hedge-fund investor, it may be useful to subdivide each style category into "liquidity tranches" defined by our smoothing index. Alternatively, our smoothing parameter estimates may be used to compute illiquidity exposure measures for portfolios of hedge funds or fund of funds, which may serve as the basis for a more systematic approach to managing portfolios that include alternative investments. 
Although we have focused on hedge funds in this paper, our analysis may be applied to other investment classes, especially to venture-capital and private-equity funds, for which illiquidity and smoothed returns are even more problematic, and where the estimation of smoothing profiles can be particularly useful for providing investors with risk transparency. More generally, our econometric model may be applied to a number of other contexts in which there may be a gap between reported results and economic realities. For example, recent events surrounding the collapse of Enron and other cases of corporate accounting irregularities have created renewed concerns about "earnings management" in which certain corporations are alleged to have abused accounting conventions so as to smooth earnings, presumably to give the appearance of stability and consistent growth. ${ }^{43}$ The impact of such smoothing can sometimes be "undone" using an econometric model such as ours.

Finally, there are a number of outstanding issues regarding our analysis of illiquidity and smoothed returns. Perhaps the most pressing issue is whether the proximate source of smoothing is inadvertent or deliberate. Our linear regression model with contemporaneous and lagged common factors may serve as the starting point for distinguishing between systematic illiquidity versus idiosyncratic smoothing behavior. However, this issue is likely to require additional information about each fund along the lines of Chandar and Bricker's (2002) study, e.g., the size of the fund, the types of the securities in which the fund invests, the accounting conventions used to mark the portfolio, the organization's compensation structure, and other operational aspects of the fund. With these additional pieces of information, we may construct more relevant common factors for our linear-regression framework, or relate the cross-sectional variation in smoothing coefficients to assets under management, security type, fee structure, and other characteristics, yielding a more complete picture of the sources of smoothed returns.

From the investors' perspective, the natural extension of our analysis is to model illiquidity directly and quantify the illiquidity premium associated with each hedge-fund investment style, perhaps in a linear-factor framework such as Chordia, Roll and Subrahmanyam (2000) and Pastor and Stambaugh (2002). Whether such factor models can forecast liquidity crises like August 1998, and whether there are "systematic" illiquidity factors that are common to categories of hedge funds are open questions that are particularly important in the context of hedge-fund investments. We hope to address these and other related questions in our ongoing research.

\footnotetext{
${ }^{43}$ See Beneish (2001) and Healy and Wahlen (1999) for reviews of the extensive literature on earnings management.
} 


\section{A Appendix}

Proofs of Propositions 3, 4, and 5 are provided in Sections A.1, A.2, and A.3, respectively. Section A.4 provides definitions of the 17 categories from TASS, and Section A.5 contains additional empirical results.

\section{A.1 Proof of Proposition 3}

The constraint (49) may be used to substitute out $\theta_{0}$, hence we need only consider $\left(\theta_{1}, \theta_{2}\right)$. Now it is well known that in the standard $\mathrm{MA}(2)$ specification where the usual identification condition is used in place of (49), i.e.,

$$
X_{t}=\epsilon_{t}+a \epsilon_{t-1}+b \epsilon_{t-2}
$$

the asymptotic distribution of the maximum likelihood estimators $(\hat{a}, \hat{b})$ is given by:

$$
\sqrt{T}\left(\left[\begin{array}{l}
\hat{a} \\
\hat{b}
\end{array}\right]-\left[\begin{array}{l}
a \\
b
\end{array}\right]\right) \stackrel{a}{\sim} \mathcal{N}(0, \mathbf{V})
$$

where

$$
\mathbf{V} \equiv\left[\begin{array}{cc}
1-b^{2} & a(1-b) \\
a(1-b) & 1-b^{2}
\end{array}\right]
$$

But under our normalization (49), there is a simple functional relation between $(\hat{a}, \hat{b})$ and $\left(\hat{\theta}_{1}, \hat{\theta}_{2}\right)$ :

$$
\hat{\theta}_{1}=\frac{\hat{a}}{1+\hat{a}+\hat{b}}, \quad \hat{\theta}_{2}=\frac{\hat{b}}{1+\hat{a}+\hat{b}} .
$$

Therefore, we can apply the delta method to obtain the asymptotic distribution of $\left(\hat{\theta}_{1}, \hat{\theta}_{2}\right)$ as:

$$
\sqrt{T}\left(\left[\begin{array}{c}
\hat{\theta}_{1} \\
\hat{\theta}_{2}
\end{array}\right]-\left[\begin{array}{c}
\theta_{1} \\
\theta_{2}
\end{array}\right]\right) \stackrel{a}{\sim} \mathcal{N}\left(0, \mathbf{J} \mathbf{V} \mathbf{J}^{\prime}\right)
$$


where the matrix $\mathbf{J}$ is Jacobian associated with $(A .3)$ :

$$
\mathbf{J}=\frac{1}{(1+a+b)^{2}}\left[\begin{array}{cc}
1+b & -a \\
-b & 1+a
\end{array}\right]
$$

Then we have:

$$
\mathbf{J V J}^{\prime}=\frac{1}{(1+a+b)^{3}}\left[\begin{array}{cc}
-(1+b)\left(-1+a-a b+b^{2}\right) & b\left(-1+a-a b+b^{2}\right) \\
b\left(-1+a-a b+b^{2}\right) & -(-1+b)\left(-1+a-a b+b^{2}\right)
\end{array}\right]
$$

and solving for $a$ and $b$ as a function of $\theta_{1}$ and $\theta_{2}$ using (A.3) and substituting these expressions into $A .6$ yields the desired result.

The process $X_{t}$ is invertible if and only if the roots of characteristic polynomial

$$
f(x)=\theta_{0} x^{2}+\theta_{1} x+\theta_{2}
$$

lie inside the unit circle in the complex plane. It is easy to see that this is equivalent to the condition that the roots of

$$
f(x)=f\left(\frac{z+1}{z-1}\right)=\frac{z^{2}+2\left(1-\theta_{1}-2 \theta_{2}\right) z+1-2 \theta_{1}}{(z-1)^{2}}
$$

lie in the left half-plane (Samuelson, 1941, was perhaps the first to state this result). Applying the Routh-Hurwitz necessary and sufficient conditions to (A.8) then yields the desired result.

\section{A.2 Proof of Proposition 4}

Theorem 1 [Herrndorf (1984)] If $\left\{\epsilon_{t}\right\}$ satisfies the following assumptions:

(A1) $\mathrm{E}\left[\epsilon_{t}\right]=\mu$ for all $t$.

(A2) $\sup _{t} \mathrm{E}\left[\left|\epsilon_{t}-\mu\right|^{\beta}\right]<\infty$ for some $\beta>2$.

(A3) $0<\sigma_{o}^{2}=\lim _{T \rightarrow \infty} \mathrm{E}\left[\frac{1}{T}\left(\sum_{j=1}^{n}\left(\epsilon_{j}-\mu\right)^{2}\right]<\infty\right.$. 
(A4) $\left\{\epsilon_{t}\right\}$ is strong-mixing with mixing coefficients $\alpha_{k}$ that satisfy:

$$
\sum_{j=1}^{\infty} \alpha_{j}^{1-\frac{2}{\beta}}<\infty
$$

then as $n$ increases without bound,

$$
W_{n}(s) \equiv \frac{1}{\sigma_{o} \sqrt{n}} \sum_{j=1}^{[n s]}\left(\epsilon_{j}-\mu\right) \Rightarrow W(s), \quad s \in[0,1]
$$

where $[n s]$ denotes the greater integer less than or equal to ns and ' $\Rightarrow$ ' denotes weak convergence.

With these results in hand, we are ready to prove Proposition 4 . Let returns $R_{t}$ be given by:

$$
R_{t}=\epsilon_{t}
$$

where $\epsilon_{t}$ satisfies assumptions (A1)-(A4) of Theorem 1, and recall:

$$
\begin{aligned}
\hat{\mu} & =\frac{1}{T} \sum_{1}^{T} \epsilon_{t} \\
\hat{\sigma}_{\mathrm{NW}}^{2} & =\frac{1}{T} \sum_{1}^{T}\left(\epsilon_{t}-\hat{\mu}\right)^{2}+\frac{2}{T} \sum_{j=1}^{\theta}\left(1-\frac{j}{\theta+1}\right) \sum_{t=j+1}^{T}\left(\epsilon_{t}-\hat{\mu}\right)\left(\epsilon_{t-j}-\hat{\mu}\right) \\
& =I_{1}+I_{2} \quad \text { where } \\
I_{1} & \equiv \frac{1}{T} \sum_{1}^{T}\left(\epsilon_{t}-\hat{\mu}\right)^{2} \\
I_{2} & \equiv \frac{2}{T} \sum_{j=1}^{\theta}\left(1-\frac{j}{\theta+1}\right) \sum_{t=j+1}^{T}\left(\epsilon_{t}-\hat{\mu}\right)\left(\epsilon_{t-j}-\hat{\mu}\right)
\end{aligned}
$$

Observe that

$$
I_{1}=\frac{1}{T} \sum_{1}^{T}\left(\epsilon_{t}-\hat{\mu}\right)^{2}=\frac{1}{T} \sum_{1}^{T} \epsilon_{t}^{2}-\hat{\mu}^{2} \stackrel{p}{\rightarrow} \sigma_{\epsilon}^{2}
$$


where

$$
\sigma_{\epsilon}^{2} \equiv \lim _{t \rightarrow \infty} \frac{1}{T} \sum_{1}^{T} \epsilon_{t}^{2}=\mathrm{E}\left[\epsilon_{t}^{2}\right]
$$

Now the second term $I_{2}$ can be written as:

$$
I_{2} \frac{T(m+1)}{2}=\sum_{j=0}^{m}(m+1-j) \sum_{t=j+1}^{T}\left(\epsilon_{t}-\hat{\mu}\right)\left(\epsilon_{t-j}-\hat{\mu}\right)=J_{1}+J_{2}+J_{3} \text { (A.19) }
$$

where

$$
\begin{aligned}
J_{1} & \equiv \sum_{j=0}^{m}(m+1-j) \sum_{t=j+1}^{T} \epsilon_{t} \epsilon_{t-j} \\
J_{2} & \equiv \sum_{j=0}^{m}(m+1-j) \sum_{t=j+1}^{T} \hat{\mu}\left(\epsilon_{t}+\epsilon_{t-j}\right) \\
J_{3} & \equiv \sum_{j=0}^{m}(m+1-j) \sum_{t=j+1}^{T} \hat{\mu}^{2}
\end{aligned}
$$


Consider the first term in (A.19):

$$
\begin{aligned}
& J_{1}=\sum_{j=0}^{m}(m+1-j) \sum_{t=j+1}^{T} \epsilon_{t} \epsilon_{t-j}=m\left(\epsilon_{1} \epsilon_{2}+\epsilon_{2} \epsilon_{3}+\cdots+\epsilon_{T-1} \epsilon_{T}\right)+ \\
& (m-1)\left(\epsilon_{1} \epsilon_{3}+\epsilon_{2} \epsilon_{4}+\cdots+\epsilon_{T-2} \epsilon_{T}\right)+ \\
& \left(\epsilon_{1} \epsilon_{m+1}+\epsilon_{2} \epsilon_{m+2}+\cdots+\epsilon_{T-m} \epsilon_{T}\right) \\
& =\epsilon_{1}\left(\left(S_{2}-S_{1}\right)+\left(S_{3}-S_{1}\right)+\cdots+\left(S_{m+1}-S_{1}\right)\right)+\cdots+ \\
& \epsilon_{T-m}\left(\left(S_{T-m+1}-S_{T-m}\right)+\cdots+\left(S_{T}-S_{T-m}\right)\right)+ \\
& \epsilon_{T-m+1}\left(\left(S_{T-m+2}-S_{T-m+1}\right)+\cdots+2\left(S_{T}-S_{T-m+1}\right)\right)+\cdots+ \\
& \epsilon_{T-1}\left(m\left(S_{T}-S_{T-1}\right)\right) \\
& =\epsilon_{1}\left(S_{2}+S_{3}+\cdots+S_{m+1}\right)-m \epsilon_{1} S_{1}+\cdots+ \\
& \epsilon_{T-m}\left(S_{T-m+1}+\cdots+S_{T}\right)-m \epsilon_{T-m} S_{T-m}+ \\
& \epsilon_{T-m+1}\left(S_{T-m+2}+\cdots+2 S_{T}\right)-m \epsilon_{T-m+1} S_{T-m+1}+\cdots+ \\
& \epsilon_{T-1} m S_{T}-m \epsilon_{T-1} S_{T-1} \\
& =S_{2} S_{1}+S_{3} S_{2}+\cdots+S_{m+1} S_{m}+S_{m+2}\left(S_{m+1}-S_{1}\right)+\cdots+ \\
& S_{T}\left(S_{T-1}-S_{T-m-1}\right)+S_{T}\left(\epsilon_{T-m+1}+\cdots+m \epsilon_{T-1}\right)-m \sum_{t=1}^{T-1} \epsilon_{t} S_{t} \\
& =\sum_{t=1}^{T-1} S_{t}^{2}-(m-1) \sum_{t=1}^{T-1} \epsilon_{t} S_{t}-\sum_{t=1}^{T-(m+1)} S_{t} S_{t+m+1}+ \\
& S_{T}\left(m S_{T-1}-\sum_{t=T-m}^{T-1} S_{t}\right)
\end{aligned}
$$

When the Functional Central Limit Theorem is applied to (A.27), we have:

$$
\begin{aligned}
& J_{1} / T^{2} \Rightarrow \sigma^{2}\left(\int_{0}^{1} W(r)(W(r)-W(\min (r+\lambda, 1))) d r\right)- \\
& \frac{(m-1)}{2 T}\left(\sigma^{2} W^{2}(1)+\sigma_{\epsilon}^{2}\right)+\frac{m}{T} \sigma^{2} W^{2}(1)
\end{aligned}
$$


Now the second term in (A.19) can be rewritten as:

$$
\begin{aligned}
J_{2} & =-\sum_{j=1}^{m}(m+1-j) \sum_{t=j+1}^{T} \hat{\mu}\left(\epsilon_{t}+\epsilon_{t-j}\right) \\
& =-\hat{\mu} \sum_{j=1}^{m}(m+1-j)\left(S_{T}-S_{j}+S_{T-j}\right) \\
& =-\frac{m(m+1)}{2} \hat{\mu} S_{T}-\hat{\mu} \sum_{j=1}^{m}(m+1-j)\left(S_{T-j}-S_{j}\right)
\end{aligned}
$$

and applying the Functional Central Limit Theorem to (A.31) yields

$$
J_{2} / T^{2} \Rightarrow-\frac{m(m+1)}{2 T^{2}} \sigma^{2} W^{2}(1)-\sigma^{2} W(1) \int_{0}^{\lambda}(\lambda-r)(W(1-r)-W(r)) d r
$$

The third term of (A.19) can be rewritten in a similar manner:

$$
\begin{aligned}
J_{3} & =\sum_{j=1}^{m}(m+1-j) \sum_{t=j+1}^{T} \hat{\mu}^{2}=\hat{\mu}^{2} \sum_{j=1}^{m}(m+1-j)(T-j-1) \\
& =\hat{\mu}^{2} \sum_{j=1}^{m}\left(j^{2}-j(T+m)+(m+1)(T-1)\right) \\
& =\hat{\mu}^{2} \frac{m(m+1)(3 T-m-5)}{6}
\end{aligned}
$$

and applying the Functional Central Limit Theorem to (A.35) yields:

$$
J_{3} / T^{2} \Rightarrow \sigma^{2} W^{2}(1) \frac{(1+m) m(3 T-m-5)}{6 T^{3}}
$$

Combining (A.28), (A.32) and (A.36) shows that:

$$
\begin{aligned}
I_{2} \Rightarrow \frac{2}{\lambda} \sigma^{2} & \left(\int_{0}^{1} W(r)[W(r)-W(\min (r+\lambda, 1))] d r-\right. \\
& \left.W(1) \int_{0}^{\lambda}(\lambda-r)(W(1-r)-W(r)) d r\right)+\sigma^{2} W^{2}(1)\left(1-\frac{\lambda^{2}}{3}\right)-\sigma_{\epsilon}^{2}
\end{aligned}
$$


and summing (A.17) and (A.37) yields the desired result.

\section{A.3 Proof of Proposition 5}

Given the weak convergence of $\hat{\bar{\sigma}}_{\mathrm{NW}}^{2}$ to the functional $f(W)$ in (87), Proposition 5 is an almost trivial consequence of the following well-known result:

Theorem 2 [Extended Continuous Mapping Theorem ${ }^{44}$ Let $h_{n}$ and $h$ be measurable mappings from $\mathrm{D}[0,1]$ - the space of all functions on $[0,1]$ that are right continuous with left-hand limits - to itself and denote by $E$ the set of $x \in \mathrm{D}[0,1]$ such that $h_{n}\left(x_{n}\right) \rightarrow h(x)$ fails to hold for some sequence $x_{n}$ converging to $x$. If $W_{n}(s) \Rightarrow W(s)$ and $E$ is of Wiener-measure zero, i.e. $\mathrm{P}(W \in E)=0$, then $h_{n}\left(W_{n}\right) \Rightarrow h(W)$.

\section{A.4 TASS Fund Category Definitions}

The following is a list of category descriptions, taken directly from TASS documentation, that define the criteria used by TASS in assigning funds in their database to one of 17 possible categories:

Equity Hedge This directional strategy involves equity-oriented investing on both the long and short sides of the market. The objective is not to be market neutral. Managers have the ability to shift from value to growth, from small to medium to large capitalization stocks, and from a net long position to a net short position. Managers may use futures and options to hedge. The focus may be regional, such as long/short US or European equity, or sector specific, such as long and short technology or healthcare stocks. Long/short equity funds tend to build and hold portfolios that are substantially more concentrated than those of traditional stock funds. US equity Hedge, European equity Hedge, Asian equity Hedge and Global equity Hedge is the regional Focus.

Dedicated Short Seller Short biased managers take short positions in mostly equities and derivatives. The short bias of a manager's portfolio must be constantly greater than zero to be classified in this category.

Fixed Income Directional This directional strategy involves investing in Fixed Income markets only on a directional basis.

Convertible Arbitrage This strategy is identified by hedge investing in the convertible securities of a company. A typical investment is to be long the convertible bond and short the common stock of the same company. Positions are designed to generate profits from the fixed income security as well as the short sale of stock, while protecting principal from market moves.

Event Driven This strategy is defined as 'special situations' investing designed to capture price movement generated by a significant pending corporate event such as a merger, corporate restructuring, liquidation, bankruptcy or reorganization. There are three popular sub-categories in event-driven strategies: risk (merger) arbitrage, distressed/high yield securities, and Regulation D.

\footnotetext{
${ }^{44}$ See Billingsley (1968) for a proof.
} 
Non Directional/Relative Value This investment strategy is designed to exploit equity and/or fixed income market inefficiencies and usually involves being simultaneously long and short matched market portfolios of the same size within a country. Market neutral portfolios are designed to be either beta or currency neutral, or both.

Global Macro Global macro managers carry long and short positions in any of the world's major capital or derivative markets. These positions reflect their views on overall market direction as influenced by major economic trends and or events. The portfolios of these funds can include stocks, bonds, currencies, and commodities in the form of cash or derivatives instruments. Most funds invest globally in both developed and emerging markets.

Global Opportunity Global macro managers carry long and short positions in any of the world's major capital or derivative markets on an opportunistic basis. These positions reflect their views on overall market direction as influenced by major economic trends and or events. The portfolios of these funds can include stocks, bonds, currencies, and commodities in the form of cash or derivatives instruments. Most funds invest globally in both developed and emerging markets.

Natural Resources This trading strategy has a focus for the natural resources around the world.

Leveraged Currency This strategy invests in currency markets around the world.

Managed Futures This strategy invests in listed financial and commodity futures markets and currency markets around the world. The managers are usually referred to as Commodity Trading Advisors, or CTAs. Trading disciplines are generally systematic or discretionary. Systematic traders tend to use price and market specific information (often technical) to make trading decisions, while discretionary managers use a judgmental approach.

Emerging Markets This strategy involves equity or fixed income investing in emerging markets around the world.

Property The main focus of the investments are property.

Fund of Funds A 'Multi Manager' fund will employ the services of two or more trading advisors or Hedge Funds who will be allocated cash by the Trading Manager to trade on behalf of the fund.

\section{A.5 Supplementary Empirical Results}

In Tables A.1-A.7, we provide corresponding empirical results to Tables 7-14 but with Live and Graveyard funds separated so that the effects of survivorship bias can be seen. Of course, since we still apply our five-year minimum returns history filter to both groups, there is still some remaining survivorship bias. Tables A.1 and A.2 contain summary statistics for the two groups of funds, Tables A.3 and A.4 report summary statistics for the maximum likelihood estimates of the smoothing model (21)-(23), Tables A.5 and A.6 report similar statistics for the regression model estimates (62) of the smoothing model, and Table A.7 contains smoothing-adjusted Sharpe ratios for the two groups of funds. Finally, Table A.8 corresponds to the regressions of Table 11 but with dependent variables $\hat{\theta}_{0}$ and $\hat{\xi}$ estimated by maximum likelihood under the alternate constraint (75). 


\begin{tabular}{|c|c|c|c|c|c|c|c|c|c|c|c|c|c|c|c|c|c|}
\hline \multirow[b]{2}{*}{ Category } & \multirow[b]{2}{*}{$N$} & \multicolumn{2}{|c|}{ Annual Mean } & \multicolumn{2}{|c|}{ Annual SD } & \multicolumn{2}{|c|}{ Skewness } & \multicolumn{2}{|c|}{ Kurtosis } & \multicolumn{2}{|c|}{$\hat{\rho}_{1}(\%)$} & \multicolumn{2}{|c|}{$\hat{\rho}_{2}(\%)$} & \multicolumn{2}{|c|}{$\hat{\rho}_{3}(\%)$} & \multicolumn{2}{|c|}{$p$-Value $(Q)$} \\
\hline & & Mean & SD & Mean & $\mathrm{SD}$ & Mean & $\mathrm{SD}$ & Mean & $\mathrm{SD}$ & Mean & $\mathrm{SD}$ & Mean & $\mathrm{SD}$ & Mean & $\mathrm{SD}$ & Mean & $\mathrm{SD}$ \\
\hline Not Categorized & 44 & 12.08 & 6.04 & 13.08 & 10.44 & 0.05 & 0.73 & 2.37 & 2.54 & 8.8 & 15.9 & 2.3 & 14.5 & 1.4 & 9.8 & 31.8 & 32.0 \\
\hline US Equity Hedge & 139 & 23.53 & 10.92 & 21.86 & 11.95 & 0.20 & 0.98 & 3.79 & 4.89 & 8.0 & 13.7 & 0.7 & 11.4 & -4.1 & 11.2 & 33.0 & 29.0 \\
\hline European Equity Hedge & 19 & 18.75 & 7.33 & 15.36 & 6.53 & 0.51 & 0.73 & 3.10 & 2.86 & 13.0 & 11.1 & 13.5 & 9.0 & -2.9 & 8.9 & 16.4 & 20.7 \\
\hline Asian Equity Hedge & 5 & 9.16 & 7.96 & 21.13 & 6.64 & 0.50 & 0.85 & 2.32 & 0.73 & 11.7 & 13.0 & 5.0 & 5.6 & -5.4 & 13.4 & 40.2 & 21.1 \\
\hline Global Equity Hedge & 24 & 15.04 & 7.67 & 18.28 & 6.31 & -0.16 & 1.06 & 4.17 & 5.83 & 10.5 & 9.9 & -0.6 & 8.8 & -4.1 & 5.4 & 41.8 & 26.9 \\
\hline Dedicated Shortseller & 6 & -0.17 & 11.15 & 23.01 & 14.51 & 0.44 & 0.17 & 2.24 & 2.63 & 2.6 & 7.4 & -0.9 & 9.0 & -5.6 & 7.0 & 28.3 & 28.7 \\
\hline Fixed-Income Directional & 12 & 10.17 & 3.39 & 9.80 & 9.08 & -1.00 & 1.33 & 5.78 & 7.49 & 22.8 & 15.8 & 14.9 & 13.4 & 1.7 & 14.1 & 17.6 & 21.8 \\
\hline Convertible Fund (Long Only) & 12 & 14.05 & 5.54 & 11.67 & 7.39 & -0.26 & 1.88 & 7.16 & 10.93 & 22.9 & 11.9 & 5.3 & 14.9 & -1.0 & 11.9 & 15.2 & 22.1 \\
\hline Event Driven & 97 & 15.61 & 6.42 & 8.96 & 6.66 & -0.58 & 1.74 & 8.10 & 11.71 & 20.0 & 16.6 & 5.8 & 13.2 & -0.9 & 12.1 & 25.2 & 28.6 \\
\hline Non-Directional/Relative Value & 63 & 13.23 & 5.91 & 7.89 & 4.84 & -0.61 & 1.74 & 6.08 & 9.52 & 18.4 & 26.0 & 15.3 & 14.0 & 5.4 & 15.8 & 14.6 & 24.0 \\
\hline Global Macro & 15 & 14.92 & 7.82 & 17.34 & 10.46 & 0.79 & 1.07 & 4.67 & 4.79 & 5.3 & 11.8 & -1.3 & 12.2 & -0.9 & 8.4 & 41.9 & 24.2 \\
\hline Global Opportunity & 1 & -17.39 & - & 31.03 & - & -0.48 & - & 2.80 & - & 23.1 & - & 14.1 & - & 0.0 & - & 20.8 & - \\
\hline Natural Resources & 1 & 14.49 & - & 18.42 & - & 0.30 & - & -0.14 & - & -10.1 & - & -1.6 & - & 7.8 & - & 40.6 & - \\
\hline Pure Leveraged Currency & 15 & 10.36 & 5.23 & 15.27 & 6.25 & 0.81 & 0.75 & 3.22 & 4.04 & 7.4 & 8.7 & -3.3 & 9.9 & -3.1 & 7.1 & 31.2 & 18.7 \\
\hline Pure Managed Futures & 28 & 10.54 & 6.19 & 16.46 & 7.62 & 0.42 & 1.55 & 5.92 & 12.20 & 0.9 & 13.2 & -4.1 & 11.4 & -2.5 & 8.6 & 32.4 & 29.9 \\
\hline Pure Emerging Market & 54 & 9.08 & 10.21 & 26.12 & 11.66 & -0.56 & 1.21 & 4.97 & 5.86 & 18.3 & 12.0 & 4.1 & 11.9 & -1.7 & 9.2 & 30.7 & 29.4 \\
\hline Pure Property & 1 & 3.96 & - & 9.41 & - & -1.33 & - & 5.43 & - & -23.1 & - & 2.3 & - & 7.3 & - & 18.9 & - \\
\hline Fund of Funds & 115 & 11.45 & 4.95 & 10.16 & 5.75 & -0.29 & 1.27 & 4.83 & 6.17 & 17.3 & 14.0 & 6.2 & 11.7 & -1.2 & 9.1 & 26.5 & 27.8 \\
\hline All Live & 651 & 14.88 & 9.33 & 15.05 & 10.65 & -0.15 & 1.36 & 5.00 & 7.63 & 13.7 & 16.5 & 4.6 & 13.1 & -1.2 & 11.1 & 28.0 & 28.3 \\
\hline
\end{tabular}

Table A.1: Means and standard deviations of basic summary statistics for 651 hedge funds in the TASS Hedge Fund Live database with at least five years of returns history during the period from November 1977 to January 2001. The columns ' $p$-Value $(Q)$ ' contain means and standard deviations of $p$-values for the Box-Pierce $Q$-statistic for each fund using the first 6 autocorrelations of returns. 


\begin{tabular}{|c|c|c|c|c|c|c|c|c|c|c|c|c|c|c|c|c|c|}
\hline \multirow[b]{2}{*}{ Category } & \multirow[b]{2}{*}{$N$} & \multicolumn{2}{|c|}{ Annual Mean } & \multicolumn{2}{|c|}{ Annual SD } & \multicolumn{2}{|c|}{ Skewness } & \multicolumn{2}{|c|}{ Kurtosis } & \multicolumn{2}{|c|}{$\hat{\rho}_{1}(\%)$} & \multicolumn{2}{|c|}{$\hat{\rho}_{2}(\%)$} & \multicolumn{2}{|c|}{$\hat{\rho}_{3}(\%)$} & \multicolumn{2}{|c|}{$p$-Value $(Q)$} \\
\hline & & Mean & SD & Mean & $\mathrm{SD}$ & Mean & $\mathrm{SD}$ & Mean & $\mathrm{SD}$ & Mean & $\mathrm{SD}$ & Mean & $\mathrm{SD}$ & Mean & $\mathrm{SD}$ & Mean & $\mathrm{SD}$ \\
\hline Not Categorized & 67 & 9.92 & 7.48 & 17.26 & 11.52 & 0.17 & 1.23 & 4.53 & 5.88 & 3.4 & 17.5 & -0.1 & 14.9 & -0.1 & 12.4 & 39.0 & 29.2 \\
\hline US Equity Hedge & 23 & 16.47 & 7.82 & 20.68 & 9.67 & 0.03 & 0.83 & 3.97 & 5.90 & 7.2 & 12.5 & 0.4 & 9.7 & -5.3 & 10.1 & 38.9 & 27.6 \\
\hline European Equity Hedge & 3 & 13.33 & 3.85 & 10.58 & 4.17 & -0.38 & 1.06 & 2.15 & 1.89 & 10.5 & 11.7 & -3.7 & 14.8 & 3.8 & 7.6 & 51.4 & 9.1 \\
\hline Asian Equity Hedge & - & - & - & - & - & - & - & - & - & - & - & - & - & - & - & - & - \\
\hline Global Equity Hedge & 3 & 3.06 & 7.16 & 10.41 & 5.29 & -0.88 & 0.97 & 2.29 & 3.48 & 27.5 & 12.9 & 3.2 & 16.9 & 7.8 & 12.4 & 42.2 & 36.6 \\
\hline Dedicated Shortseller & 1 & 3.32 & - & 12.78 & - & 0.78 & - & 2.46 & - & 15.5 & - & -13.5 & - & -12.0 & - & 52.4 & - \\
\hline Fixed-Income Directional & 1 & 5.58 & - & 6.49 & - & -0.15 & - & 0.50 & - & 7.7 & - & 4.2 & - & 4.1 & - & 24.0 & - \\
\hline Convertible Fund (Long Only) & 3 & 18.55 & 2.34 & 8.48 & 2.77 & 0.09 & 0.31 & 2.05 & 2.71 & 20.8 & 16.5 & 9.7 & 4.5 & -6.5 & 16.7 & 25.2 & 40.7 \\
\hline Event Driven & 12 & 13.22 & 8.67 & 13.98 & 22.43 & -0.66 & 2.45 & 9.55 & 11.85 & 26.6 & 17.8 & 11.4 & 14.8 & 5.9 & 13.1 & 29.7 & 37.5 \\
\hline Non-Directional/Relative Value & 22 & 10.58 & 8.26 & 9.02 & 5.67 & -1.18 & 1.61 & 7.47 & 9.56 & 17.8 & 14.5 & 3.5 & 16.3 & 3.9 & 10.4 & 24.4 & 26.8 \\
\hline Global Macro & 10 & 19.49 & 7.70 & 21.29 & 7.83 & 0.14 & 0.86 & 4.64 & 9.40 & 10.1 & 19.2 & 1.6 & 8.7 & -0.8 & 8.0 & 20.6 & 13.3 \\
\hline Global Opportunity & - & - & - & - & - & - & - & - & - & - & - & - & - & - & - & - & - \\
\hline Natural Resources & 2 & 9.84 & 5.78 & 19.15 & 1.38 & 0.56 & 0.59 & 1.95 & 1.24 & 12.5 & 9.0 & 13.6 & 11.9 & -1.0 & 6.7 & 51.1 & 61.2 \\
\hline Pure Leveraged Currency & 11 & 7.83 & 9.18 & 19.78 & 11.48 & -0.07 & 1.28 & 3.90 & 6.13 & 2.2 & 8.2 & -10.1 & 7.8 & -6.1 & 9.3 & 41.4 & 34.8 \\
\hline Pure Managed Futures & 65 & 9.19 & 10.35 & 24.02 & 19.41 & 0.13 & 1.25 & 4.51 & 5.98 & -0.6 & 12.9 & -3.7 & 9.4 & -3.9 & 11.5 & 36.7 & 28.9 \\
\hline Pure Emerging Market & 18 & 11.06 & 13.11 & 28.05 & 21.07 & -1.08 & 2.12 & 9.79 & 12.04 & 20.2 & 11.6 & 5.1 & 10.9 & -0.7 & 8.4 & 38.1 & 34.0 \\
\hline Pure Property & - & - & - & - & - & - & - & - & - & - & - & - & - & - & - & - & - \\
\hline Fund of Funds & 17 & 8.24 & 5.82 & 9.50 & 4.87 & -0.04 & 1.53 & 4.39 & 6.25 & 19.2 & 14.6 & 2.2 & 9.6 & 2.9 & 10.2 & 24.6 & 24.9 \\
\hline All Graveyard & 258 & 10.80 & 9.17 & 18.61 & 15.21 & -0.14 & 1.45 & 5.17 & 7.40 & 8.2 & 16.8 & 0.2 & 12.7 & -1.0 & 11.4 & 35.2 & 29.3 \\
\hline
\end{tabular}

Table A.2: Means and standard deviations of basic summary statistics for 258 hedge funds in the TASS Hedge Fund Graveyard database with at least five years of returns history during the period from November 1977 to January 2001. The columns ' $p$-Value $(Q)$ ' contain means and standard deviations of $p$-values for the Box-Pierce $Q$-statistic for each fund using the first 6 autocorrelations of returns. 


\begin{tabular}{|c|c|c|c|c|c|c|c|c|c|c|c|c|c|c|c|c|c|}
\hline \multirow{3}{*}{ Category } & \multirow{3}{*}{$N$} & \multicolumn{8}{|c|}{ MA(2) with Constrained Sum } & \multicolumn{8}{|c|}{ MA(2) with Constrained $\sigma_{\eta}$} \\
\hline & & \multicolumn{2}{|c|}{$\hat{\theta}_{0}$} & \multicolumn{2}{|c|}{$\hat{\theta}_{1}$} & \multicolumn{2}{|c|}{$\hat{\theta}_{2}$} & \multicolumn{2}{|c|}{$\hat{\xi}$} & \multicolumn{2}{|c|}{$\hat{\theta}_{0}$} & \multicolumn{2}{|c|}{$\hat{\theta}_{1}$} & \multicolumn{2}{|c|}{$\hat{\theta}_{2}$} & \multicolumn{2}{|c|}{$\hat{\xi}$} \\
\hline & & Mean & $\mathrm{SD}$ & Mean & $\mathrm{SD}$ & Mean & $\mathrm{SD}$ & Mean & $\mathrm{SD}$ & Mean & $\mathrm{SD}$ & Mean & $\mathrm{SD}$ & Mean & SD & Mean & $\mathrm{SD}$ \\
\hline Not Categorized & 44 & 0.973 & 0.273 & 0.049 & 0.149 & -0.023 & 0.174 & 1.075 & 0.704 & 0.942 & 0.269 & 0.046 & 0.145 & -0.015 & 0.160 & 1.006 & 0.584 \\
\hline US Equity Hedge & 139 & 0.951 & 0.213 & 0.065 & 0.159 & -0.016 & 0.156 & 1.004 & 0.562 & 0.974 & 0.194 & 0.071 & 0.147 & -0.008 & 0.151 & 1.035 & 0.416 \\
\hline European Equity Hedge & 19 & 0.790 & 0.115 & 0.077 & 0.088 & 0.133 & 0.073 & 0.673 & 0.196 & 0.902 & 0.170 & 0.096 & 0.101 & 0.156 & 0.095 & 0.893 & 0.317 \\
\hline Asian Equity Hedge & 5 & 0.942 & 0.296 & 0.053 & 0.188 & 0.005 & 0.109 & 0.998 & 0.712 & 0.904 & 0.198 & 0.064 & 0.167 & 0.013 & 0.096 & 0.883 & 0.404 \\
\hline Global Equity Hedge & 24 & 0.926 & 0.143 & 0.095 & 0.091 & -0.020 & 0.099 & 0.903 & 0.271 & 0.994 & 0.173 & 0.100 & 0.098 & -0.018 & 0.100 & 1.045 & 0.346 \\
\hline Dedicated Shortseller & 6 & 1.031 & 0.220 & 0.008 & 0.109 & -0.039 & 0.135 & 1.131 & 0.528 & 1.149 & 0.152 & 0.024 & 0.115 & -0.031 & 0.142 & 1.368 & 0.363 \\
\hline Fixed-Income Directional & 12 & 0.752 & 0.177 & 0.160 & 0.105 & 0.088 & 0.126 & 0.652 & 0.280 & 0.733 & 0.203 & 0.157 & 0.104 & 0.093 & 0.128 & 0.633 & 0.303 \\
\hline Convertible Fund (Long Only) & 12 & 0.868 & 0.392 & 0.189 & 0.069 & -0.057 & 0.387 & 1.074 & 1.516 & 0.896 & 0.300 & 0.202 & 0.086 & -0.027 & 0.263 & 0.997 & 0.650 \\
\hline Event Driven & 97 & 0.816 & 0.170 & 0.148 & 0.128 & 0.036 & 0.115 & 0.747 & 0.285 & 0.856 & 0.240 & 0.154 & 0.126 & 0.038 & 0.113 & 0.842 & 0.439 \\
\hline Non-Directional/Relative Value & 63 & 0.809 & 0.253 & 0.077 & 0.279 & 0.114 & 0.133 & 0.831 & 0.697 & 0.764 & 0.296 & 0.070 & 0.275 & 0.110 & 0.127 & 0.777 & 0.793 \\
\hline Global Macro & 15 & 1.006 & 0.186 & 0.046 & 0.115 & -0.053 & 0.168 & 1.088 & 0.422 & 1.054 & 0.214 & 0.052 & 0.120 & -0.049 & 0.188 & 1.205 & 0.525 \\
\hline Global Opportunity & 1 & 0.737 & - & 0.162 & - & 0.100 & - & 0.580 & - & 0.632 & - & 0.139 & - & 0.086 & - & 0.426 & - \\
\hline Natural Resources & 1 & 1.111 & - & -0.113 & - & 0.003 & - & 1.246 & - & 0.861 & - & -0.088 & - & 0.002 & - & 0.748 & - \\
\hline Pure Leveraged Currency & 15 & 0.970 & 0.132 & 0.074 & 0.091 & -0.044 & 0.121 & 0.986 & 0.271 & 0.926 & 0.099 & 0.076 & 0.084 & -0.035 & 0.115 & 0.892 & 0.186 \\
\hline Pure Managed Futures & 28 & 1.138 & 0.305 & -0.034 & 0.171 & -0.104 & 0.219 & 1.470 & 0.904 & 1.129 & 0.253 & -0.030 & 0.165 & -0.090 & 0.190 & 1.406 & 0.621 \\
\hline Pure Emerging Market & 54 & 0.836 & 0.165 & 0.148 & 0.087 & 0.016 & 0.139 & 0.774 & 0.328 & 0.797 & 0.162 & 0.141 & 0.082 & 0.021 & 0.136 & 0.706 & 0.296 \\
\hline Pure Property & 1 & 1.232 & - & -0.306 & - & 0.074 & - & 1.618 & - & 0.951 & - & -0.236 & - & 0.057 & - & 0.963 & - \\
\hline Fund of Funds & 115 & 0.848 & 0.220 & 0.119 & 0.132 & 0.034 & 0.136 & 0.817 & 0.522 & 0.859 & 0.232 & 0.122 & 0.126 & 0.035 & 0.133 & 0.841 & 0.470 \\
\hline All & 651 & 0.891 & 0.231 & 0.093 & 0.160 & 0.016 & 0.158 & 0.906 & 0.578 & 0.899 & 0.242 & 0.096 & 0.155 & 0.021 & 0.148 & 0.923 & 0.512 \\
\hline
\end{tabular}

Table A.3: Means and standard deviations of maximum likelihood estimates of MA(2) smoothing process $R_{t}^{o}=\theta_{0} R_{t}+\theta_{1} R_{t-1}+$ $\theta_{2} R_{t-2}, \xi \equiv \theta_{0}^{2}+\theta_{1}^{2}+\theta_{2}^{2}$, for 651 funds in the TASS Hedge Fund Live database with at least five years of returns history during the period from November 1977 to January 2001. 


\begin{tabular}{|c|c|c|c|c|c|c|c|c|c|c|c|c|c|c|c|c|c|}
\hline \multirow{3}{*}{ Category } & \multirow{3}{*}{$N$} & \multicolumn{8}{|c|}{ MA(2) with Constrained Sum } & \multicolumn{8}{|c|}{ MA(2) with Constrained $\sigma_{\eta}$} \\
\hline & & \multicolumn{2}{|c|}{$\hat{\theta}_{0}$} & \multicolumn{2}{|c|}{$\hat{\theta}_{1}$} & \multicolumn{2}{|c|}{$\hat{\theta}_{2}$} & \multicolumn{2}{|c|}{$\hat{\xi}$} & \multicolumn{2}{|c|}{$\hat{\theta}_{0}$} & \multicolumn{2}{|c|}{$\hat{\theta}_{1}$} & \multicolumn{2}{|c|}{$\hat{\theta}_{2}$} & \multicolumn{2}{|c|}{$\hat{\xi}$} \\
\hline & & Mean & $\mathrm{SD}$ & Mean & $\mathrm{SD}$ & Mean & $\mathrm{SD}$ & Mean & $\mathrm{SD}$ & Mean & $\mathrm{SD}$ & Mean & $\mathrm{SD}$ & Mean & $\mathrm{SD}$ & Mean & $\mathrm{SD}$ \\
\hline Not Categorized & 67 & 1.079 & 0.353 & -0.009 & 0.194 & -0.070 & 0.267 & 1.399 & 1.226 & 0.993 & 0.268 & -0.007 & 0.165 & -0.049 & 0.214 & 1.130 & 0.613 \\
\hline US Equity Hedge & 23 & 0.945 & 0.179 & 0.053 & 0.113 & 0.002 & 0.115 & 0.951 & 0.363 & 0.993 & 0.212 & 0.065 & 0.126 & 0.000 & 0.123 & 1.063 & 0.471 \\
\hline European Equity Hedge & 3 & 0.984 & 0.251 & 0.073 & 0.107 & -0.057 & 0.147 & 1.041 & 0.544 & 0.859 & 0.201 & 0.065 & 0.094 & -0.049 & 0.127 & 0.788 & 0.378 \\
\hline Asian Equity Hedge & 0 & - & - & - & - & - & - & - & - & - & - & - & - & - & - & - & - \\
\hline Global Equity Hedge & 3 & 0.790 & 0.099 & 0.220 & 0.043 & -0.011 & 0.057 & 0.683 & 0.131 & 0.670 & 0.196 & 0.179 & 0.003 & -0.014 & 0.044 & 0.508 & 0.242 \\
\hline Dedicated Shortseller & 1 & 0.999 & - & 0.166 & - & -0.165 & - & 1.052 & - & 1.035 & - & 0.172 & - & -0.171 & - & 1.131 & - \\
\hline Fixed-Income Directional & 1 & 0.902 & - & 0.064 & - & 0.033 & - & 0.820 & - & 0.977 & - & 0.069 & - & 0.036 & - & 0.961 & - \\
\hline Convertible Fund (Long Only) & 3 & 0.753 & 0.121 & 0.138 & 0.113 & 0.109 & 0.013 & 0.617 & 0.166 & 0.885 & 0.062 & 0.182 & 0.155 & 0.131 & 0.033 & 0.854 & 0.158 \\
\hline Event Driven & 12 & 0.761 & 0.174 & 0.184 & 0.135 & 0.055 & 0.101 & 0.670 & 0.286 & 0.740 & 0.270 & 0.166 & 0.115 & 0.058 & 0.099 & 0.666 & 0.438 \\
\hline Non-Directional/Relative Value & 22 & 0.844 & 0.196 & 0.142 & 0.099 & 0.014 & 0.137 & 0.796 & 0.317 & 0.768 & 0.203 & 0.135 & 0.101 & 0.014 & 0.127 & 0.673 & 0.332 \\
\hline Global Macro & 9 & 0.869 & 0.155 & 0.135 & 0.061 & -0.005 & 0.126 & 0.813 & 0.302 & 0.818 & 0.188 & 0.123 & 0.050 & -0.002 & 0.124 & 0.732 & 0.351 \\
\hline Global Opportunity & 0 & - & - & - & - & - & - & - & - & - & - & - & - & - & - & - & - \\
\hline Natural Resources & 2 & 0.811 & 0.115 & 0.079 & 0.030 & 0.110 & 0.085 & 0.687 & 0.164 & 0.845 & 0.050 & 0.084 & 0.039 & 0.119 & 0.099 & 0.741 & 0.055 \\
\hline Pure Leveraged Currency & 11 & 1.272 & 0.446 & -0.024 & 0.147 & -0.248 & 0.331 & 1.980 & 2.016 & 1.107 & 0.163 & 0.000 & 0.107 & -0.183 & 0.169 & 1.319 & 0.424 \\
\hline Pure Managed Futures & 65 & 1.129 & 0.325 & -0.053 & 0.233 & -0.076 & 0.159 & 1.467 & 1.295 & 1.082 & 0.244 & -0.037 & 0.193 & -0.066 & 0.144 & 1.292 & 0.642 \\
\hline Pure Emerging Market & 18 & 0.817 & 0.148 & 0.154 & 0.085 & 0.029 & 0.109 & 0.730 & 0.254 & 0.789 & 0.181 & 0.145 & 0.078 & 0.028 & 0.107 & 0.692 & 0.313 \\
\hline Pure Property & 0 & - & - & - & - & - & - & - & - & - & - & - & - & - & - & - & - \\
\hline Fund of Funds & 17 & 0.845 & 0.165 & 0.168 & 0.103 & -0.013 & 0.107 & 0.789 & 0.250 & 0.823 & 0.208 & 0.158 & 0.090 & -0.012 & 0.106 & 0.761 & 0.324 \\
\hline All & 257 & 1.001 & 0.314 & 0.042 & 0.190 & -0.042 & 0.196 & 1.177 & 1.064 & 0.950 & 0.259 & 0.046 & 0.164 & -0.031 & 0.162 & 1.025 & 0.569 \\
\hline
\end{tabular}

Table A.4: Means and standard deviations of maximum likelihood estimates of MA(2) smoothing process $R_{t}^{o}=\theta_{0} R_{t}+\theta_{1} R_{t-1}+$ $\theta_{2} R_{t-2}, \xi \equiv \theta_{0}^{2}+\theta_{1}^{2}+\theta_{2}^{2}$, for 257 funds in the TASS Hedge Fund Graveyard database with at least five years of returns history during the period from November 1977 to January 2001. 


\begin{tabular}{|c|c|c|c|c|c|c|c|c|c|c|c|c|c|}
\hline \multirow[b]{2}{*}{ Category } & \multirow[b]{2}{*}{$N$} & \multicolumn{2}{|c|}{$\hat{\theta}_{0}$} & \multicolumn{2}{|c|}{$\hat{\theta}_{1}$} & \multicolumn{2}{|c|}{$\hat{\theta}_{2}$} & \multicolumn{2}{|r|}{$\hat{\xi}$} & \multicolumn{2}{|c|}{ D.W. } & \multicolumn{2}{|c|}{$R^{2}(\%)$} \\
\hline & & Mean & SD & Mean & SD & Mean & SD & Mean & SD & Mean & SD & Mean & SD \\
\hline Not Categorized & 44 & 1.598 & 4.141 & -0.613 & 3.212 & 0.015 & 2.294 & 34.919 & 108.677 & 1.81 & 0.32 & 15.0 & 13.9 \\
\hline US Equity Hedge & 139 & 0.713 & 1.557 & 0.080 & 0.433 & 0.207 & 1.268 & 4.747 & 41.449 & 1.80 & 0.28 & 24.8 & 17.4 \\
\hline European Equity Hedge & 19 & 0.581 & 0.113 & 0.344 & 0.735 & 0.075 & 0.756 & 1.527 & 4.614 & 1.76 & 0.19 & 18.0 & 9.3 \\
\hline Asian Equity Hedge & 5 & 0.405 & 0.252 & 0.323 & 0.179 & 0.272 & 0.088 & 0.425 & 0.086 & 1.82 & 0.24 & 7.4 & 4.5 \\
\hline Global Equity Hedge & 24 & 0.913 & 0.323 & 0.028 & 0.331 & 0.059 & 0.354 & 1.163 & 0.956 & 1.69 & 0.20 & 24.3 & 19.9 \\
\hline Dedicated Shortseller & 6 & 0.886 & 0.189 & 0.104 & 0.106 & 0.010 & 0.202 & 0.869 & 0.376 & 1.96 & 0.17 & 41.1 & 15.0 \\
\hline Fixed-Income Directional & 12 & -1.495 & 6.678 & 4.689 & 15.156 & -2.193 & 8.493 & 346.600 & 1198.277 & 1.61 & 0.30 & 14.1 & 9.7 \\
\hline Convertible Fund (Long Only) & 12 & 0.513 & 0.239 & 0.354 & 0.160 & 0.133 & 0.162 & 0.506 & 0.152 & 1.51 & 0.22 & 23.8 & 15.2 \\
\hline Event Driven & 97 & 0.550 & 0.279 & 0.330 & 0.288 & 0.120 & 0.232 & 0.638 & 0.661 & 1.64 & 0.36 & 18.0 & 11.4 \\
\hline Non-Directional/Relative Value & 63 & 0.607 & 2.010 & 0.762 & 1.808 & -0.369 & 3.342 & 19.268 & 80.833 & 1.63 & 0.51 & 12.7 & 9.5 \\
\hline Global Macro & 15 & 0.541 & 0.428 & 0.182 & 0.424 & 0.277 & 0.161 & 0.765 & 0.491 & 1.84 & 0.29 & 12.0 & 7.0 \\
\hline Global Opportunity & 1 & 0.619 & - & 0.191 & - & 0.191 & - & 0.455 & - & 1.55 & - & 30.9 & - \\
\hline Natural Resources & 1 & 0.640 & - & 0.175 & - & 0.186 & - & 0.474 & - & 2.20 & - & 2.3 & - \\
\hline Pure Leveraged Currency & 15 & 0.049 & 1.238 & 0.596 & 0.971 & 0.354 & 1.241 & 4.234 & 10.045 & 1.85 & 0.15 & 4.7 & 7.4 \\
\hline Pure Managed Futures & 28 & -0.290 & 1.930 & 0.776 & 2.494 & 0.514 & 2.027 & 14.502 & 41.277 & 1.96 & 0.26 & 3.8 & 3.4 \\
\hline Pure Emerging Market & 54 & 0.928 & 0.916 & 0.125 & 0.527 & -0.053 & 0.506 & 2.226 & 7.470 & 1.52 & 0.28 & 22.0 & 10.8 \\
\hline Pure Property & 1 & 1.319 & - & -0.024 & - & -0.295 & - & 1.828 & - & 2.31 & - & 15.4 & - \\
\hline Fund of Funds & 115 & 0.616 & 1.287 & -0.070 & 2.694 & 0.454 & 3.231 & 19.776 & 183.336 & 1.63 & 0.30 & 22.0 & 14.8 \\
\hline All & 651 & 0.636 & 1.888 & 0.256 & 2.649 & 0.109 & 2.284 & 16.252 & 184.926 & 1.71 & 0.34 & 19.1 & 14.7 \\
\hline
\end{tabular}

Table A.5: Means and standard deviations of linear regression estimates of MA(2) smoothing process $R_{t}^{o}=\theta_{0} R_{t}+\theta_{1} R_{t-1}+$ $\theta_{2} R_{t-2}, \xi \equiv \theta_{0}^{2}+\theta_{1}^{2}+\theta_{2}^{2}$ under the assumption of a linear single-factor model for $R_{t}$ where the factor is the total return of the $\mathrm{S} \& \mathrm{P} 500$ Index, for 651 hedge funds in the TASS Hedge Fund Live database with at least five years of returns history during the period from November 1977 to January 2001. 


\begin{tabular}{|c|c|c|c|c|c|c|c|c|c|c|c|c|c|}
\hline \multirow[b]{2}{*}{ Category } & \multirow{2}{*}{$N$} & \multicolumn{2}{|c|}{$\hat{\theta}_{0}$} & \multicolumn{2}{|c|}{$\hat{\theta}_{1}$} & \multicolumn{2}{|c|}{$\hat{\theta}_{2}$} & \multicolumn{2}{|r|}{$\hat{\xi}$} & \multicolumn{2}{|c|}{ D.W. } & \multicolumn{2}{|c|}{$R^{2}(\%)$} \\
\hline & & Mean & $\mathrm{SD}$ & Mean & $\mathrm{SD}$ & Mean & $\mathrm{SD}$ & Mean & $\mathrm{SD}$ & Mean & $\mathrm{SD}$ & Mean & $\mathrm{SD}$ \\
\hline Not Categorized & 67 & 0.042 & 10.672 & 1.163 & 11.752 & -0.206 & 2.251 & 254.635 & 1841.566 & 1.89 & 0.33 & 12.6 & 18.5 \\
\hline US Equity Hedge & 23 & 0.586 & 1.129 & 0.182 & 0.266 & 0.232 & 0.900 & 2.492 & 8.220 & 1.81 & 0.26 & 33.8 & 16.6 \\
\hline European Equity Hedge & 3 & 0.434 & 0.329 & 0.312 & 0.173 & 0.254 & 0.275 & 0.493 & 0.173 & 1.78 & 0.17 & 18.3 & 21.0 \\
\hline Asian Equity Hedge & - & - & - & - & - & - & - & - & — & - & - & - & - \\
\hline Global Equity Hedge & 3 & 0.308 & 0.626 & 0.294 & 0.271 & 0.397 & 0.361 & 0.737 & 0.293 & 1.40 & 0.26 & 4.1 & 1.3 \\
\hline Dedicated Shortseller & 1 & 1.040 & - & 0.176 & - & -0.216 & - & 1.159 & - & 1.84 & - & 54.7 & - \\
\hline Fixed-Income Directional & 1 & -0.738 & - & 0.748 & - & 0.990 & - & 2.084 & - & 1.83 & - & 1.6 & - \\
\hline Convertible Fund (Long Only) & 3 & 0.636 & 0.383 & 0.295 & 0.127 & 0.068 & 0.272 & 0.655 & 0.428 & 1.63 & 0.32 & 30.1 & 16.3 \\
\hline Event Driven & 12 & 0.837 & 1.223 & -0.008 & 1.244 & 0.171 & 0.159 & 3.543 & 10.629 & 1.50 & 0.38 & 18.1 & 11.0 \\
\hline Non-Directional/Relative Value & 22 & 0.748 & 7.341 & 1.275 & 3.420 & -1.023 & 7.574 & 120.592 & 461.012 & 1.59 & 0.28 & 10.5 & 8.2 \\
\hline Global Macro & 9 & 0.587 & 0.173 & 0.214 & 0.139 & 0.198 & 0.234 & 0.522 & 0.138 & 1.63 & 0.22 & 16.0 & 9.3 \\
\hline Global Opportunity & - & - & - & - & - & - & - & - & - & - & - & - & - \\
\hline Natural Resources & 2 & 0.717 & 0.184 & 0.072 & 0.089 & 0.211 & 0.095 & 0.589 & 0.211 & 1.71 & 0.19 & 2.7 & 1.2 \\
\hline Pure Leveraged Currency & 11 & -0.255 & 1.590 & 0.037 & 1.150 & 1.218 & 2.690 & 11.631 & 36.324 & 1.95 & 0.16 & 4.0 & 3.5 \\
\hline Pure Managed Futures & 65 & 0.079 & 1.418 & 0.662 & 1.132 & 0.260 & 1.406 & 5.700 & 15.336 & 2.00 & 0.26 & 6.8 & 6.5 \\
\hline Pure Emerging Market & 18 & 0.811 & 0.231 & 0.256 & 0.151 & -0.067 & 0.237 & 0.852 & 0.460 & 1.46 & 0.30 & 24.9 & 9.8 \\
\hline Pure Property & - & - & - & - & - & - & - & - & - & - & - & - & - \\
\hline Fund of Funds & 17 & 1.064 & 2.613 & 0.093 & 1.469 & -0.158 & 1.366 & 11.379 & 40.134 & 1.59 & 0.30 & 19.1 & 17.0 \\
\hline All & 257 & 0.346 & 5.928 & 0.643 & 6.112 & 0.010 & 2.680 & 79.904 & 950.698 & 1.80 & 0.34 & 14.4 & 15.6 \\
\hline
\end{tabular}

Table A.6: Means and standard deviations of linear regression estimates of MA(2) smoothing process $R_{t}^{o}=\theta_{0} R_{t}+\theta_{1} R_{t-1}+$ $\theta_{2} R_{t-2}, \xi \equiv \theta_{0}^{2}+\theta_{1}^{2}+\theta_{2}^{2}$ under the assumption of a linear single-factor model for $R_{t}$ where the factor is the total return of the $\mathrm{S} \& \mathrm{P} 500$ Index, for 257 hedge funds in the TASS Hedge Fund Graveyard database with at least five years of returns history during the period from November 1977 to January 2001. 


\begin{tabular}{|c|c|c|c|c|c|c|c|c|c|c|c|c|c|c|}
\hline \multirow{3}{*}{ Category } & \multicolumn{7}{|c|}{ Sharpe Ratios For Live Funds } & \multicolumn{7}{|c|}{ Sharpe Ratios For Graveyard Funds } \\
\hline & \multirow{2}{*}{$N$} & \multicolumn{2}{|c|}{ SR } & \multicolumn{2}{|c|}{$\mathrm{SR}^{*}$} & \multicolumn{2}{|c|}{$\mathrm{SR}^{* *}$} & \multirow[t]{2}{*}{$N$} & \multicolumn{2}{|c|}{ SR } & \multicolumn{2}{|c|}{$\mathrm{SR}^{*}$} & \multicolumn{2}{|c|}{$\mathrm{SR}^{* *}$} \\
\hline & & Mean & $\mathrm{SD}$ & Mean & $\mathrm{SD}$ & Mean & $\mathrm{SD}$ & & Mean & $\mathrm{SD}$ & Mean & $\mathrm{SD}$ & Mean & $\mathrm{SD}$ \\
\hline Not Categorized & 44 & 1.55 & 1.34 & 1.41 & 1.00 & 1.33 & 0.94 & 67 & 0.84 & 0.79 & 0.83 & 0.70 & 0.77 & 0.65 \\
\hline US Equity Hedge & 139 & 1.31 & 0.77 & 1.36 & 0.76 & 1.27 & 0.70 & 23 & 0.99 & 0.54 & 1.06 & 0.60 & 1.00 & 0.57 \\
\hline European Equity Hedge & 19 & 1.44 & 0.78 & 1.46 & 0.85 & 1.36 & 0.78 & 3 & 1.36 & 0.57 & 1.26 & 0.49 & 1.18 & 0.46 \\
\hline Asian Equity Hedge & 5 & 0.50 & 0.39 & 0.52 & 0.39 & 0.49 & 0.37 & 0 & - & - & - & - & - & - \\
\hline Global Equity Hedge & 24 & 0.95 & 0.60 & 1.00 & 0.66 & 0.94 & 0.61 & 3 & 0.55 & 0.75 & 0.51 & 0.59 & 0.48 & 0.55 \\
\hline Dedicated Shortseller & 6 & 0.28 & 0.65 & 0.33 & 0.70 & 0.31 & 0.67 & 1 & 0.26 & - & 0.30 & - & 0.28 & - \\
\hline Fixed-Income Directional & 12 & 2.11 & 2.42 & 1.87 & 2.31 & 1.75 & 2.14 & 1 & 0.86 & - & 0.87 & - & 0.84 & - \\
\hline Convertible Fund (Long Only) & 12 & 1.67 & 1.18 & 1.48 & 0.72 & 1.38 & 0.69 & 3 & 2.45 & 1.26 & 2.39 & 1.07 & 2.23 & 1.00 \\
\hline Event Driven & 97 & 2.45 & 1.46 & 2.31 & 1.58 & 2.17 & 1.47 & 12 & 1.61 & 1.16 & 1.47 & 1.39 & 1.37 & 1.29 \\
\hline Non-Directional/Relative Value & 63 & 2.36 & 1.82 & 2.21 & 2.52 & 2.06 & 2.35 & 22 & 1.73 & 1.93 & 1.53 & 1.91 & 1.42 & 1.76 \\
\hline Global Macro & 15 & 1.12 & 0.77 & 1.30 & 0.86 & 1.22 & 0.82 & 9 & 1.02 & 0.51 & 0.87 & 0.34 & 0.82 & 0.32 \\
\hline Global Opportunity & 1 & -0.56 & - & -0.39 & - & -0.37 & - & 0 & - & - & - & - & - & - \\
\hline Natural Resources & 1 & 0.79 & - & 0.75 & - & 0.69 & - & 2 & 0.50 & 0.27 & 0.46 & 0.23 & 0.43 & 0.22 \\
\hline Pure Leveraged Currency & 15 & 0.83 & 0.50 & 0.83 & 0.50 & 0.78 & 0.47 & 11 & 0.35 & 0.32 & 0.41 & 0.39 & 0.38 & 0.37 \\
\hline Pure Managed Futures & 28 & 0.81 & 0.71 & 0.92 & 0.66 & 0.87 & 0.63 & 65 & 0.43 & 0.43 & 0.51 & 0.52 & 0.48 & 0.49 \\
\hline Pure Emerging Market & 54 & 0.39 & 0.48 & 0.37 & 0.48 & 0.34 & 0.44 & 18 & 0.39 & 0.36 & 0.34 & 0.30 & 0.32 & 0.27 \\
\hline Pure Property & 1 & 0.42 & - & 0.45 & - & 0.41 & - & 0 & - & - & - & - & - & - \\
\hline Fund of Funds & 115 & 1.48 & 1.02 & 1.35 & 0.90 & 1.27 & 0.83 & 17 & 1.15 & 0.98 & 0.95 & 0.70 & 0.89 & 0.65 \\
\hline All & 651 & 1.50 & 1.29 & 1.45 & 1.35 & 1.36 & 1.26 & 257 & 0.85 & 0.95 & 0.83 & 0.90 & 0.78 & 0.84 \\
\hline
\end{tabular}

Table A.7: Means and standard deviations of Sharpe ratios of 651 funds in the TASS Hedge Funds Live database and 257 funds in the TASS Hedge Fund Graveyard database, both with at least five years of returns history during the period from November 1977 to January 2001. SR is the standard Sharpe ratio, SR* is the smoothing-adjusted Sharpe ratio of Lo (2002), and $\mathrm{SR}^{* *}$ is the smoothing-adjusted Sharpe ratio using $\hat{\sigma}_{\mathrm{NW}}$. All Sharpe ratios are computed with respect to a 0 benchmark. 


\begin{tabular}{|c|c|c|c|c|}
\hline Regressor & $\hat{\theta}_{0}$ & $\hat{\xi}$ & $\hat{\theta}_{0}$ & $\hat{\xi}$ \\
\hline Constant & $\begin{array}{r}1.007 \\
(42.02)\end{array}$ & $\begin{array}{r}1.152 \\
(21.91)\end{array}$ & $\begin{array}{r}1.029 \\
(35.56)\end{array}$ & $\begin{array}{r}1.212 \\
(19.04)\end{array}$ \\
\hline US Equity Hedge & $\begin{array}{c}0.020 \\
(0.69)\end{array}$ & $\begin{array}{c}-0.009 \\
(0.15)\end{array}$ & $\begin{array}{c}0.026 \\
(0.85)\end{array}$ & $\begin{array}{c}-0.004 \\
(0.07)\end{array}$ \\
\hline European Equity Hedge & $\begin{array}{c}-0.063 \\
(1.19)\end{array}$ & $\begin{array}{c}-0.175 \\
(1.50)\end{array}$ & $\begin{array}{c}-0.120 \\
(1.97)\end{array}$ & $\begin{array}{c}-0.281 \\
(2.10)\end{array}$ \\
\hline Asian Equity Hedge & $\begin{array}{c}-0.054 \\
(0.52)\end{array}$ & $\begin{array}{r}-0.167 \\
(0.73)\end{array}$ & $\begin{array}{r}-0.030 \\
(0.28)\end{array}$ & $\begin{array}{c}-0.131 \\
(0.54)\end{array}$ \\
\hline Global Equity Hedge & $\begin{array}{c}0.005 \\
(0.11)\end{array}$ & $\begin{array}{c}-0.053 \\
(0.49)\end{array}$ & $\begin{array}{c}0.032 \\
(0.64)\end{array}$ & $\begin{array}{c}0.006 \\
(0.05)\end{array}$ \\
\hline Dedicated Shortseller & $\begin{array}{c}0.178 \\
(2.01)\end{array}$ & $\begin{array}{c}0.291 \\
(1.50)\end{array}$ & $\begin{array}{c}0.184 \\
(2.06)\end{array}$ & $\begin{array}{c}0.293 \\
(1.49)\end{array}$ \\
\hline Fixed-Income Directional & $\begin{array}{c}-0.203 \\
(3.04)\end{array}$ & $\begin{array}{c}-0.386 \\
(2.63)\end{array}$ & $\begin{array}{c}-0.196 \\
(2.92)\end{array}$ & $\begin{array}{r}-0.375 \\
(2.54)\end{array}$ \\
\hline Convertible Fund (Long Only) & $\begin{array}{c}-0.060 \\
(0.95)\end{array}$ & $\begin{array}{c}-0.073 \\
(0.53)\end{array}$ & $\begin{array}{c}-0.064 \\
(1.01)\end{array}$ & $\begin{array}{r}-0.086 \\
(0.62)\end{array}$ \\
\hline Event Driven & $\begin{array}{c}-0.116 \\
(3.74)\end{array}$ & $\begin{array}{c}-0.228 \\
(3.36)\end{array}$ & $\begin{array}{c}-0.124 \\
(3.85)\end{array}$ & $\begin{array}{r}-0.247 \\
(3.49)\end{array}$ \\
\hline Non-Directional/Relative Value & $\begin{array}{c}-0.194 \\
(5.88)\end{array}$ & $\begin{array}{c}-0.303 \\
(4.18)\end{array}$ & $\begin{array}{c}-0.180 \\
(5.26)\end{array}$ & $\begin{array}{r}-0.281 \\
(3.73)\end{array}$ \\
\hline Global Macro & $\begin{array}{c}0.004 \\
(0.09)\end{array}$ & $\begin{array}{c}-0.029 \\
(0.26)\end{array}$ & $\begin{array}{c}0.034 \\
(0.63)\end{array}$ & $\begin{array}{c}0.026 \\
(0.22)\end{array}$ \\
\hline Global Opportunity & $\begin{array}{c}-0.314 \\
(1.37)\end{array}$ & $\begin{array}{c}-0.598 \\
(1.19)\end{array}$ & $\begin{array}{c}-0.309 \\
(1.35)\end{array}$ & $\begin{array}{c}-0.59 \\
(1.18)\end{array}$ \\
\hline Natural Resources & $\begin{array}{c}-0.096 \\
(0.72)\end{array}$ & $\begin{array}{c}-0.281 \\
(0.96)\end{array}$ & $\begin{array}{r}-0.095 \\
(0.72)\end{array}$ & $\begin{array}{c}-0.284 \\
(0.97)\end{array}$ \\
\hline Pure Leveraged Currency & $\begin{array}{c}0.042 \\
(0.85)\end{array}$ & $\begin{array}{c}0.019 \\
(0.17)\end{array}$ & $\begin{array}{c}0.045 \\
(0.89)\end{array}$ & $\begin{array}{c}0.022 \\
(0.20)\end{array}$ \\
\hline Pure Managed Futures & $\begin{array}{c}0.133 \\
(4.16)\end{array}$ & $\begin{array}{c}0.267 \\
(3.78)\end{array}$ & $\begin{array}{c}0.142 \\
(4.25)\end{array}$ & $\begin{array}{c}0.284 \\
(3.87)\end{array}$ \\
\hline Pure Emerging Market & $\begin{array}{c}-0.161 \\
(4.63)\end{array}$ & $\begin{array}{c}-0.344 \\
(4.50)\end{array}$ & $\begin{array}{c}-0.146 \\
(3.53)\end{array}$ & $\begin{array}{r}-0.311 \\
(3.42)\end{array}$ \\
\hline Pure Property & $\begin{array}{c}-0.056 \\
(0.25)\end{array}$ & $\begin{array}{r}-0.190 \\
(0.38)\end{array}$ & $\begin{array}{c}-0.028 \\
(0.12)\end{array}$ & $\begin{array}{c}-0.146 \\
(0.29)\end{array}$ \\
\hline Fund of Funds & $\begin{array}{c}-0.099 \\
(3.32)\end{array}$ & $\begin{array}{c}-0.211 \\
(3.21)\end{array}$ & $\begin{array}{c}-0.092 \\
(3.03)\end{array}$ & $\begin{array}{c}-0.199 \\
(2.96)\end{array}$ \\
\hline OPEN & $\begin{array}{c}-0.061 \\
(3.27)\end{array}$ & $\begin{array}{c}-0.128 \\
(3.13)\end{array}$ & $\begin{array}{c}-0.055 \\
(2.78)\end{array}$ & $\begin{array}{c}-0.118 \\
(2.73)\end{array}$ \\
\hline USBASED & & & $\begin{array}{c}0.012 \\
(0.68)\end{array}$ & $\begin{array}{r}0.022 \\
(0.58)\end{array}$ \\
\hline GF-GLB & & & $\begin{array}{c}-0.034 \\
(1.69)\end{array}$ & $\begin{array}{c}-0.078 \\
(1.78)\end{array}$ \\
\hline GF-USA & & & $\begin{array}{c}-0.043 \\
(2.09)\end{array}$ & $\begin{array}{r}-0.087 \\
(1.92)\end{array}$ \\
\hline GF-APC & & & $\begin{array}{r}-0.051 \\
(1.73)\end{array}$ & $\begin{array}{c}-0.104 \\
(1.61)\end{array}$ \\
\hline GF-WEU & & & $\begin{array}{c}0.048 \\
(1.70)\end{array}$ & $\begin{array}{c}0.079 \\
(1.28)\end{array}$ \\
\hline GF-EEU & & & $\begin{array}{c}-0.058 \\
(1.46)\end{array}$ & $\begin{array}{c}-0.133 \\
(1.51)\end{array}$ \\
\hline GF-AFR & & & $\begin{array}{c}0.071 \\
(1.27)\end{array}$ & $\begin{array}{r}0.137 \\
(1.12)\end{array}$ \\
\hline Sample Size & 908 & 908 & 891 & 891 \\
\hline Adjusted $R^{2}(\%)$ & 15.7 & 11.4 & 16.9 & 12.6 \\
\hline
\end{tabular}

Table A.8: Regressions of maximum likelihood estimated smoothing coefficient $\hat{\theta}_{0}$ and smoothing index $\hat{\xi}$ on indicator variables for 908 hedge funds in the TASS Hedge Fund Combined (Live and Graveyard) database with at least five years of returns history during the period from November 1977 to January 2001, where the maximum likelihood estimator $\hat{\sigma}_{\eta}$ is constrained to equal a nonparametric estimator $\tilde{\sigma}_{\eta}$ of the innovation standard deviation. Absolute values of $t$-statistics are given in parentheses. The indicator variables are OPEN (1 if the fund is open, 0 otherwise); the fund categories ( 1 if the fund belongs to the category, 0 otherwise); USBASED ( 1 if the fund is based in the US, 0 otherwise); and geographical focus categories ( 1 if the geographical focus of the fund is in a given region, 0 otherwise, where the regions are USA, Asia Pacific, Western Europe, Eastern Europe, and Africa, respectively). 


\section{References}

Ackermann, C., McEnally, R. and D. Ravenscraft, 1999, "The Performance of Hedge Funds: Risk, Return, and Incentives", Journal of Finance 54, 833-874.

Agarwal, V. and N. Naik, 2000a, "Performance Evaluation of Hedge Funds with Buy-andHold and Option-Based Strategies", Hedge Fund Centre Working Paper No. HF-003, London Business School.

Agarwal, V. and N. Naik, 2000b, "On Taking the" Alternative" Route: The Risks, Rewards, and Performance Persistence of Hedge Funds", Journal of Alternative Investments 2, 6-23.

Agarwal, V. and N. Naik, 2000c, "Multi-Period Performance Persistence Analysis of Hedge Funds Source", Journal of Financial and Quantitative Analysis 35, 327-342.

Agarwal, V. and N. Naik, 2002, "Risks and Portfolio Decisions Involving Hedge Funds", Institute of Finance and Accounting Working Paper No. 364, London Business School.

Asness, C., Krail, R. and J. Liew, 2001, "Do Hedge Funds Hedge?", The Journal of Portfolio Management 28, 6-19.

Atchison, M., K. Butler, and R. Simonds, 1987, "Nonsynchronous Security Trading and Market Index Autocorrelation", Journal of Finance 42, 111-118.

Baquero, G., Horst, J. and M. Verbeek, 2002, "Survival, Look-Ahead Bias and the Performance of Hedge Funds", Erasmus University Rotterdam Working Paper.

Bhattacharya, S. and P. Pfleiderer, 1985, "Delegated Portfolio Management", Journal of Economic Theory 36, 1-25.

Beneish, M., 2001, "Earnings Management: A Perspective", Managerial Finance 27, 3-17.

Billingsley, P., 1968, Convergence of Probability Measures. New York: John Wiley and Sons.

Black, F., 1986, "Noise", Journal of Finance 41, 529-544.

Brockwell, P., and R. Davis, 1991, Time Series: Theory and Methods, Second Edition. New York: Springer-Verlag.

Brown, S. and W. Goetzmann, 2001, "Hedge Funds With Style", NBER Working Paper No. 8173.

Brown, S., Goetzmann, W., Ibbotson, R. and S. Ross, 1992, "Survivorship Bias in Performance Studies", Review of Financial Studies 5, 553-580.

Brown, S., Goetzmann, W. and R. Ibbotson, 1999, "Offshore Hedge Funds: Survival and Performance 1989-1995", Journal of Business 72, 91-118.

Brown, S., Goetzmann, W. and B. Liang, 2002, "Fees on Fees in Funds of Funds", Yale ICF Work Paper No. 02-33.

Brown, S., Goetzmann, W. and J. Park, 1997, "Conditions for Survival: Changing Risk and the Performance of Hedge Fund Managers and CTAs", Yale School of Management Work Paper No. F-59. 
Brown, S., Goetzmann, W. and J. Park, 2000, "Hedge Funds and the Asian Currency Crisis", Journal of Portfolio Management 26, 95-101.

Brown, S., Goetzmann, W. and J. Park, 2001, "Careers and Survival: Competition and Risks in the Hedge Fund and CTA Industry", Journal of Finance 56, 1869-1886.

Campbell, J., Lo, A., and C. MacKinlay, 1997, The Econometrics of Financial Markets. Princeton, NJ: Princeton University Press.

Carpenter, J., 2000, "Does Option Compensation Increase Managerial Risk Appetite?", Journal of Finance 55, 2311-2331.

Carpenter, J., Dybvig, P. and H. Farnsworth, 2001, "Portfolio Performance and Agency", unpublished working paper, Stern School of Business, New York University.

Carpenter, J. and A. Lynch, 1999, "Survivorship Bias and Attrition Effects in Measures of Performance Persistence", Journal of Financial Economics 54, 337-374.

Cecchetti, S. and N. Mark, 1990, "Evaluating Empirical Tests of Asset Pricing Models", American Economic Review 80, 48-51.

Chandar, N. and R. Bricker, 2002, "Incentives, Discretion, and Asset Valuation in ClosedEnd Mutual Funds", Journal of Accounting Research 40, 1037-1070.

Cohen, K., Hawawini, G., Maier, S., Schwartz, R. and D. Whitcomb, 1983a, "Estimating and Adjusting for the Intervalling-Effect Bias in Beta," Management Science 29, 135148.

Cohen, K., Hawawini, G, Maier, S., Schwartz, R. and D. Whitcomb, 1983b, "Friction in the Trading Process and the Estimation of Systematic Risk", Journal of Financial Economics 12, 263-278.

Cohen, K., Maier, S., Schwartz, R. and D. Whitcomb, 1978, "The Returns Generation Process, Returns Variance, and the Effect of Thinness in Securities Markets", Journal of Finance 33, 149-167.

Cohen, K., Maier, S, Schwartz, R. and D. Whitcomb, 1979, "On the Existence of Serial Correlation in an Efficient Securities Market", TIMS Studies in the Management Sciences $11,151-168$.

Cohen, K., Maier, S., Schwartz, R. and D. Whitcomb, 1986, The Microstructure of Securities Markets. Englewood Cliffs, NJ: Prentice Hall.

Dimson, E., 1979, "Risk Measurement When Shares Are Subject to Infrequent Trading", Journal of Financial Economics 7, 197-226.

Edwards, F., and M. Caglayan, 2001, "Hedge Fund and Commodity Fund Investments in Bull and Bear Markets", The Journal of Portfolio Management 27, 97-108.

Elton, E. and M. Gruber, 2002, "Incentive Fees and Mutual Funds", to appear in Journal of Finance.

Fama, E., 1970, "Efficient Capital Markets: A Review of Theory and Empirical Work", Journal of Finance 25, 383-417.

Fisher, L., 1966, "Some New Stock Market Indexes", Journal of Business 39, 191-225. 
Fung, W. and D. Hsieh, 1997a, "Empirical Characteristics of Dynamic Trading Strategies: The Case of Hedge Funds", Review of Financial Studies 10, 275-302.

Fung, W. and D. Hsieh, 1997b, "Investment Style and Survivorship Bias in the Returns of CTAs: The Information Content of Track Records", Journal of Portfolio Management $24,30-41$.

Fung, W. and D. Hsieh, 1999, "A Primer on Hedge Funds", Journal of Empirical Finance $6,309-31$.

Fung, W. and D. Hsieh, 2000, "Performance Characteristics of Hedge Funds and Commodity Funds: Natural versus Spurious Biases", Journal of Financial and Quantitative Analysis 35, 291-307.

Fung, W. and D. Hsieh, 2001, "The Risk in Hedge Fund Strategies: Theory and Evidence from Trend Followers", Review of Financial Studies 14, 313-341.

Fung, W. and D. Hsieh, 2002, "Asset-Based Style Factors for Hedge Funds", Financial Analysts Journal 58, 16-27.

Goetzmann, W., Ingersoll, J. and S. Ross, 1997, "High Water Marks and Hedge Fund Management Contracts", to appear in Journal of Finance.

Goetzmann, W., Ingersoll, J., Spiegel, M. and I. Welch, 2002, "Sharpening Sharpe Ratios", National Bureau of Economic Research Working Paper No. W9116.

Goodwin, T., 1993, "Business-Cycle Analysis with a Markov-Switching Model", Journal of Business and Economic Statistics 11, 331-339.

Granger, C., 1980, "Long Memory Relations and the Aggregation of Dynamic Models", Journal of Econometrics 14, 227-238.

Granger, C., 1988, "Aggregation of Time Series Variables-A Survey", Federal Reserve Bank of Minneapolis Institute for Empirical Macroeconomics, Discussion Paper 1.

Grossman, S., 1976, "On The Efficiency of Competitive Stock Markets Where Trades Have Diverse Information", Journal of Finance 31, 573-585.

Grossman, S. and J. Stiglitz, 1980, "On the Impossibility of Informationally Efficient Markets", American Economic Review 70, 393-408.

Hamilton, J., 1989, "A New Approach to the Economic Analysis of Nonstationary Time Series and the Business Cycle", Econometrica 57, 357-384.

Hamilton, J., 1990, "Analysis of Time Series Subject to Changes in Regime", Journal of Econometrics 45, 39-70.

Hamilton, J., 1996, "Specification Testing in Markov-Switching Time Series Models", Journal of Econometrics 70, 127-157.

Hansen, L., 1982, "Large Sample Properties of Generalized Method of Moments Estimators", Econometrica 50, 1029-1054.

Healy, P. and J. Wahlen, 1999, "A Review of the Earnings Management Literature and Its Implications for Standard Setting", Accounting Horizons 14, 365-383. 
Hendricks, D., Patel, J. and R. Zeckhauser, 1997, "The J-Shape of Performance Persistence Given Survivorship Bias", Review of Economics and Statistics 79, 161-170.

Herrndorf, N., 1984, "A Functional Central Limit Theorem For Weakly Dependent Sequences of Random Variables", Annals of Probability 12, 141-153.

Horst, J., Nijman, T. and M. Verbeek, 2001, "Eliminating Look-Ahead Bias in Evaluating Persistence in Mutual Fund Performance", Journal of Empirical Finance 8, 345-373.

Jobson, J. and R. Korkie, 1981, "Performance Hypothesis Testing with the Sharpe and Treynor Measures", Journal of Finance 36, 889-908.

Kadlec, G. and D. Patterson, 1999, "A Transactions Data Analysis of Nonsynchronous Trading", Review of Financial Studies 12, 609-630.

Kandel, S. and R. Stambaugh, 1991, "Asset Returns and Intertemporal Preferences", Journal of Monetary Economics 27, 39-71.

Kao, D., 2002, "Battle for Alphas: Hedge Funds versus Long-Only Portfolios", Financial Analysts Journal 58, 16-36.

Leroy, S., 1973, "Risk Aversion and the Martingale Property of Stock Returns", International Economic Review 14, 436-446.

Liang, B., 1999, "On the Performance of Hedge Funds", Financial Analysts Journal 55, $72-85$.

Liang, B., 2000, "Hedge Funds: The Living and the Dead", Journal of Financial and Quantitative Analysis 35, 309-326.

Liang, B., 2001, "Hedge Fund Performance: 1990-1999", Financial Analysts Journal 57, $11-18$.

Lo, A., 2001, "Risk Management For Hedge Funds: Introduction and Overview", to appear in Financial Analysts Journal 57, 16-33.

Lo, A., 2002, "The Statistics of Sharpe Ratios", Financial Analysts Journal 58, 36-50.

Lo, A. and C. MacKinlay, 1988, "Stock Market Prices Do Not Follow Random Walks: Evidence from a Simple Specification Test", Review of Financial Studies 1, 41-66.

Lo, A. and C. MacKinlay, 1990, "An Econometric Analysis of Nonsynchronous Trading", Journal of Econometrics 45, 181-212.

Lo, A. and C. MacKinlay, 1999, A Non-Random Walk Down Wall Street. Princeton, NJ: Princeton University Press.

Lochoff, R., 2002, "Hedge Funds and Hope", The Journal of Portfolio Management 28, 92-99.

Lucas, R., 1978, "Asset Prices in an Exchange Economy", Econometrica 46, 1429-1446.

Newey, W. and K. West, 1987, "A Simple Positive Definite Heteroscedasticity and Autocorrelation Consistent Covariance Matrix", Econometrica 55, 703-705.

Richardson, M. and J. Stock, 1989, "Drawing Inferences from Statistics Based on Multiyear Asset Returns", Journal of Financial Economics 25, 323-348. 
Rubinstein, M., 1976, "The Valuation of Uncertain Income Streams and the Pricing of Options", Bell Journal of Economics 7, 407-425.

Samuelson, P., 1941, "Conditions that the Roots of a Polynomial Be Less than Unity in Absolute Value", Annals of mathematical Statistics 45, 689-693.

Samuelson, P., 1965, "Proof that Properly Anticipated Prices Fluctuate Randomly", Industrial Management Review 6, 41-49.

Schneeweis, T. and R. Spurgin, 1996, "Survivor Bias in Commodity Trading Advisor Performance", Journal of Futures Markets 16, 757-772.

Scholes, M., and J. Williams, 1977, "Estimating Betas from Nonsynchronous Data", Journal of Financial Economics 5, 309-328.

Shanken, J., 1987, "Nonsynchronous Data and the Covariance-Factor Structure of Returns," Journal of Finance 42, 221-232.

Sharpe, W., 1994, "The Sharpe Ratio", Journal of Portfolio Management 21, 49-58.

Spurgin, R., 2001, "How to Game Your Sharpe Ratio", The Journal of Alternative Investments 4, 38-46.

Turner, C., Startz, R. and C. Nelson, 1989, "A Markov Model of Heteroskedasticity, Risk, and Learning in the Stock Market", Journal of Financial Economics 25, 3-22.

Weisman, A., 2002, "Informationless Investing and Hedge Fund Performance Measurement Bias", The Journal of Portfolio Management 28, 80-91.

Working, H., 1960, "Note on the Correlation of First Differences of Averages in a Random Chain", Econometrica 28, 916-918. 